\title{
MASTE
}

\section{FABRICATION AND PROPERTIES OF HOT PRESSED \\ BISMUTH TUNGSTATE}

\section{BY}

WILLIAM LAVERLE STREICHER

B.S., University of Illinois, 1977

\section{THESIS}

Submitted in partial fulfillment of the requirements for the degree of Master of Science in Ceramic Engineering

in the Graduate College of the

University of I1linois at Urbana-Champaign, 1978

\author{
Urbana, Illinois
}

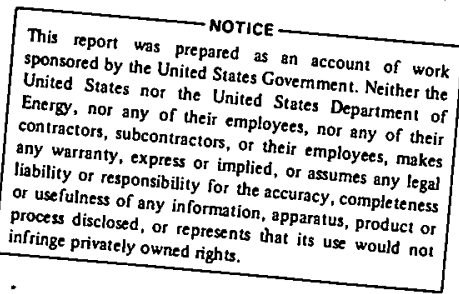




\section{DISCLAIMER}

This report was prepared as an account of work sponsored by an agency of the United States Government. Neither the United States Government nor any agency Thereof, nor any of their employees, makes any warranty, express or implied, or assumes any legal liability or responsibility for the accuracy, completeness, or usefulness of any information, apparatus, product, or process disclosed, or represents that its use would not infringe privately owned rights. Reference herein to any specific commercial product, process, or service by trade name, trademark, manufacturer, or otherwise does not necessarily constitute or imply its endorsement, recommendation, or favoring by the United States Government or any agency thereof. The views and opinions of authors expressed herein do not necessarily state or reflect those of the United States Government or any agency thereof. 


\section{DISCLAIMER}

Portions of this document may be illegible in electronic image products. Images are produced from the best available original document. 
ABSTRACT

$\mathrm{Bi}_{2}{ }^{\mathrm{WO}_{6}}$ is a synthetic polar material that is a possible candidate for energy conversion and detection systems. Previous research on this material has been concerned with crystal growth and sintering characteristics of polycrystalline compacts. This study involves itself with the fabrication of polycrystalline compacts by hot pressing techniques. Densities approaching theoretical crystal density were achieved by hot pressing at $850^{\circ} \mathrm{C}$ for one hour with pressures exceeding $35 \mathrm{MPa}$.

Before hot pressing, the sintering range was derermined by high temperature dilatometry of unfired $\mathrm{Bi}_{2} \mathrm{WO}_{6}$ ceramics. Hot pressed discs were characterized by scanning electron microscopy, differential scanning calorimetry, and x-ray diffraction. Electrical properties were determined by d.c. resistivity, capacitance, and conductance measurements, a.c. poling, d.c. poling, and current-voltage measurements. 
ACKNOWLEDGEMENTS

The author is very thankful for the guidance provided by Dr. D. A. Payne during the course of the research. Fellow members of Dr. Payne's research group also deserve thanks for their assistance, especially Dr. S. M. Park, who aided the author with the scanning electron microscope work.

Nick Vassos of the Coordinated Science Laboratory Materials Processing Laboratory gave assistance during the building of the high temperature sample holder for electrical measurements, William Schaede of the Ceramic Engineering Department Machine Shop was very helpful on many occasions, especially in building the furnace used for hot pressing. Many other members of the faculty, staff, and graduate students of the Ceramic Engineering Department also offered assistance to the author.

The work was funded by the United States Department of Energy under Contract Number EY-76-C-02-1198. 
TABLE OF CONTENTS

Chapter

ONE

TWO
INTRODUCTION . . . . . . . . . . . . . . . . . . 1

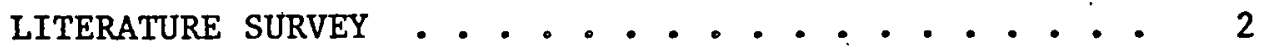

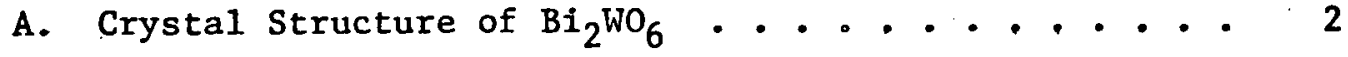

B. Phase Diagram. ... . . . . . . . . . . . . . . 2

c. Transformations of $\mathrm{Bi}_{2} \mathrm{WO}_{6}$. . . . . . . . . . . . 5

1. Melting Point . . . . . . . . . ... 5

2. Phase Transformation(s) - . . . . . . . . . 5

3. Curie Point • . . . . . . . . . . . . . 9

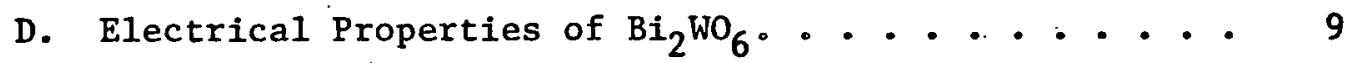

1. Dielectric Constant . . . . . . . . . . . 9

2. Electrical Conductivity . . . . . . . . . . 10

3. Piezoelectricity . . . . . . . . . . . . . 10

4. Ferroelectricity . . . . . . . . . . . . 11

E. Thermal Expansion of $\mathrm{Bi}_{2} \mathrm{WO}_{6}$. . . . . . . . . . . . 14

F. Sintering of $\mathrm{Bi}_{2} \mathrm{WO}_{6}$. . . . . . . . . . . . . . . . 14

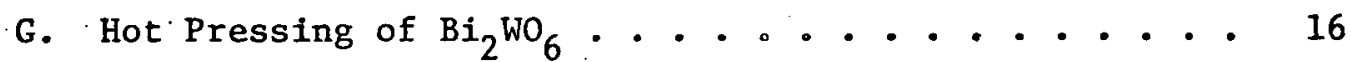

H. Electrode Polarization . . . . . . . . . . . . 17

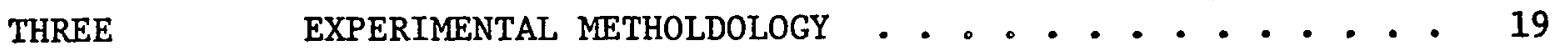

A. Material Preparation . . . . . . . . . . . . . 19

B. Sample Preparation . . . . . . . . . . . . . . . 19

1. Dry Pressing . . . . . . . . . . . . . . 19

2. Settling . . . . . . . . . . . . . . . 20

3. Tape Casting . . . . . . . . . . . . . . 20

C. Thermal Expansion . . . . . . . . . . . . . . . 22

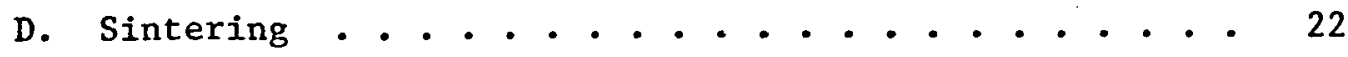


E. Hot Pressing . . . . . . . . . . . . 22

F. Differential Scanning Calorimetry . . . . . . . 25

G. Electrical Measurements ............. 26

1. Sample Preparation ............ 26

2. Resistance Measurements . . . . . . . . 26

3. Capacitance and Conductance Measurements . . . 26

4. a.c. Poling ............. 30

5. Current - Voltage Measurements ........ 30

6. d.c. Poling and Piezoelectric Measurements . . . 30

H. X-ray Diffraction. . . . . . . . . . . 33 .

FOUR $\quad$ RESULTS AND DISCUSSION . . . . . . . . . 35

A. Powder Preparation .............. 35

B. Dry Pressing . . . . . . . . . . . . 35

C. Thermal Expansion .. . . . . . . . . . 39

D. Sintering ................ 4 42

E. Hot Pressing . . . . . . . . . . . . . 42

F. X-ray Diffractometry . . . . . . . . . . 44

G. Microstructure of Hot Pressed $\mathrm{Bi}_{2} \mathrm{WO}_{6}$. . . . . . 44

H. Differential Scanning Calorimetry. . . . . . . . 52

I. Electrical Measurements . . . . . . . . 52

1. d.c. Conductivity . . . . . . . . 52

2. Dielectric Constant and a.c. Conductivity . . . 56

3. a.c. Poling ............... 65

4. Current - Voltage Analysis . . . . . . . 73

5. Piezoelectricity . . . . . . . . . 78

FIVE CONCLUSION . . . . . . . . . . . . . . 80 
vii

Chapter

Page

References ................. 81

Appendix A: Chemicals Utilized . . . . . . . 84 
viii

LIST OF FIGURES

Figure

Page

1. Environment for the (a) Bismuth and (b) Tungsten Ions in $\mathrm{Bi}_{2} \mathrm{WO}_{6}$.................... 3

2. Crystal Structure of $\mathrm{Bi}_{2} \mathrm{WO}_{6}$ on (a) (100) and (b) (010) ... 4

3. Phase Relations in $\mathrm{Bi}_{2} \mathrm{O}_{3}-$ WO ${ }_{3}$ System ............ 6

4. Differential Thermal Analysis of Polycrystalline $\mathrm{Bi}_{2} \mathrm{WO}_{6}$ - 8

5. Polarization Reversal and Dielectric Hysteresis . . . . 12

6. Thermal Expansion Behavior of Pressed $\mathrm{Bi}_{2} \mathrm{WO}_{6}$ Pellets .... 15

7. Settling of $\mathrm{Bi}_{2} \mathrm{WO}_{6}$ Powder ................ 21

8. Hot Press ...................... 23

9. Hot Press Die Assembly. ............... 24

10. "Orientation" of $\mathrm{Bi}_{2} \mathrm{WO}_{6}$ Sections ............. 27

11. High Temperature Sample Holder ............. 28

12. Sample Holder for Electrical Measurements . . . . . . . 29

13. a.c. Poling Circuit ................ 31

14. Experimental Setup for Current - Voltage Measurements . • 32

15. d.c. Poling Circuit .............. 34

16. Pulverized Minus 200- mesh $\mathrm{Bi}_{2} \mathrm{WO}_{6}$ Powder .......... 36

17. Ball Milled $\mathrm{Bi}_{2} \mathrm{WO}_{6}$ Powder . . . . . . . . . . 37

18. Pressed Density of $\mathrm{Bi}_{2} \mathrm{WO}_{6}$ at Various Compaction Pressures . 38

19. Thermal Expansion Behavior of Dry Pressed $\mathrm{Bi}_{2} \mathrm{WO}_{6}$. . . . 40

20. Thermal Expansion Behavior of Dry Pressed $\mathrm{Bi}_{2} \mathrm{WO}_{6} \cdot$. . . . 41

21. Shrinkage Rate During Hot Pressing . . . . . . . . . 43

22. Pressure Dependence of Density For Hot Pressed $\mathrm{Bi}_{2} \mathrm{WO}_{6}$. . 45

23. Hot Pressed $\mathrm{Bi}_{2} \mathrm{WO}_{6}$. . . . . . . . . . . . . 46

24. Hot Pressed $\mathrm{Bi}_{2} \mathrm{WO}_{6}$ Fabricated by the Settling Method . . . 48 
Figure

25. Hot Pressed $\mathrm{Bi}_{2} \mathrm{WO}_{6}$ Fabricated by Tape Casting . . . . . .

26. Poled Hot Pressed $\mathrm{Bi}_{2} \mathrm{WO}_{6}$ with Piezoelectric Response . . 50

27. Poled Hot Pressed $\mathrm{Bi}_{2} \mathrm{WO}_{6}$ with Piezoelectric Response . . 51

28. Differential Scanning Calorimetry of Hot Pressed. $\mathrm{Bi}_{2} \mathrm{WO}_{6} \cdot$ - 53

29. d.c. Conductivity - Inverse Temperature Dependence of $\mathrm{Bi}_{2} \mathrm{WO}_{6}$ Fabricated by the Settling Method ......... 54

30. d.c. Conductivity - Inverse Temperature Dependence of $\mathrm{Bi}_{2} \mathrm{WO}_{6}$ Fabricated by the Settling Method . . . . . . 55

31. Temperature Dependence of Dielectric Constant for Hot Pressed $\mathrm{Bi}_{2} \mathrm{WO}_{6}$. . . . . . . . . . . . . .

32. Temperature Dependence of a.c. Conductivity for Hot Pressed $\mathrm{Bi}_{2} \mathrm{WO}_{6}$.......................

33. Temperature Dependence of Dielectric Constant for Annealed Hot Pressed $\mathrm{Bi}_{2} \mathrm{WO}_{6}$. . . . . . . . . . . . .

34. Temperature Dependence of a.c. Conductivity for Annealed Hot Pressed $\mathrm{Bi}_{2} \mathrm{WO}_{6}$. . . . . . . . . . . . . .

35. Temperature Dependence of Dielectric Constant for Annealed Hot Pressed $\mathrm{Bi}_{2}{ }^{\mathrm{WO}_{6}}$ Fabricated by the Settling Method . .

36. Temperature Dependence of a.c. Conductivity for Annealed Hot Pressed $\mathrm{Bi}_{2} \mathrm{WO}_{6}$ Fabricated by the Settling Method . .

37. Temperature Dependence of Dielectric Constant for Annealed Hot Pressed $\mathrm{Bi}_{2} \mathrm{WO}_{6}$ Fabricated by the Settling Method . . :

38. Temperature Dependence of a.c. Conductivity for Annealed Hot Pressed $\mathrm{Bi}_{2} \mathrm{WO}_{6}$ Fabricated by the Settling Method . .

39. Hysteresis Loop for Hot Pressed $\mathrm{Bi}_{2} \mathrm{WO}_{6}$ Fabricated by the Settling Method ...................

40. Hysteresis Loop for Hot Pressed $\mathrm{Bi}_{2} \mathrm{WO}_{6}$ Fabricated by the Settling Method .................

41. Temperature Dependence of Remanent Polarization for Hot Pressed Bi..2 Wn 6 Fabricated by the Settling Method .... .

42. Temperature Dependence of Remanent Polarization for Hot Pressed $\mathrm{Bi}_{2} \mathrm{WO}_{6}$ Fabricated by the Settling Method ..... 
43. Temperature Dependence of Remanent Polarization for Hot Pressed $\mathrm{Bi}_{2} \mathrm{WO}_{6}$ Fabricated by the Settling Method . . . . . 71

44. Temperature Dependence of Remanent Polarization for Hot Pressed $\mathrm{Bi}_{2} \mathrm{WO}_{6}$ Fabricated by the Tape Casting Method . . . 72

45. Current Density versus Applied Field . . . . . . . . . 74

46. Current Density versus Applied Field . . . . . . . . 75

47. Schottky Plot for Hot Pressed $\mathrm{Bi}_{2} \mathrm{WO}_{6} \ldots \ldots \ldots$

48. Schottky Plot for Hot Pressed $\mathrm{Bi}_{2} \mathrm{WO}_{6}$. . . . . . . 77 
CHAPTER ONE

\section{INTRODUCTION}

$\mathrm{Bi}_{2} \mathrm{WO}_{6}$ is a synthetic polar material that seems ideally suited for piezoelectric applications, such as energy conversion and detection systems. It is the most refractory compound in the bismuth oxide-tungsten oxide system, and is one of the simplest members of the bismuth titanate family of layered materials. Other compounds in the bismuth titanate family are used in catalysis, galvanic energy cells, and as dielectric, acoustooptic, and electrooptic devices.

The intrinsic properties of $\mathrm{Bi}_{2} \mathrm{WO}_{6}$ should be determined on strain-free single domain crystals. However, a high temperature disruptive phase transformation has caused much difficulty in growing useable crystals, and to date only small crystals have been obtained. Previous investigators have also encountered difficulties in producing dense polycrystalline compacts by using ceramic fabrication techniques. Dense compacts would enable valuable characterization of the properties of $\mathrm{Bi}_{2} \mathrm{WO}_{6}$.

The research undertaken was concerned with the fabrication of dense compacts of $\mathrm{Bi}_{2} \mathrm{WO}_{6}$ by hot pressing techniques. The dense compacts were used to determine dielectric and electrical properties of polycrystalline $\mathrm{Bi}_{2} \mathrm{WO}_{6}{ }^{\circ}$ Additional information on the material characteristics are reported. 
CHAPTER TWO

\section{LITERATURE SURVEY}

A. Crystal Structure of $\mathrm{Bi}_{2} \mathrm{WO}_{6}$

$\mathrm{BI}_{2} \mathrm{WO}_{6}$ is a member of the bismuth titanate family, which are layered materials of the general formula $\mathrm{Bi}_{2} \mathrm{M}_{n-1} \mathrm{R}_{n} \mathrm{O}_{3 n+3^{-}}$. Crystals in this family resemble mica in morphology with $\left(\mathrm{Bi}_{2} \mathrm{O}_{2}\right)^{2+}$ layers alternated with $\left(M_{n-1} R_{n} O_{3 n+1}\right)^{2-}$ pervoskite-1ike layers stacked in the c-direction. ${ }^{1}$ All the materials have the same prototypic symmetry of tetragonal point group $4 / \mathrm{mmm}_{0}{ }^{2}$ Newnham et al ${ }^{1}$ reported that members of the bismuth titanate family have a low temperature space group of $\mathrm{A} 2{ }_{1}$ am.. (orthorhombic mm2) if $n$ is even. When $\mathbf{n}$ is odd, the low temperature structure appears to be B2cd (orthorhombic mm2). $\mathrm{Bi}_{2} \mathrm{WO}_{6}$ is one of the simplest members of the bismuth titanate family with $n=1$, Therefore the material is composed of $\left(\mathrm{Bi}_{2}{ }^{0}{ }_{2}\right)^{2+}$ layers alternating with $\left(\text { WO }_{4}\right)^{2-}$ layers. Wolfe and Newnham ${ }^{2}$ determined the room temperature structure (from $x$-ray and neutron diffraction studies on ceramic specimens) to be orthorhombic mn2, $B 2 c d\left(C_{2 v}^{17}\right)$, with unit cell parameters of $a=5.451$, $b=5.436$, and $c=16.427 \AA$ Gal'perin et $a 0^{3}$ and Blaise ${ }^{4}$ found values for unit cell parameters in close agreement with these. Wolfe $e^{5}$ determined the interatomic distances for the first coordination sphere of bismuth and tungsten. ions as shown in Figure 1. In addition, Wolfe ${ }^{5}$ projected the crystal structure onto the (100) and (010) faces as illustrated in Figure 2.

\section{B. Phase Diagram}

The latest investigation of the $\mathrm{Bi}_{2} \mathrm{O}_{3}-\mathrm{WO}_{3}$ phase system was completed by 

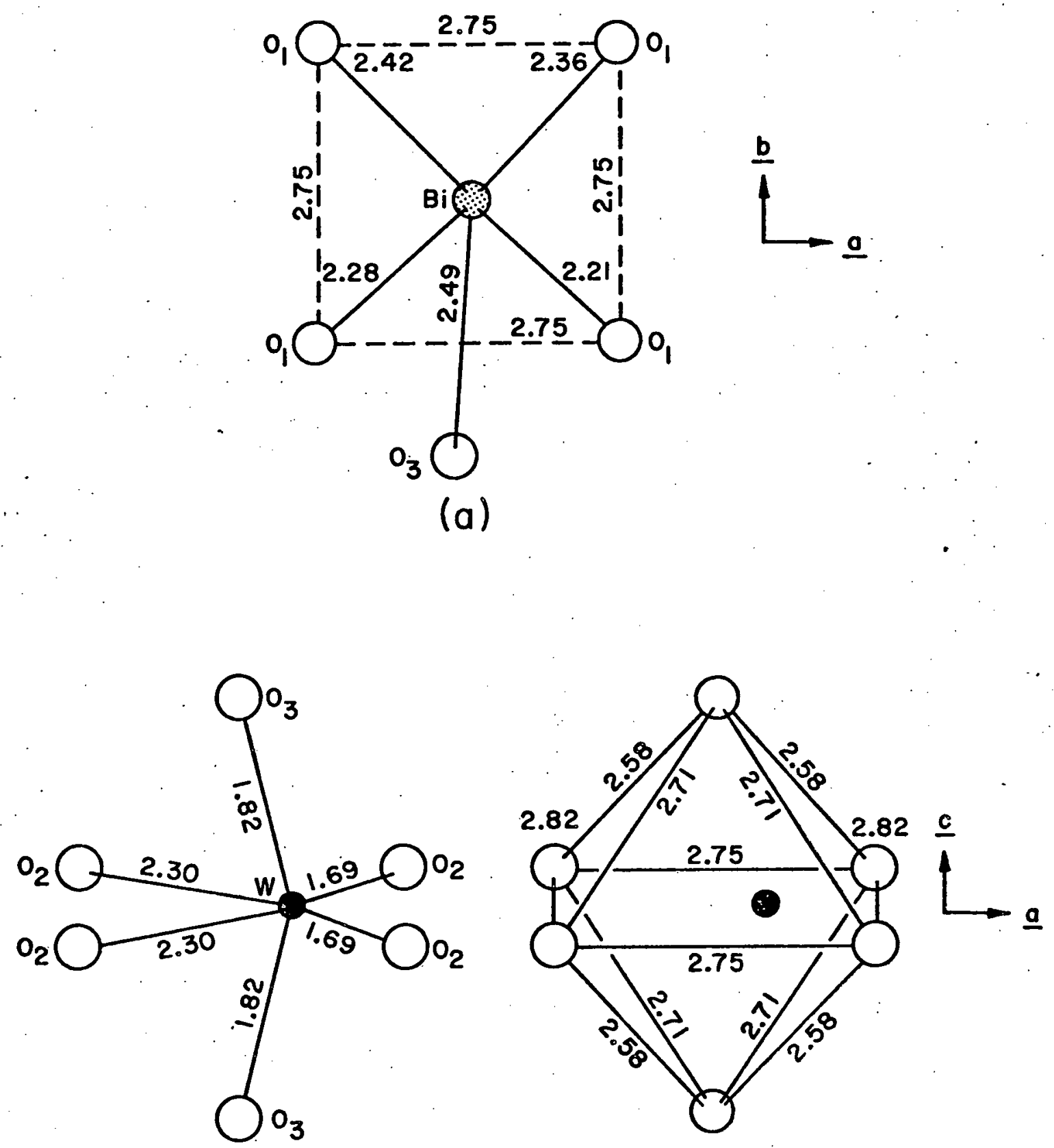

(b)

Figure 1. Environment for the (a) Bismuth and

(b) Tungsten Ions in $\mathrm{Bi}_{2} \mathrm{WO}_{6}$ (all numbers in $\AA) .5$ 


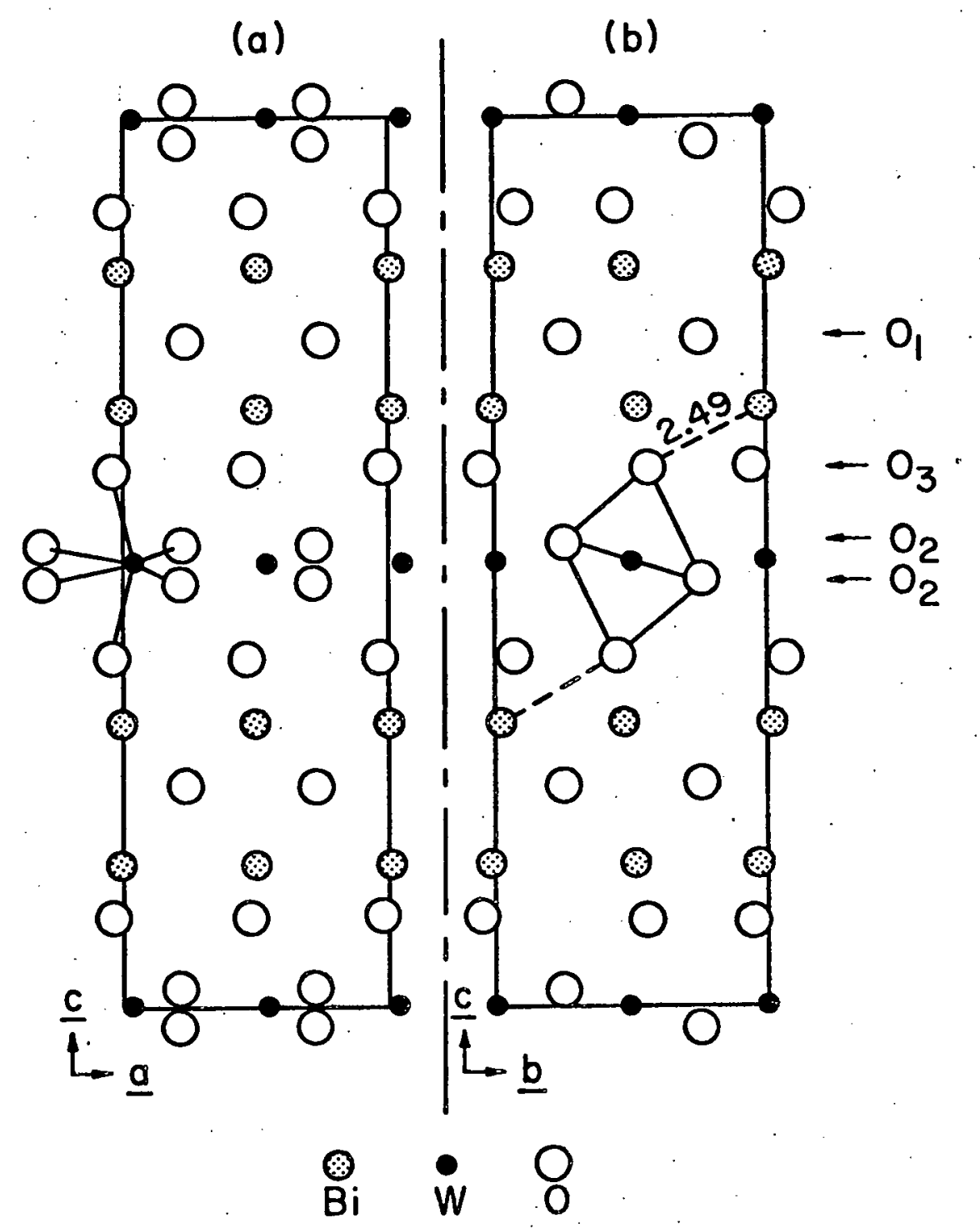

Figure 2. Crystal Structure of $\mathrm{Bi}_{2} \mathrm{WO}_{6}$ Projected on (a) (100) and (b) (010). Solid lines in (b) outline an octahedron and dashed lines indicate the short $\mathrm{Bi}$ - bonds responsible for the tilting motion of the octahedron. 5 
Hoda and Chang ${ }^{6}$ in 1974. This study is the most extensive to date, with over 40 different compositions being prepared, reacted, annealed, and analyzed by differential thermal analysis (DTA) and $x$-ray powder diffraction (XRD). The phase diagram is illustrated in Figure 3. It can be seen that four intermediate phases $7 \mathrm{Bi}_{2} \mathrm{O}_{3} \cdot \mathrm{WO}_{3}, 7 \mathrm{Bi}_{2} \mathrm{O}_{3} \cdot 2 \mathrm{WO}_{3}, \mathrm{Bi}_{2} \mathrm{O}_{3} \cdot \mathrm{WO}_{3}$, and $\mathrm{Bi}_{2} \mathrm{O}_{3} \cdot 2 \mathrm{WO}_{3}$ where formed, with $\mathrm{Bi}_{2} \mathrm{WO}_{6}\left(\mathrm{Bi}_{2} \mathrm{O}_{3} \cdot \mathrm{WO}_{3}\right)$ being the most refractory. Analysis of $x$-ray diffraction data for $\mathrm{Bi}_{2} \mathrm{WO}_{6}$ allowed determination of orthorhombic unit cell parameters of $a_{0}=5.45, b_{0}=5.46$, and $c_{0}=16.42 \AA$, which are in close agreement with previous workers.

Previous phase studies were of a limited extent. Of these Gal'perin et $a 1 .^{3}$ obtained results in closest agreement. Other investigators referred to by Hoda and Chang ${ }^{6}$, obtained results that do not totally agree with Figure 3 , or with one another. For the purpose of this research the phase diagram illustrated in Figure 3 was assumed to be accurate due to the extensiveness of the recent investigation.

C. Transformations of $\mathrm{Bi}_{2} \mathrm{WO}_{6}$

1. Melting Point

Various investigators have found $\mathrm{Bi}_{2} \mathrm{WO}_{6}$ to melt congruently in the temperature range of 1060 to $1080^{\circ} \mathrm{C}$. Speranskaya ${ }^{7}$ and Hoda and Chang ${ }^{6}$ reported a melting point of $1080^{\circ} \mathrm{C}$, which was determined during their phase analysis work. Smolyaninov and Belyaev ${ }^{8}$ reported a value of $1064^{\circ} \mathrm{C}$. Rook ${ }^{9}$ found a melting point of $1062^{\circ} \mathrm{C}$ by DTA, and Wolfe ${ }^{5}$ reported a value of $1060^{\circ} \mathrm{C}$ in his thesis.

\section{Phase Transformation(s)}

As discussed in the crystal structure section, members in the bismuth 


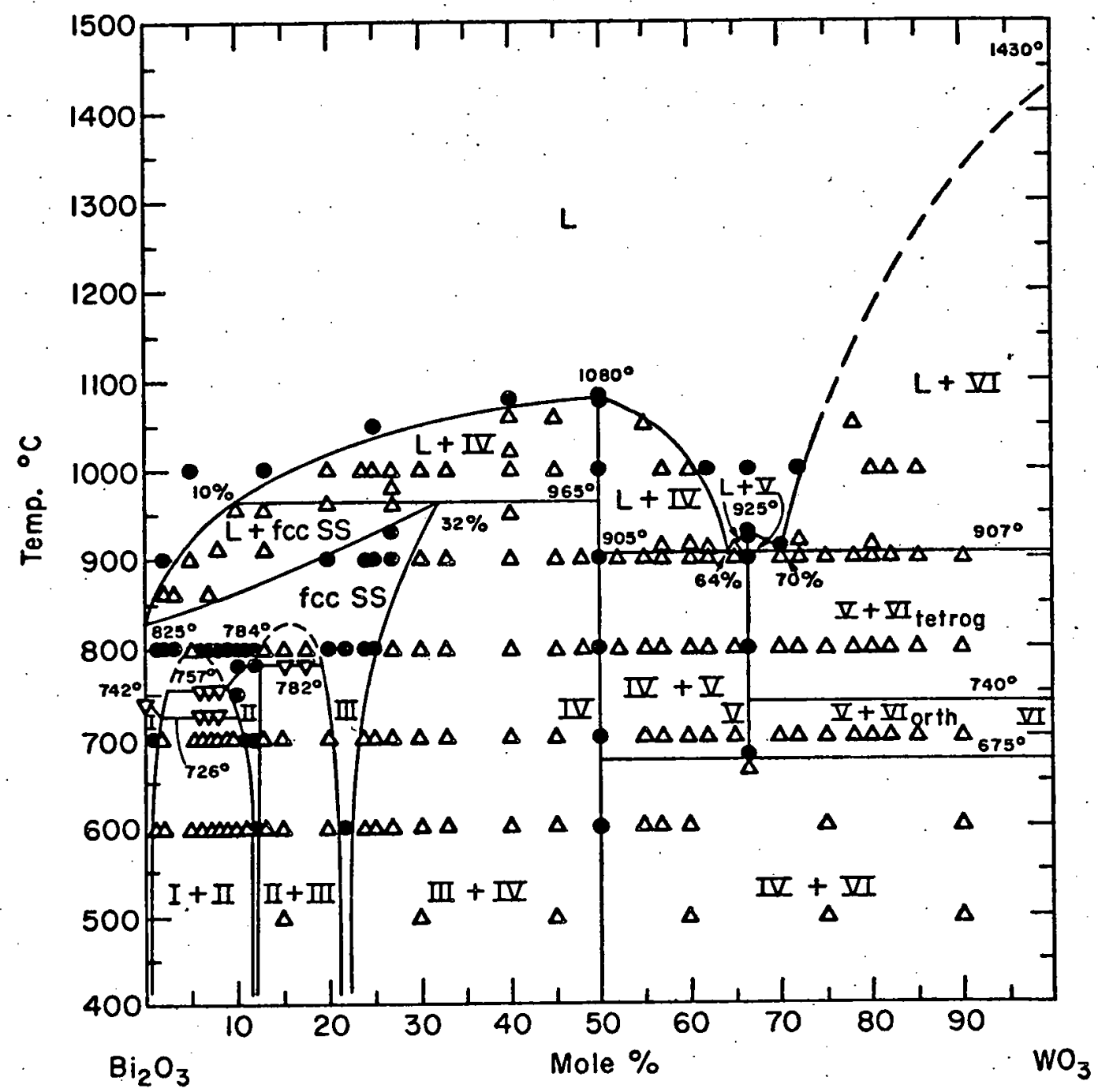

Figure 3. Phase Relations in the $\mathrm{Bi}_{2} \mathrm{O}_{3}-\mathrm{WO}_{3}$ System. 6

- = 1 phase

$\Delta=2$ phases

$\nabla=$ transition point by DTA

S.S. = solid solution

$\mathrm{L}=$ liquid

I, II, III, IV, V, and VI represent, respectively $\mathrm{Bi}_{2} \mathrm{O}_{3}, 7 \mathrm{Bi}_{2} \mathrm{O}_{3} \cdot \mathrm{WO}_{3}$, $7 \mathrm{Bi}_{2} \mathrm{O}_{3} \cdot 2 \mathrm{WO}_{3}, \mathrm{Bi}_{2} \mathrm{O}_{3} \cdot \mathrm{WO}_{3}, \mathrm{Bi}_{2} \mathrm{O}_{3} \cdot 2 \mathrm{WO}_{3}$, and $\mathrm{WO}_{3}$ 
titanate family have a perovskite-like layer $\left(M_{n-1} R_{n} 0_{3 n+1}\right)^{2-}$. Newkirk et al. 1 $r$ e ported $t$ hat $m$ e mbers of the bismuth titanate family have one high temperature phase transformation when $\mathrm{n}$ is odd, and two high temperature phase transformations when $\mathrm{n}$ is even. Since $\mathrm{n}=1$ for $\mathrm{Bi}_{2} \mathrm{WO}_{6}$, one high temperature phase transformation would be expected. Several investigators have reported finding only one transformation in their studies, Wolfe 5 reported a "reversible" phase transformation at $940^{\circ} \mathrm{C}$. Speranskaya ${ }^{7}$ and Newkirk et al. ${ }^{10}$ reported a phase transformation at $935^{\circ} \mathrm{C}$ determined by DTA. Speranskaya ${ }^{7}$ reported it to be a "destructive phase transformation". Newkirk et al. 10 found the transformation to cause cracking of the crystals during cooling in Czochralski growth. Fay ${ }^{11}$ reported density versus firing temperature data for sintering of $\mathrm{Bi}_{2}{ }^{\mathrm{WO}}{ }_{6}$ with a discontinuity at $935^{\circ} \mathrm{C}$, which was associated with the high temperature transformation.

Other investigators have found the phase transformation to exhibit thermal hysteresis. Payne and Horsey ${ }^{12}$ found the temperature at which crystals grown by the Czochralski crystal growth method would crack on cooling was $850^{\circ} \mathrm{C}$, not $935^{\circ} \mathrm{C}$ as reported by Wolfe, ${ }^{5}$ A similar hystere sis was reported by Payne and Theokritof $\mathrm{f}^{13}$ when they studied small hydrothermally grown crystals by hot stage microscopy. On heating the transformation occurred between $990-1010^{\circ} \mathrm{C}$ and on cooling at $860^{\circ} \mathrm{C}$. Shukla ${ }^{14}$ conducted a similar experiment and found the transformation to occur between $975-1030^{\circ} \mathrm{C}$ on heating and $860-810^{\circ} \mathrm{C}$ on cooling. Yanovskii et al. ${ }^{15}$ also reported thermal hysteresis. They found two endothermic peaks by DTA (a small one at $920^{\circ} \mathrm{C}$ and a large one at $960^{\circ} \mathrm{C}$ ) on heating and one at $840^{\circ} \mathrm{C}$ on cooling. The crystals they studied were grown from a vanadate flux. Rook ${ }^{9}$ also observed hysteresis by DTA as shown in Figure 4. On heating, an endothermic peak occurred between $987-1018^{\circ} \mathrm{C}$ and on cooling, an exothermic peak between $883-878^{\circ} \mathrm{C}$. 


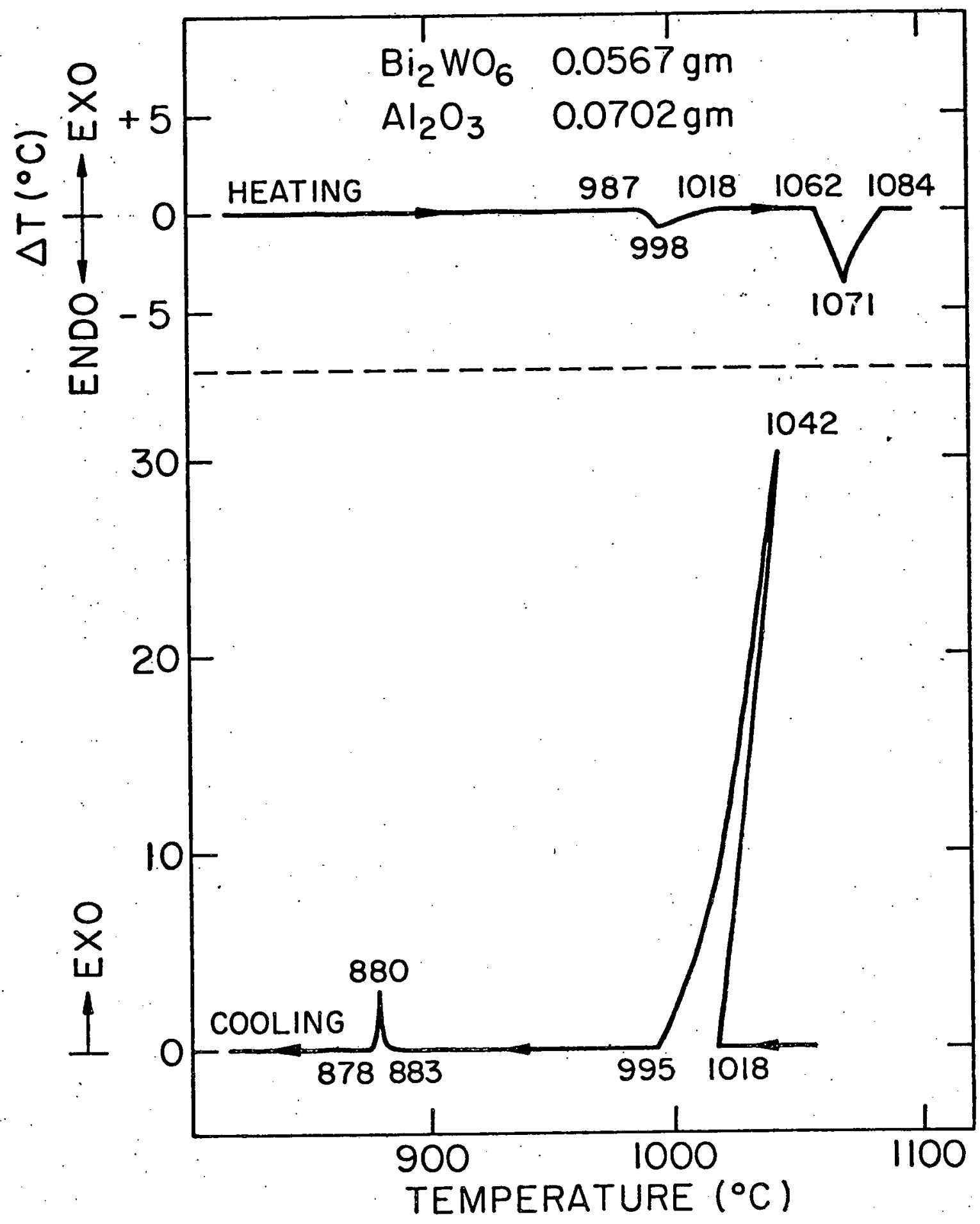

Figure 4. Differential Thermal Analysis of Polycrystalline $\mathrm{Bi}_{2} \mathrm{WO}_{6} \cdot 9$ 
Newkirk et al. ${ }^{10}$ reported a small peak in dielectric constant and conductivity data versus temperature between $300-500^{\circ} \mathrm{C}$, from single crystal and polycrystalline measurements. Ismailzade and Mirishli ${ }^{16}$ also reported a similar peak for polycrystalline $\mathrm{Bi}_{2} \mathrm{WO}_{6} \cdot$ Newkirk et al. saw a corresponding peak from DTA studies, but did not attempt to explain its existence. No other investigation has claimed that a phase transformation occurs in this temperature range,

\section{Curie Point}

A Curie point for $\mathrm{Bi}_{2} \mathrm{WO}_{6}$ has not been found by experimentation. Newkirk et $a 1 .^{10}$ and Yavonskii et al. ${ }^{15}$ have claimed the Curie point coincides with the phase transformation around $935^{\circ} \mathrm{C}$. Wolfe ${ }^{5}$ calculated a value of $1250^{\circ} \mathrm{C}$ based upon crystal chemical data (temperature is above the melting point).

\section{Electrical Properties of $\mathrm{Bi}_{2} \mathrm{WO}_{6}$}

1. Dielectric Constant

A capacitor is a device that can store electric charge. The capacitance of a capacitor is the ratio of charge stored to the applied voltage. The real part of the dielectric constant $\left(K^{\prime}\right)$ is related to the capacitance (C in farads) and material parameters by equation (2.1). 17 In the equation $\mathrm{d}$ is the distance

$$
\mathrm{K}^{\prime}=\frac{\mathrm{dC}}{\mathrm{A} \varepsilon_{\mathrm{o}}}
$$

between electrodes, $A$ is the area of the electrodes, and $\varepsilon_{0}$ is the permittivity of vacuum $\left(8.85 \times 10^{-12} \mathrm{~F} / \mathrm{m}\right)$. It is easily seen that the dielectric constant is a parameter that allows easy comparison of the charge storage capability of different materials. 
Yanovskii et al. ${ }^{15}$ reported room temperature dielectric constants of $\mathrm{K}_{33}^{\prime}=100$ and $\mathrm{K}^{\prime}{ }_{22}=58$ (measured at $70 \mathrm{~Hz}$ ) for vanadate flux grown single crystals of $\mathrm{Bi}_{2} \mathrm{WO}_{6} \cdot$. Newkirk et al. ${ }^{10}$ found a dielectric constant of $\mathrm{K}^{-}=50$ (room temperature value at $1000 \mathrm{kHz}$ ) for polycrystalline $\mathrm{Bi}_{2} \mathrm{WO}_{6}{ }^{\circ}$ They also found that the dielectric constant increased with temperature. Ismailzade and Mirishli $i^{16}$ reported $K^{\prime}=70$ for a room temperature dielectric constant at $160 \mathrm{kHz}$ for polycrystalline specimens with a similar temperature dependence.

\section{Electrical Conductivity}

When an electric field is applied across a ceramic; an equilibrium current is eventually set up due to the migration of charge carriers, such as electrons, holes, ions, and vacancies. The amount of charge transported across a unit area in unit time per the applied field is defined as the electrical conductivity. 18 The value of the electrical conductivity depends on the composition, structure, and temperature of the material.

Yanovskii et al. ${ }^{15}$ found the electrical conductivity of a $\mathrm{Bi}_{2} \mathrm{WO}_{6}$ single crystal (vanadate flux grown) ranged from $10^{-10} \mathrm{chm}^{-1}-\mathrm{cm}^{-1}$ at room temperature to $10^{-3} \mathrm{ohm}^{-1}-\mathrm{cm}^{-1}$ at $800^{\circ} \mathrm{C}$. Takahashi and Iwahara found the conductivity ranged from $10^{-4} \mathrm{ohn}^{-1}-\mathrm{cm}^{-1}$ at $600^{\circ} \mathrm{C}$ to $10^{-2} \mathrm{ohm}^{-1}-\mathrm{cm}^{-1}$ at $900^{\circ} \mathrm{C}$. They also reported that the intermediate compounds in the $\mathrm{Bi}_{2} \mathrm{O}_{3}{ }^{-\mathrm{WO}}{ }_{3}$ system were oxide ion conductors with $3 \mathrm{Bi}_{2} \mathrm{O}_{3} \cdot \mathrm{WO}_{3}$ and its solid solutions being fast ion conductors.

\section{Piezoelectricity}

When a crystal is acentric (i.e. lacks a center of symmetry) the application of mechanical stress creates an electric charge in the material. Conversely, the application of an electric field to the crystal will generate an elastic strain. This phenomenon is called piezoelectricity, and is dependent 
on the orientation of the crystal. The directionality precludes polycrystalline samples from having a net piezoelectric response, unless the domains are reorientated. The piezoelectric effect is nullified by the isotropic randomness of crystallites within a polycrystalline body, 20

The crystal structure of $\mathrm{Bi}_{2} \mathrm{WO}_{6}$ would imply that a single crystal of the material should be piezoelectric. Difficulty in growing crystals has prevented much testing of the material for piezoelectricity. However, Yanovskil et al. ${ }^{15}$ have observed piezoelectric response in vanadate flux grown crystals. They reported values for the piezoelectric coefficient $\left(d_{i j}\right.$ in reduced notation $\left.^{20}\right)$. This coefficient relates the polarization $\left(\mathrm{P}_{i}\right.$ - charge per unit area) to the mechanical stress $\left(\sigma_{j}\right)$ by equation (2.2). The actual values

$$
P_{i}=d_{i j} \sigma_{j}
$$

obtained by Yanovskii et al. ${ }^{15}$ where $\mathrm{d}_{33}=+120 \times 10^{-8}, \mathrm{~d}_{31}=+42 \times 10^{-8}$, and $d_{32}=-25.5 \times 10^{-8}$ in CGSE units。 In SI units these values are equivalent to $\mathrm{d}_{33}=+40 \times 10^{-12}, \mathrm{~d}_{31}=14 \times 10^{-12}$, and $\mathrm{d}_{32}=8.5 \times 10^{-12}$ coulomb/newton. The values have error terms no larger than $20 \%$ of the reported value.

\section{Ferroelectricity}

When a dielectric crystal is of a polar point group with a built-in spontaneous polar axis, the material is pyroelectric. Fluctuation in temperature causes a change in polarization, and a subsequent change in surface charge. Some pyroelectric crystals have a component of the polar vector, which can be experimentally reorientated by an applied external electric field. This polarization reversal behavior is known as ferroelectricity. 21

The phenomenon of ferroelectricity can be studied by investigating the polarization-field hysteresis behavior of a polar material. Figure 5 shows a 


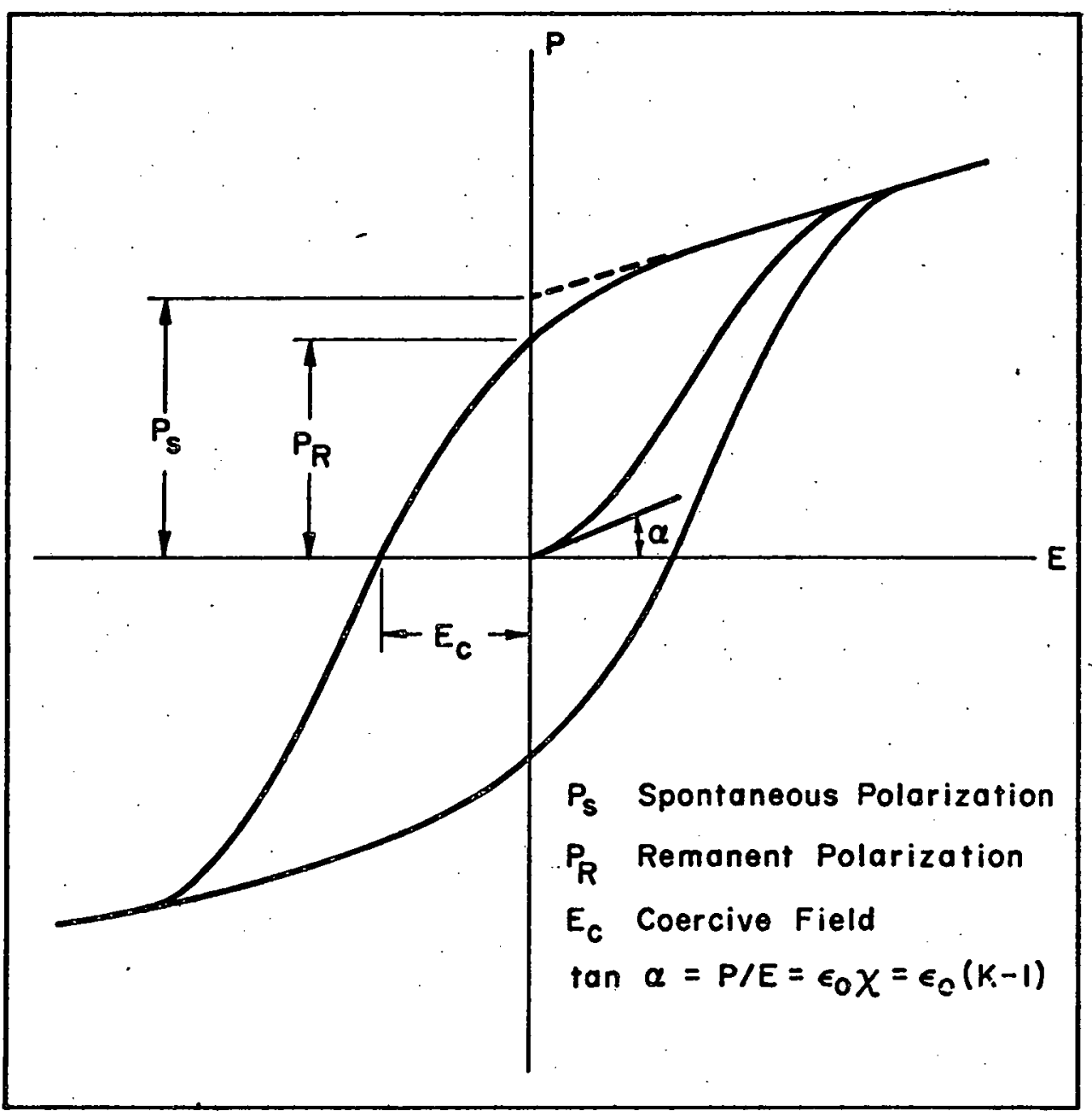

Figure 5. Polarization Reversal and Dielectric Hysteresis. 22 
typical hysteresis loop for a ceramic specimen. As the electric field is increased, the degree of orientation of the dipoles in the field direction increases, which increases the polarization $(P)$. Eventually the field reaches a maximum value with a corresponding maximum value of polarization. Extrapolation of the linear portion of the curve to the $P$ axis defines the spontaneous polarization $\left(\mathrm{P}_{\mathbf{S}}\right)$. As the field is reduced the polarization decreases to the remanent polarization $\left(P_{r}\right)$ at zero field. Then as the field is reversed the polarization reaches zero at the coercive field $\left(E_{c}\right)$ before reaching a maximum in the opposite sense. The process repeats itself each time the field is reversed to give the illustrated hysteresis loop.

Diaz-Colon ${ }^{23}$ has reported measuring a spontaneous polarization $P_{S}<2$ for a $\mathrm{Bi}_{2} \mathrm{WO}_{6}$ crystal using a pulse-field method. He noted that the crystal would shatter under high fields. Ismailzade and Mirishli ${ }^{16}$ unsuccessfully attempted to develop a hysteresis loop for polycrystalline $\mathrm{Bi}_{2} \mathrm{WO}_{6}$. They utilized fields of $18-20 \mathrm{KV} / \mathrm{cm}$ at temperatures up to $150^{\circ} \mathrm{C}$. Wolfe $\mathrm{e}^{5}$ has calculated the spontaneous polarization of $\mathrm{Bi}_{2} \mathrm{WO}_{6}$ to be $0.42 \mathrm{C} / \mathrm{N}$.

Another feature of ferroelectrics is the presence of a Curie point. The curie point is the temperature at which a material transforms from a ferroelectric state to a paraelectric state (nonferroelectric) on heating. This change is due to the transformation from a polar to a nonpolar prototypic state. As the material is heated to the Curie point the spontaneous polarization decreases to zero. The dielectric constant reaches an anomalously high value at the Curie point, as the structure reorders. Above the Curie point the dielectric constant decreases hyperbolically with temperature according to the Curie-Wiess Law ${ }^{21}$. As mentioned earlier, no one has conclusively found a Curie point for $\mathrm{Bi}_{2}{ }^{\mathrm{WO}_{6}}$ :

In the previous section it was stated that a polycrystalline piezoelectric material will show no net piezoelectric effect. However, if the material 
is also ferroelectric, the ceramic can have a net piezoelectric effect superimposed by poling. 20 Poling is the application of an external field to reorientate the dipoles as close as possible to the poling direction. This gives the ceramic a net dipole moment along one axis similar to that found in a crystal. Usually poling is accomplished by applying a field greater than the coercive field at a temperature above the Curie point and then cooling the sample with the field still applied. There is no report in the literature that anyone has attempted to pole polycrystalline $\mathrm{Bi}_{2} \mathrm{WO}_{6}$.

E. Thermal Expansion of $\mathrm{Bi}_{2} \mathrm{WO}_{6}$

Fay $^{11}$ recorded the thermal expansion behavior of unfired polycrystalline $\mathrm{Bi}_{2} \mathrm{WO}_{6}$, which is illustrated in Figure 6. The calculated coefficient of thermal expansion between $200-600^{\circ} \mathrm{C}$ was $15 \times 10^{-6} /{ }^{\circ} \mathrm{C}$. In the $625-885^{\circ} \mathrm{C}$ temperature range the material contracted due to sintering. A large thermal expansion (2.4\% 1inear strain developed) occurred between 885 and $930^{\circ} \mathrm{C}$, which is attributed to the phase transformation. On reheating, a similar (upper) curve was developed, except the strain developed was $1.5 \%$ at the phase transformation. When the cylindrical sample used in the test was examined it was noted to have radial cracks, due to the strain developed in passing through the phase transformation.

F. Sintering of $\mathrm{Bi}_{2}{ }^{\mathrm{WO}_{6}}$

Densification of ceramics may be accomplished by a firing process known as solid state sintering. Preformed ceramic samples are fired at temperatures equal to one-half to three-quarters of their melting point, at which point the grains and pores change their size and shape. Since densification of the compacts is desirable, firing should decrease the amount of porosity. Sintering is driven by free-energy changes, such as decreases in surface area and 


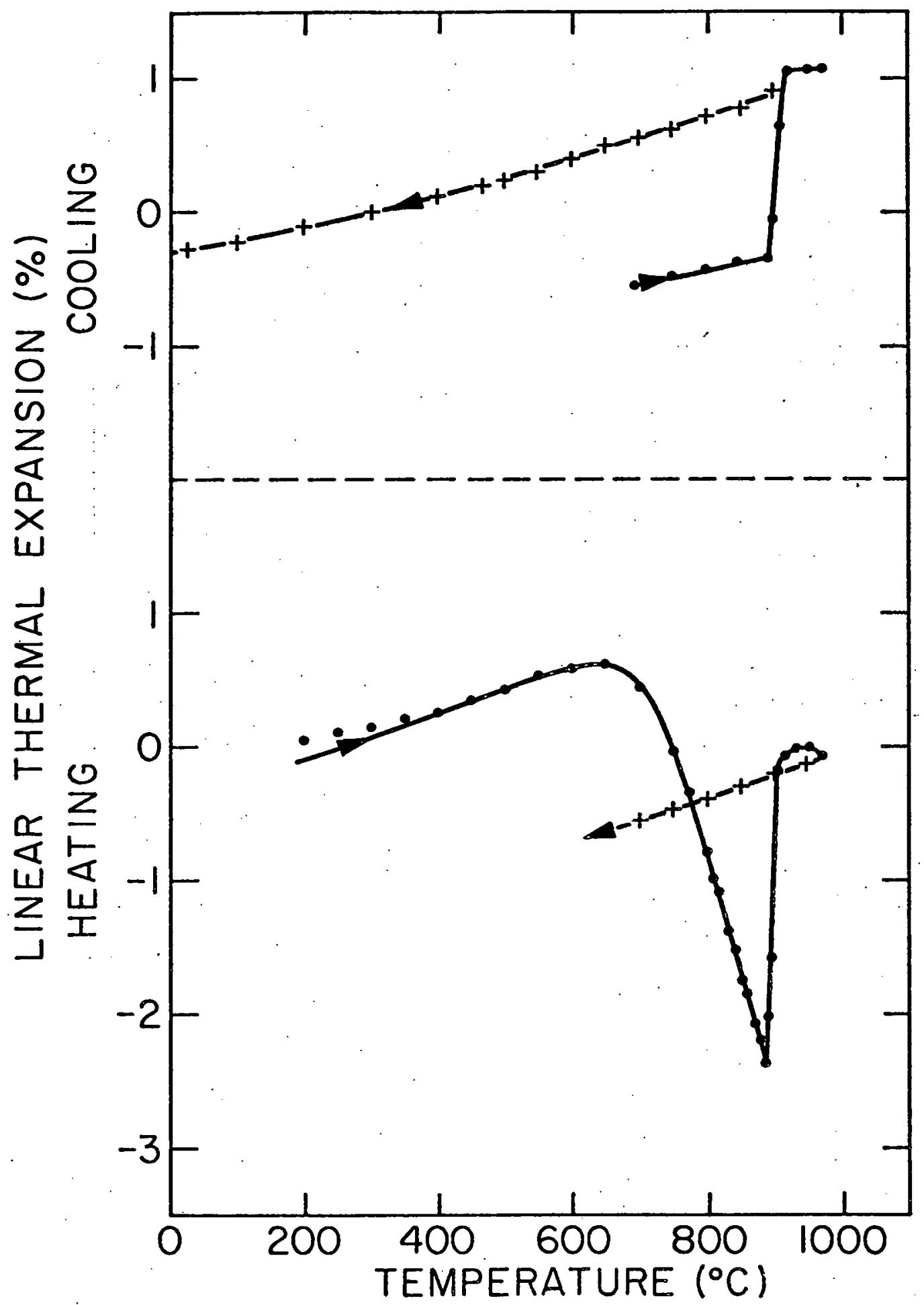

Figure 6. Therma1 Expansion Behavior of Pressed $\mathrm{Bi}_{2}{ }_{2}{ }_{6}$ Pellets. ${ }^{11}$ 
lowering of surface free-energy by elimination of solid-vapor interfaces. These processes result in the formation of new lower energy solid-solid interfaces. 24

Newkirk et al. ${ }^{10}$ reported sintering $\mathrm{Bi}_{2} \mathrm{WO}_{6}$ to greater than $90 \%$ theoretical density at $900^{\circ} \mathrm{C}$ for an unspecified time. This result is questionable, because a value of $7.35 \mathrm{~g} / \mathrm{cc}$ was given in the same paper for the theoretical density of $\mathrm{Bi}_{2} \mathrm{WO}_{6}$. This value is much lower than that reported by Yanovskii et al. ${ }^{15}(9.52 \mathrm{~g} / \mathrm{cc})$. Takahashi and Iwahara ${ }^{19}$ reported to have sintered $\mathrm{Bi}_{2}{ }^{\mathrm{WO}}{ }_{6}$ at $950^{\circ} \mathrm{C}$ in air for ten hours. The compacts obtained were reported to have $5 \%$ porosity, measured by a picnometric method in n-butanol. Ismailzade and Mirish $1 \mathrm{i}^{16}$ reported firing $\mathrm{Bi}_{2} \mathrm{WO}_{6}$ at $900^{\circ} \mathrm{C}$ for 15 hours. No densities for the sintered compacts were given. Rook $^{9}$ reported that sintering $\mathrm{Bi}_{2}{ }^{\text {WO }} 6$ for 16 hours at $950^{\circ} \mathrm{C}$ achieved compacts of $85 \%$ theoretical density $(8.09 \mathrm{~g} / \mathrm{cc})$. Finally, Fay $^{11}$ reported to have achieved $84 \%$ theoretical density $(8.00 \mathrm{~g} / \mathrm{cc})$ by sintering at temperatures between 925 and $950^{\circ} \mathrm{C}$ for one hour.

G. Hot pressing $\mathrm{Bi}_{2}{ }^{\text {WO }} 6$

A large amount of general literature is available on the densification of ceramics by the hot pressing technique. ${ }^{25-29}$ Briefly, hot pressing is the enhancement of densification by simultaneous application of external pressures and heat. The pressure augments the normal driving forces that achieve densification by solid state sintering. The equipment needed for hot pressing is a press to apply the external pressure, a punch and die assembly to transmit the pressure to the ceramic, and a furnace to apply thermal energy. One benefit of using hot pressing is that fine-grained dense ceramics can be produced by using lower temperatures, and excessive grain growth is prevented. This can be useful for fabrication of ferroelectric ceramics, because a finegrain microstructure is often desired. For instance, fine-grained dense PZT 
ceramics with superior electrical properties have been fabricated by hot pressing. 30

Complete densification of polycrystalline $\mathrm{Bi}_{2} \mathrm{WO}_{6}$ may be achieved by hot pressing, since sintering does not achieve a high density material. Johnson ${ }^{31}$ and Fay ${ }^{11}$ worked on the hot pressing of $\mathrm{Bi}_{2} \mathrm{WO}_{6}$. Johnson hot pressed at $750^{\circ} \mathrm{C}$ and $3000 \mathrm{psi}$ and Fay at $950^{\circ} \mathrm{C}$ and 2000 psi. Neither investigator reported the densities achieved or any properties of the hot pressed material.

\section{H. Electrode Polarization}

The passage of an electric current through an electrolyte, such as a dielectric solid or glass, may be accompanied. by a phenomenon termed electrode polarization. Electrode polarization refers to the build-up of layers of carrier ions at the sample-electrode interface. The degree of ionic buildup is dependent on the "blocking" ability of the electrodes. Macedo et al. 33 speculated that a highly resistive oxide layer on the electrode, or a thin air gap between the electrode and sample, would enhance the ionic build-up. The research showed this to be true when silver painted electrodes and clamped on stainless steel electrodes were used on $\mathrm{K}_{2} \mathrm{O}-0.3 \mathrm{SiO}_{2}$ glass. The silver electrodes were found to give a higher dielectric constant at frequencies less than $100 \mathrm{hz}$. This is possibly the result of the silver paint being somewhat resistive, which causes partial blocking at the electrode interface. Kim and Tomozawa ${ }^{34}$ found paste electrodes of gold or silver on soda-lime glass gave higher dielectric constants at low frequencies $(<10 \mathrm{kHz})$ than gold or silver evaporated electrodes. Greater charge transport across the evaporated electrodes (less blocking capability) caused the lower dielectric constant and was attributed to the presence of an alkali hydroxide phase at the glass-electrode interface. Also the frit present in the paste electrodes (bonding agent) could 
make the electrode more resistive, causing space charge layers to form giving a higher dielectric constant. Electrodes could cause similar effects in the electrical properties of other ionic conductors, such as imperfect dielectric solids. 


\section{CHAPTER THREE}

\section{EXPERIMENTAL METHODOLOGY}

\section{A. Material Preparation}

$\mathrm{Bi}_{2}{ }^{\mathrm{WO}} 6$ was prepared by solid state reaction of the constituent oxides at $850^{\circ} \mathrm{C} \mathrm{--}$ approximately $100^{\circ} \mathrm{C}$ below the high temperature phase transformation. Initially $\mathrm{Bi}_{2} \mathrm{O}_{3}$ and $\mathrm{WO}_{3}$ powders were weighed in equal molar ratios to obtain a total batch of 135 grams (see Appendix A for list of materials used). Mixing was accomplished by placing the powders in a plastic jar, which contained several nylon balls, and the jar was agitated on a "spec-mixer" for five minutes. Thoroughly mixed powder was reacted in a covered platinum crucible for 72 hours at the prescribed temperature of $850^{\circ} \mathrm{C}$. Synthesized $\mathrm{Bi}_{2} \mathrm{WO}_{6}$ was pulverized and checked for reaction completion by XRP. Any impurity phases present in quantities greater than 5 volume percent could be detected by XRD.

\section{B. Sample Preparation}

1. Dry Pressing

Samples were preformed for hot pressing and thermal expansion measurements by dry pressing. Reacted $\mathrm{Bi}_{2} \mathrm{WO}_{6}$ was pulverized in a mortar and pestle to a particle size less than 200-mesh. Three weight percent carbowax 6000 was added as a binder with excess distilled water, mixed by stirring, dried at $100^{\circ} \mathrm{C}$, and granulated by rolling between hands to produce spherical particles. The powder was sieved with $-40+200$ mesh granules being used for dry pressing and the oversized and undersized fractions being regranulated. 
One-half inch diameter discs were pressed on a Dennison hydraulic press to a pressed. thickness of one-quarter to one-half inch and were later used in sintering and hot pressing studies. Rectangular bars $(1.3 \times 0.6 \times 7.6 \mathrm{~cm})$ were pressed on a Carver laboratory press, and were later used in thermal expansion measurements

\section{Settling}

An attempt to orientate plate-like $\mathrm{Bi}_{2} \mathrm{WO}_{6}$ particles was undertaken by allowing them to settle out of a liquid suspension (settling method). Fine $\mathrm{Bi}_{2} \mathrm{WO}_{6}$ powder $(1-5 \mathrm{\mu m}$ diameter) was produced by dry ball milling for 3 hours in an alumina lined ball mill. Ten weight percent of the milled $\mathrm{Bi}_{2} \mathrm{WO}_{6}$ powder was added to a solution of distilled water containing 10 weight percent carbowax 6000, which was added to increase the suspension's viscosity and stability without introducing cation impurities. The suspension was placed in a fritted funnel (see Figure 7) and allowed to settle for 5 minutes, before applying a vacuum to facilitate compaction of the settled mass. The vacuum was interrupted after 2 minutes and the excess liquid was decanted off. These steps were repeated several times until a settled layer of sufficient thickness was obtained. The material was dried at $80^{\circ} \mathrm{C}$ in the funnel, and a $1 / 2$ inch diameter cork bore was used to obtain disc specimens.

\section{Tape Casting}

$\mathrm{Bi}_{2} \mathrm{WO}_{6}$ powder was tape cast by Johanson Dielectrics into 2 mil sheets. In the tape casting process a slurry of ceramic powder, binder, plasticizer, and liquid is mixed and cast over a substrate (i.e. stainless steel belt). The thickness of the sheet was controlled by a doctor blade, which is a gate adjusted to allow a certain thickness of material to flow over the substrate 


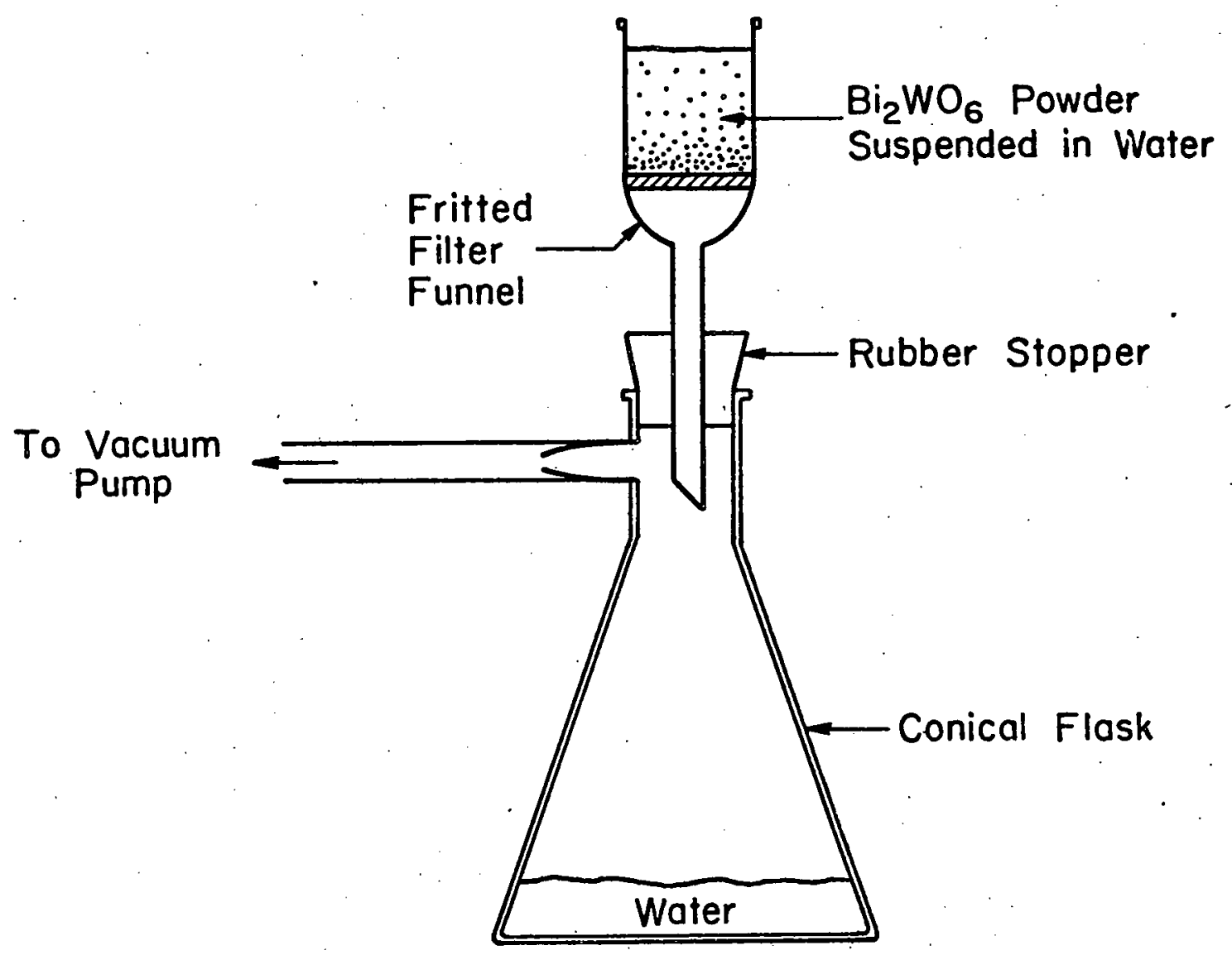

Figure 7. Settling of $\mathrm{Bi}_{2}{ }^{\text {WO }}{ }_{6}$ Powder. 
surface. Cast material dries and forms a flexible sheet. ${ }^{35}$ Tape cast sheets were laminated to form a 50 layer thickness, and one-half inch diameter discs were cored out with a thin walled cork bore. These discs were laminated together to obtain a final thickness of approximately $1 / 2$ inch which was used in hot pressing experiments.

\section{Thermal Expansion}

Dry pressed $\mathrm{Bi}_{2} \mathrm{WO}_{6}$ bars $(1.3 \times 0.6 \times 7.6 \mathrm{~cm})$ at $65 \%$ theoretical density were cut to a length of $5 \pm 0.005 \mathrm{~cm}$.. . An Orton automatic recording dilatometer was used to determine thermal expansion as a function of temperature, at a rate of $3^{\circ} \mathrm{C}$ per minute. The specimens were heated to temperatures above the phase transformation temperature and allowed to cool back while recording the subsequent contraction. The cooling rate could not be controlled, but was estimated at approximately $5-10^{\circ} \mathrm{C}$ per minute.

\section{Sintering}

A brief sintering experiment was conducted to confirm the results reported in Chapter Two. Dry pressed discs ( $79 \%$ dense) were fired at $915^{\circ} \mathrm{C}$ for 10 hours, and at $940^{\circ} \mathrm{C}$ for 10 hours. The density of the fired discs was calculated.

\section{E. Hot Pressing}

Equipment used for the hot pressing experiment is illustrated in Figures 8 and 9. Figure 8 shows the arrangement of the furnace and provisions for cooling the press platens, monitering temperature, and recording the linear displacement along the pressing axis. Figure 9 shows a cross-section of the furnace and die assembly. Punches were $1 / 2$ inch diameter 998 


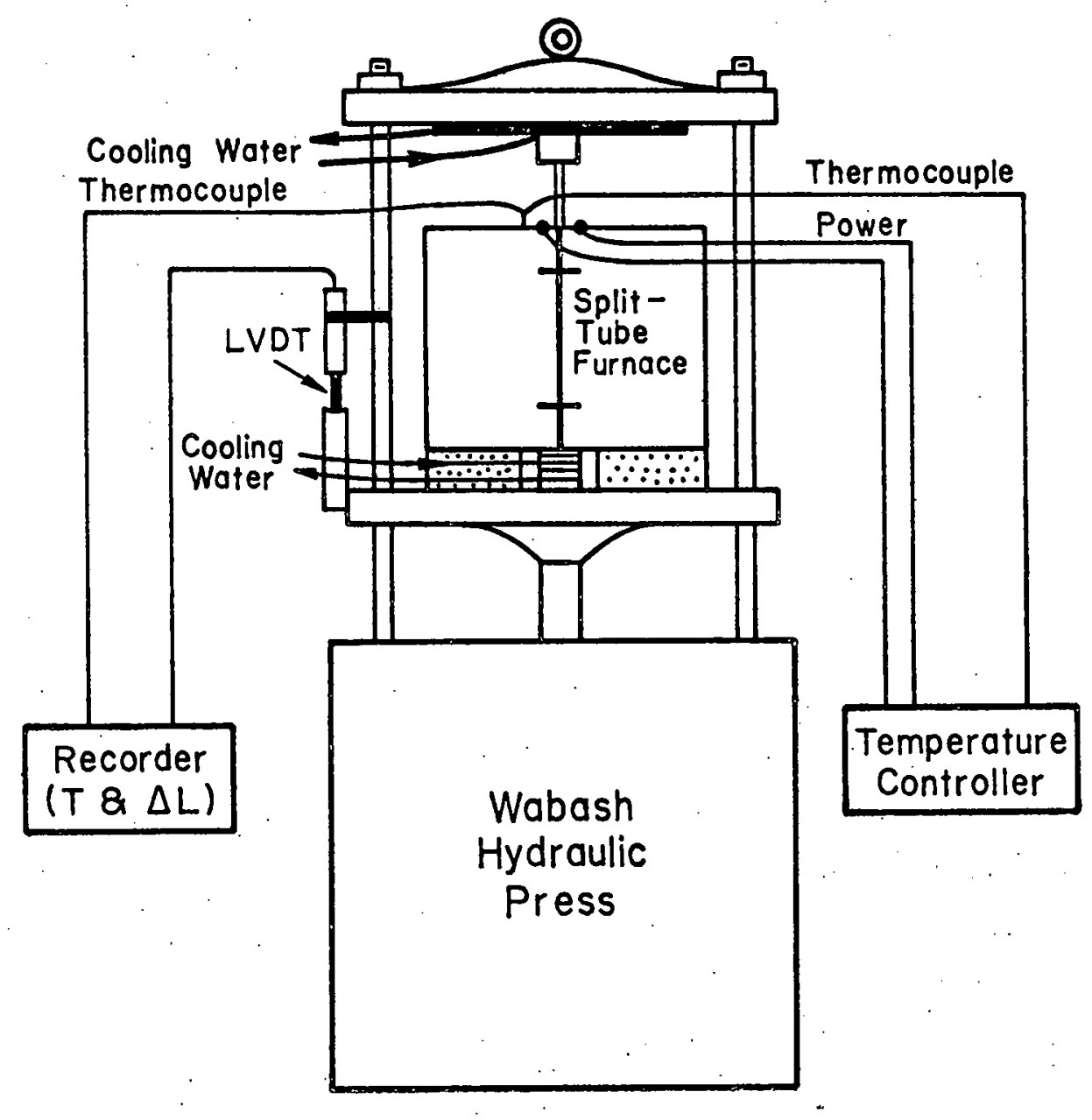

Figure 8. Hot Press. 


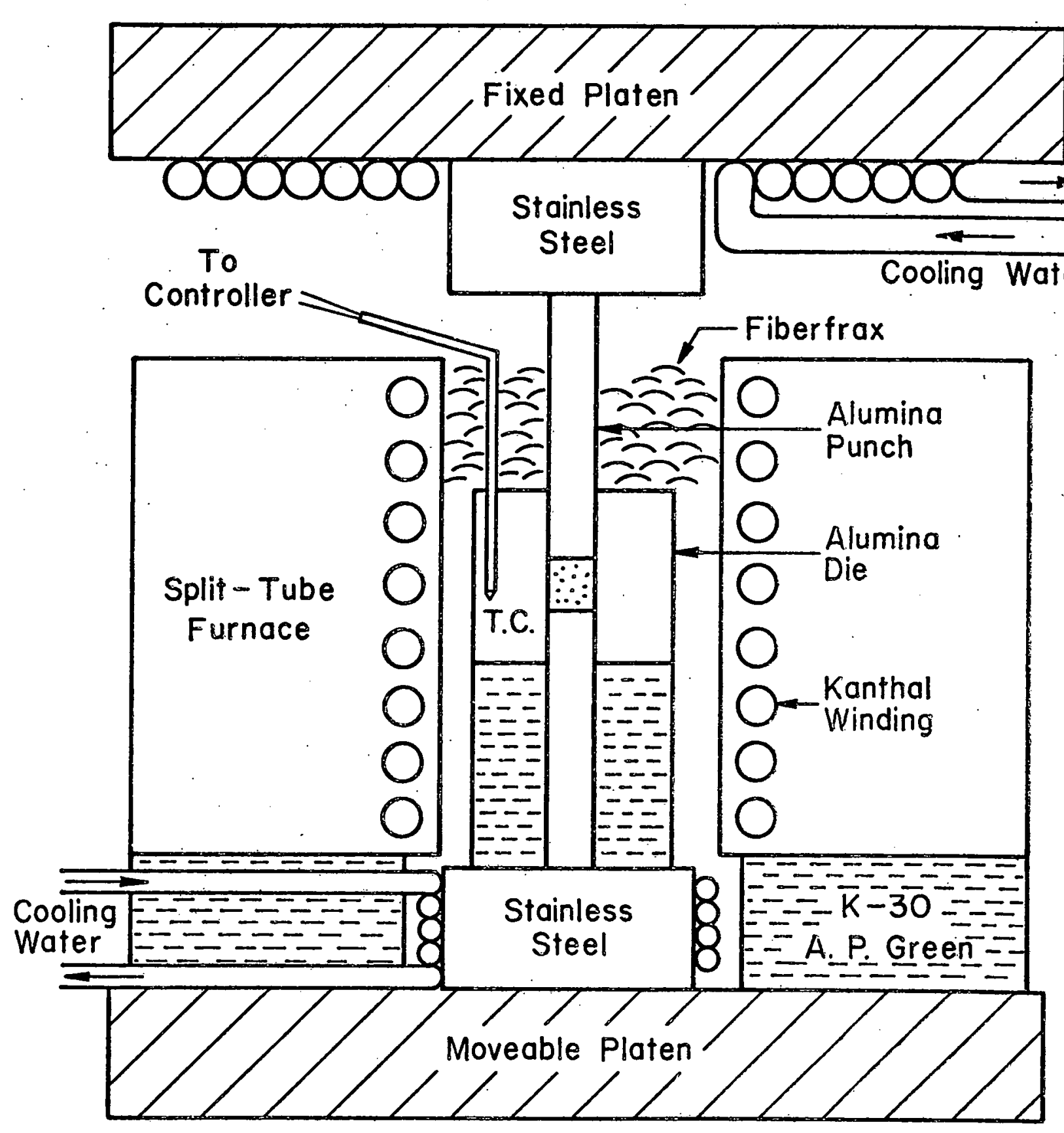

Figure 9. Hot Press Die Assembly. 
alumina rod from McDanel, and the die was 995 alumina from Western Gold and Platinum Company. The split-tube furnace used Lindberg semi-cylindrical heating units, which allowed easy access to the die assembly.

A standard hot pressing procedure was used for a11 samples. A prepressed $1 / 2$ inch diameter disc was placed in the die assembly, which was placed in the split-tube furnace with the thermocouple inserted into the well (see Figure 9). The furnace was closed, and Fiberfrax insulation packed around the upper portion of the die assembly. The die assembly was heated to $800^{\circ} \mathrm{C}$ in 2 hours, at which time pressure was applied. The assembly was then heated to $850^{\circ} \mathrm{C}$ and held at this temperature for 1 hour, while the sample temperature and linear shrinkage along the pressing axis was monitered on the recorder. At this time the pressure was relieved, the furnace opened momentarily while the sample was ejected from the die; and then the furnace was closed again to slowly cool the sample. Ejection of the sample was achieved by removing the refractory support and forcing the die down over the lower punch with a stainless steel tube. This allowed the upper punch to be removed; and left the sample sitting on the lower punch, which protruded out of the lower face of the die. When the sample made from tape cast material was hot pressed a slower initial heating rate was used to prevent too rapid burnout of the binder.

\section{F. Differential Scanning Calorimetry}

A Dupont differential scanning calorimeter (DSC) was used to detect any possible transformations, which might occur when heating powder or hot pressed samples to $550^{\circ} \mathrm{C}$. Data was also taken on cooling to room temperature and upon reheating to $550^{\circ} \mathrm{C}$. Hot pressed specimens were cut so that a flat surface was always in contact with the bottom of the aluminum sample holder. This 
facilitated quick thermal response for the calorimeter.

\section{G. Electrical Measurements}

1. Sample Preparation

Hot pressed $\mathrm{Bi}_{2} \mathrm{WO}_{6}$ discs were cut into sections as shown in Figure 10. Sections for electrical measurements were either parallel ( || - rectangular cross section) or perpendicular ( $\perp$ - half circle cross section) to the pressing axis. The thin sections were polished with 500 grit silicon carbide to the desired thickness, while ensuring parallel faces were maintained. Prior to taking electrical measurements the specimens were electroded with aluminum or palladium-gold by vacuum evaporation.

\section{Resistance Measurements}

Samples electroded with palladium-gold were used to determine the low field resistance $(0,1-1.3$ volts at constant current) as a function of temperature. A sample holder (Figure 11). with a Keithley 610B electrometer was used for the measurements. The sample holder was constructed from alumina structural parts and platinum leads to ensure Its capability for high temperature measurements (i.e. $1000^{\circ} \mathrm{C}$ ). D.c. conductivity was calculated as a function of reciprocal absolute temperature for an Arrhenius plot of activation energy.

\section{Capacitance and Conductance Measurements}

In conjunction with resistance measurements a Hewlett Packard 4270A automatic capacitance bridge was used to determine capacitance and conductance as a function of temperature until the samples were so lossy that readings could not be balanced by the bridge. Weak field measurements ( 1 volt rms) were made at $1 \mathrm{kHz}, 10 \mathrm{kHz}, 100 \mathrm{kHz}$, and $1 \mathrm{MHz}$. Other hot pressed $\mathrm{Bi}_{2}{ }^{\mathrm{WO}}{ }_{6}$ samples were measured in a separate sample holder, as illustrated in Figure 12. This 


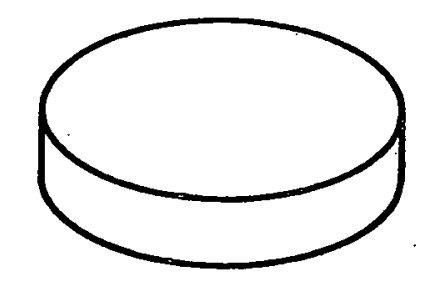

\section{Hot-Pressed Disc}

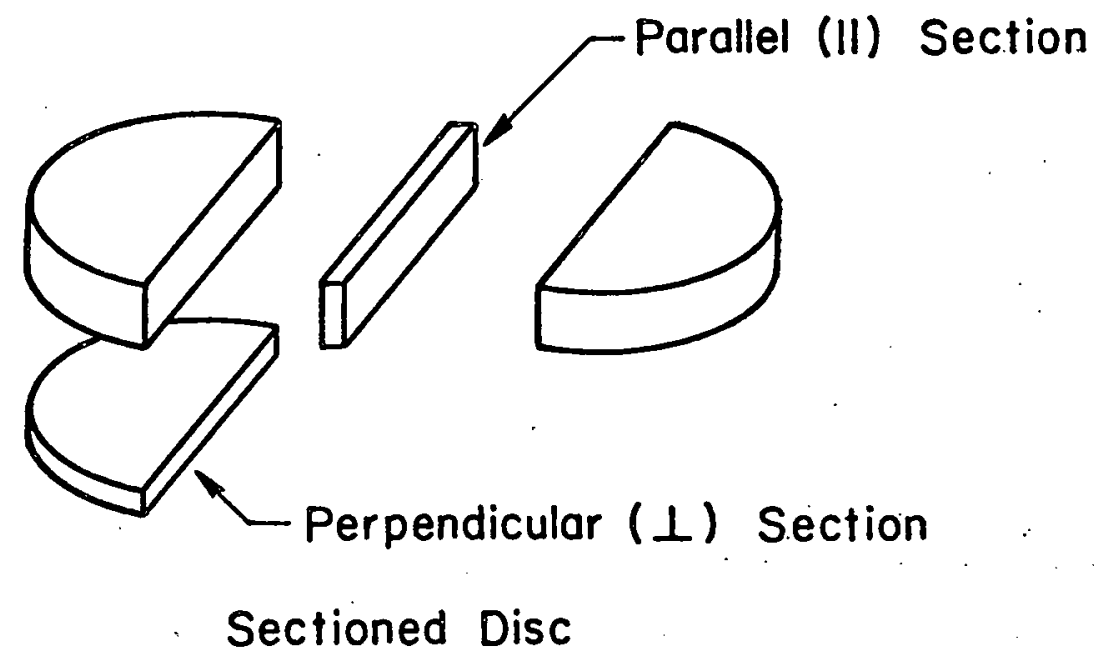

Figure 10. "Orientation" of $\mathrm{Bi}_{2} \mathrm{WO}_{6}$ Section. 


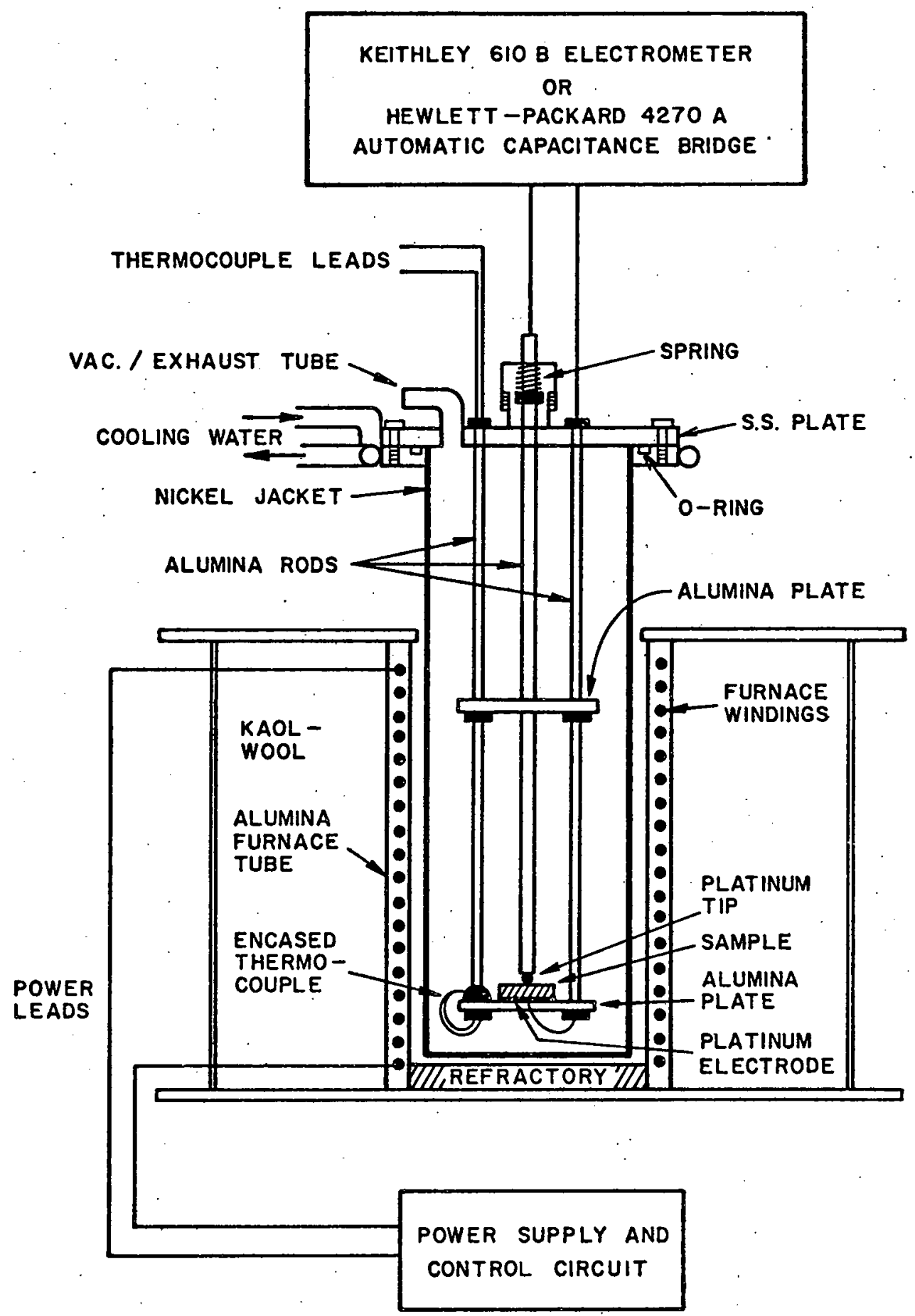

Figure 11. High Temperature Sample Holder. 


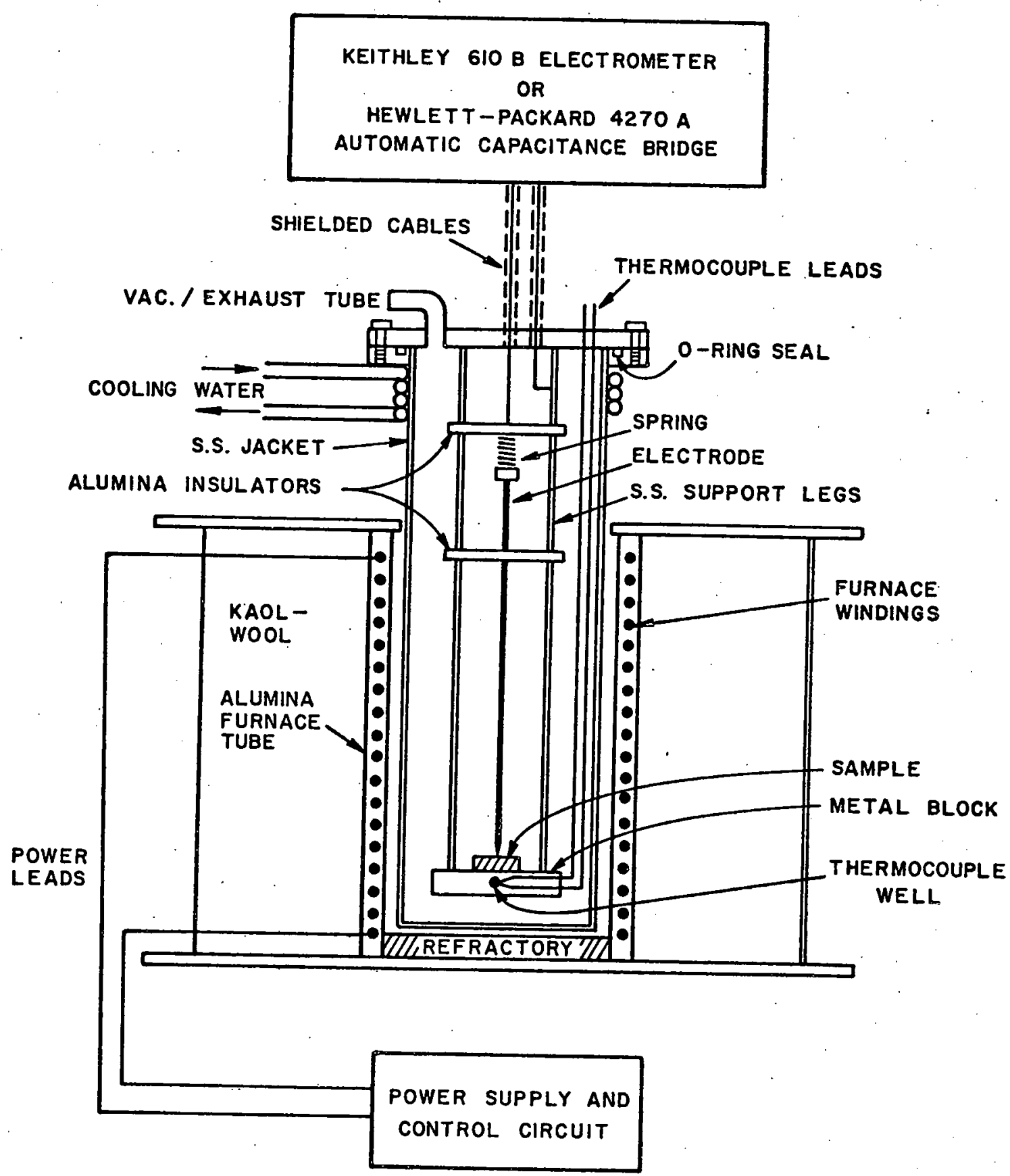

Figure 12. Sample Holder for Electrical Measurements. 
sample holder was constructed of metallic materials capable of withstanding temperatures up to $500^{\circ} \mathrm{C}$. When using this sample holder capacitance and conductance measurements were recorded as the sample cooled down from $500^{\circ} \mathrm{C}$. Dielectric constant and a.c. conductivity values were calculated as a function of temperature.

\section{4. a.c. Poling}

Samples with palladium-gold electrodes were used to determine the remanent polarization $\left(P_{r}\right)$ as a function of temperature for hot pressed $\mathrm{Bi}_{2} \mathrm{WO}_{6}$. The basic a.c. poling circuit, which used a Sawyer Tower bridge, is shown in Figure 13. Samples were placed in a silicone oil filled chamber and heated to $180^{\circ} \mathrm{C}$. Remanent polarization was calculated from oscillographs taken on a cooling in an applied field of $1.5 \mathrm{KV}$.

\section{Current-Voltage Measurements}

The current passing through hot pressed $\mathrm{BI}_{2} \mathrm{WO}_{6}$ samples electroded with aluminum or palladium-gold contacts was determined as a function of voltage. The circuit is shown in Figure 14, and consists of a Keithley 240 regulated high voltage power supply in series with the sample and a Keithley 610B electrometer. The sample holder (see Figure 13 for detailed drawing) was maintained at $150^{\circ} \mathrm{C}$, while current measurements were being made. A finite time was needed for the current to equilibrate at a saturation value at each new voltage level. A log-log plot of saturation current versus applied field was constructed.

\section{6. d.c. Poling and Piezoelectric Measurements}

Two procedures were used to d.c. pole $\mathrm{Bi}_{2} \mathrm{WO}_{6} \cdot$ A first set of samples were sent to Endevco for d.c. poling experiments. These samples were electroded 


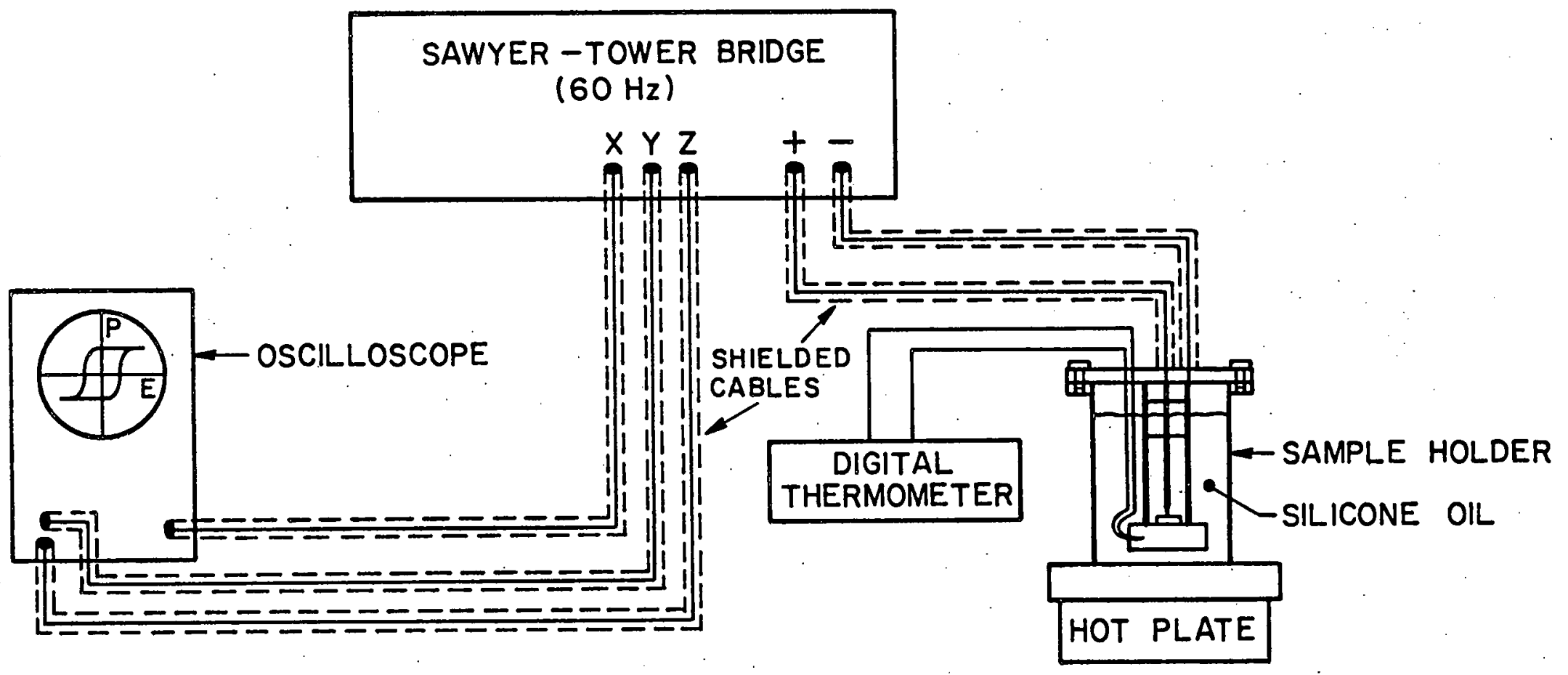

Figure 13. a.c. Pollng Circuit. 


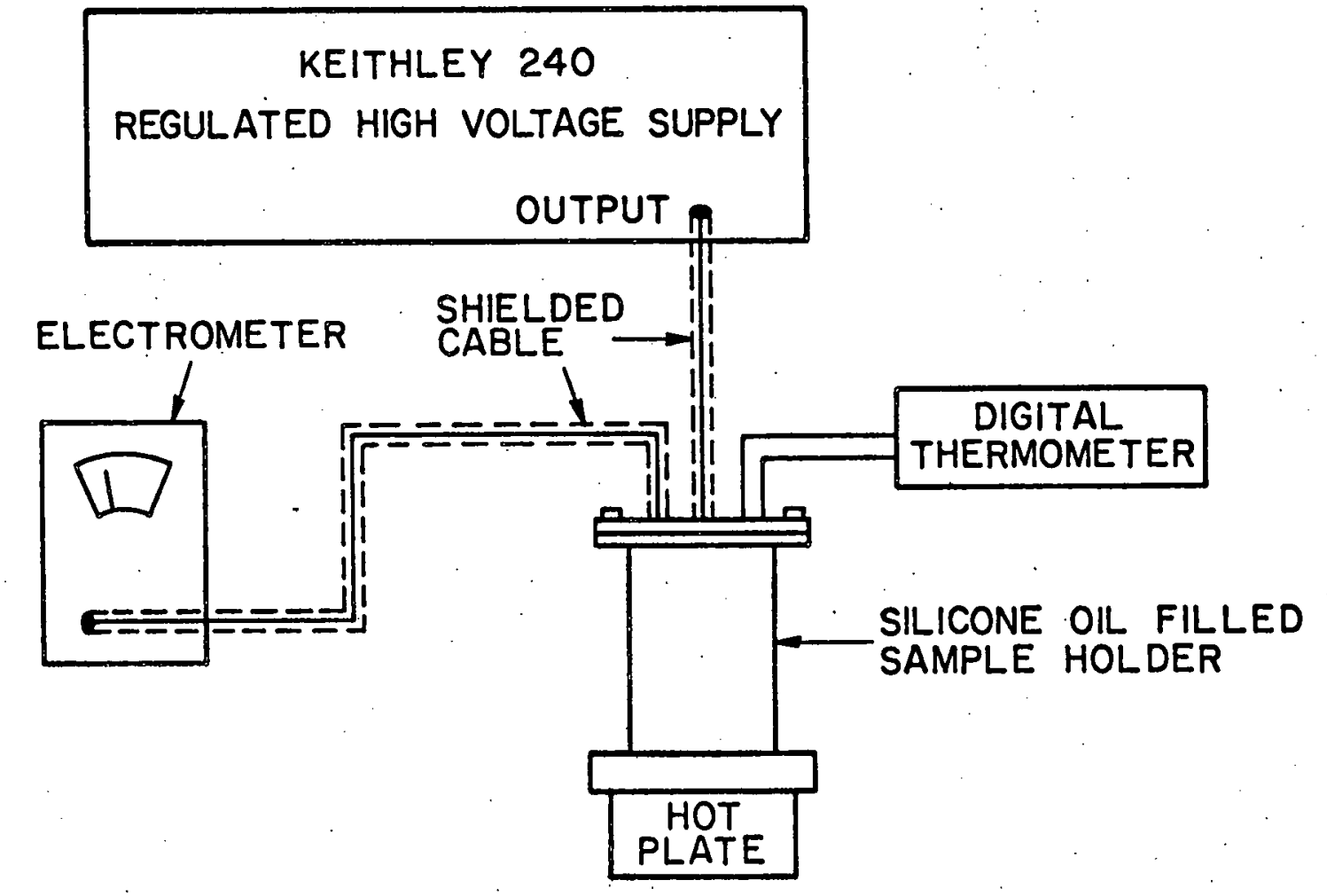

Figure 14, Experimental Setup for Current-Voltage, Measurements. 
with aluminum electrodes, and immersed in a silicone oil bath which was placed In a vacuum chamber for 1 hour at $100^{\circ} \mathrm{C}$ and $3^{\prime \prime} \mathrm{Hg}$ vacuum. Voids were impregnated and the surface coated with the high dielectric strength oil. Samples were removed from the vacuum chamber, immersed in silicone oil, and heated to $205^{\circ} \mathrm{C}$. A field was applied and limited to a value where the leakage current reached $0.15 \mathrm{~mA}$. The samples were then cooled down to room temperature with the field still applied; at which timethe field was removed and the samples removed for piezoelectric measurements 。

A second set of samples were d.c. poled by the author in a similar fashion, but without the vacuum treatment. These samples were electroded with aluminum or palladium-gold contacts and poled in silicone oil (Figure 15). The sample holder was similar to that illustrated in Figure 12. Using this procedure, the oil was heated to $180^{\circ} \mathrm{C}$ and a voltage applied, which corresponded to $0.1 \mathrm{~mA}$ leakage current. The voltage was maintained while cooling the sample to room temperature. Piezoelectric coefficients $\left(d_{33}\right)$ of all poled specimens were determined on a Berlincourt Piezo $d_{33}$ meter at $100 \mathrm{~Hz}$.

\section{H. X-ray Diffraction}

Hot pressed $\mathrm{Bi}_{2} \mathrm{WO}_{6}$ samples prepared by the settling methed were cut into parallel and perpendicular sections (see Figure 10). X-ray diffraction patterns were run for powder samples of reaction sintered $\mathrm{Bi}_{2} \mathrm{WO}_{6}$ and hot pressed samples having the two orientations. The diffraction peaks obtained on each pattern were characterized by determining the set of diffracting crystal planes and measuring the area under each peak, which is directly related to the peak intensity. The relative intensities of the peaks produced by the same crystal planes, but different samples, could be compared. Any preferred orfentation of $\mathrm{Bi}_{2} \mathrm{WO}_{6}$ grains should cause detectable variations in relative peak intensities between samples analyzed. 


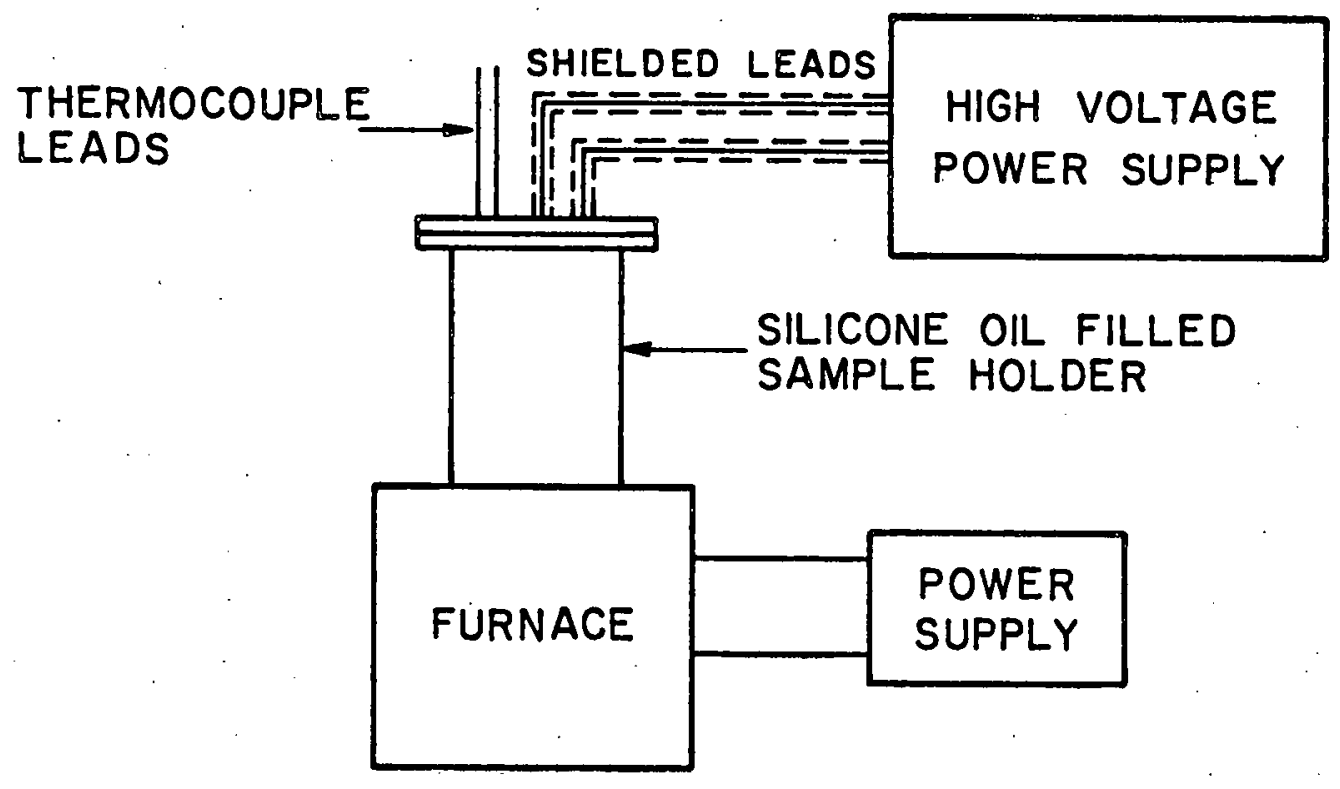

Figure 15. d.c. Pollng Circuit. 
CHAPTER FOUR

RESULTS AND DISCUSSION

\section{A. Powder Preparation}

Solid state reaction of $\mathrm{Bi}_{2} \mathrm{O}_{3}$ and $\mathrm{WO}_{3}$ for 72 hours at $850^{\circ} \mathrm{C}$ gave a porous sintered mass of material that was identified as $\mathrm{Bi}_{2} \mathrm{WO}_{6}$ by $\mathrm{XRD}$. When the material was pulverized in a mortar and pestle, the particles had a very angular morphology as shown in the photomicrograph given in Figure 16. Ball milled material had a similar overall morphology (Figure 17). Platelike particles are more apparent in the lower photomicrograph of Figure 17. Particle size is much more uniform and smaller when the material is ball milled.

Hydrothermally recrystallized material ${ }^{13}$ and material formed by quenching the melt ${ }^{11}$ have been shown to form crystallites that have a platelike morphology. It was originally hoped that size reduction of reaction sintered $\mathrm{Bi}_{2} \mathrm{WO}_{6}$ would give similar plate-like crystallites by the action of preferential cleavage. Plate-like morphology would allow the possible orientation of crystallites by the proper application of applied stress. Examination of photomicrographs indicated that this morphology was probably not attained.

\section{B. Dry Pressing}

Figure 18 shows the variation of pressed density with applied pressure. The relatively high density achieved by dry pressing was most likely attributed 


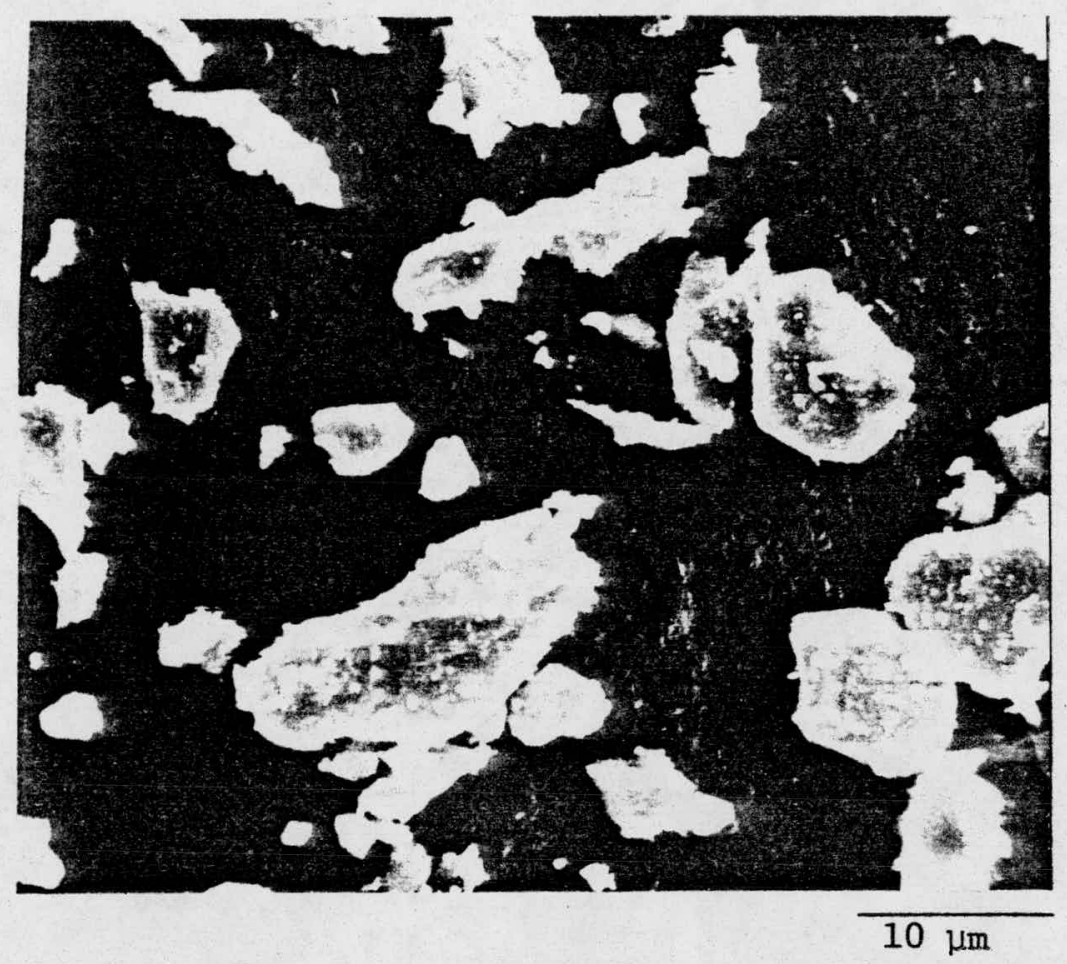

Figure 16. Pulverized Minus 200-mesh $\mathrm{Bi}_{2} \mathrm{WO}_{6}$ Powder.

to good particle size distribution resulting from size reduction of the reaction sintered material. ${ }^{36}$ Fay $^{11}$ reported even higher densities, especially at lower pressures. This was probably due to a different particle size distribution and a different particle morphology, which was obtained by synthesizing $\mathrm{Bi}_{2} \mathrm{WO}_{6}$ from the melt. These factors would be such that the packing efficiency 

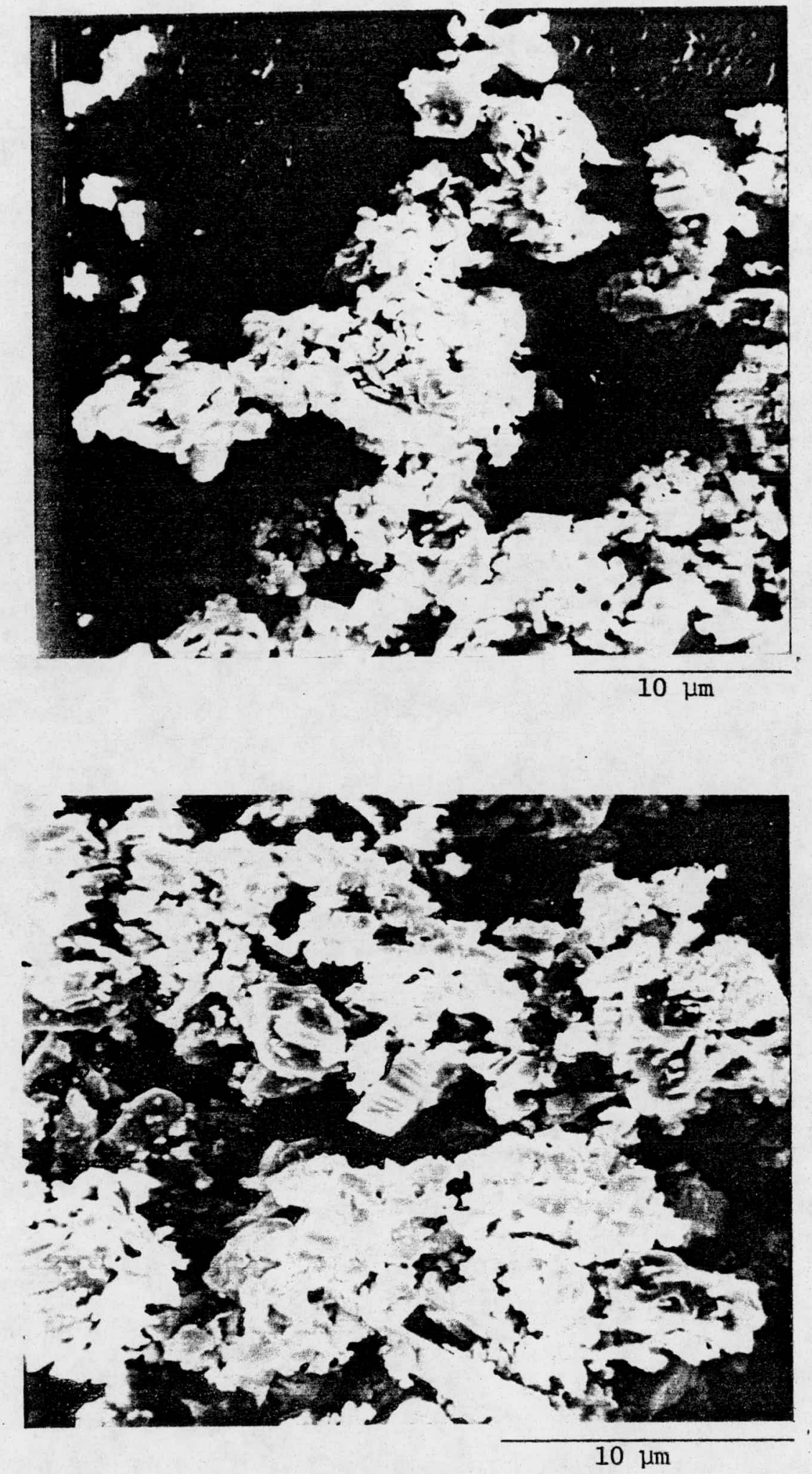

Figure 17. Ball Milled $\mathrm{Bi}_{2} \mathrm{WO}_{6}$ Powder. 


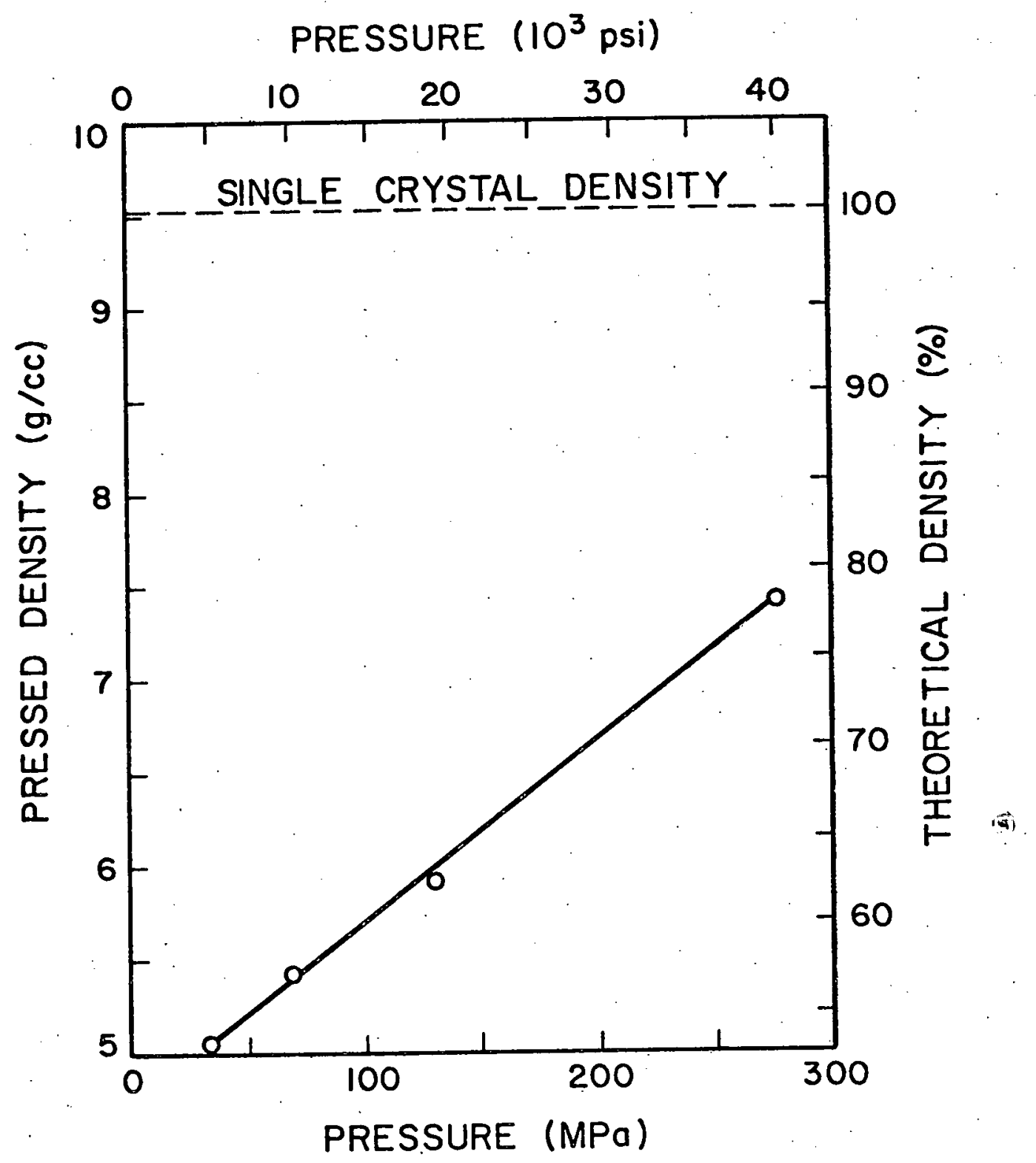

Figure 18. Pressed Density of $\mathrm{Bi}_{2} \mathrm{WO}_{6}$ at Various Compaction Pressures. 
was greater, allowing the attainment of higher densities.

\section{Thermal Expansion}

The Orton recording dilatometer was used to determine the thermal expansion behavior of unfired $\mathrm{Bi}_{2} \mathrm{WO}_{6}$ bars. Figures 19 and 20 illustrate thermal expansion versus temperature for $\mathrm{Bi}_{2} \mathrm{WO}_{6}$ synthesized at $850^{\circ} \mathrm{C}$, and by quenching from the melt, respectively. In Figure 19 the plateau at $300^{\circ} \mathrm{C}$ was probably due to binder burnout, causing a slight contraction opposing thermal expansion of the material. The following linear portion of the curve corresponded to a coefficient of thermal expansion of $13 \times 10^{-6} /{ }^{\circ} \mathrm{C}$. On further heating, contraction started at $680^{\circ} \mathrm{C}$ and continued until $910^{\circ} \mathrm{C}$. This contraction was due to solid state sintering of the unfired bar. At $910^{\circ} \mathrm{C}$ an abrupt expansion occurred corresponding to the phase transformation, which continúed to $945^{\circ} \mathrm{C}$. During the expansion, a $1.5 \%$ 1inear extension strain developed and a corresponding coefficient of thermal expansion of $475 \times 10^{-6} /{ }^{\circ} \mathrm{C}$. Hysteresis in thermal contraction occurred between $870-$ $840^{\circ} \mathrm{C}$ on cooling.

$\mathrm{Bi}_{2} \mathrm{WO}_{6}$ synthesized from the melt gave a similar type of thermal expansion behavior (Figure 20). The plateau due to binder burnout occurred at $380^{\circ} \mathrm{C}$. The following linear portion of the curve corresponded to a coefficient of thermal expansion of $13.7 \times 10^{-6} /{ }^{\circ} \mathrm{C}$. Contraction due to sintering started between 770 to $850^{\circ} \mathrm{C}$, and expansion due to the phase transformation on heating was $680 \times 10^{-6} /{ }^{\circ} \mathrm{C}$, with a corresponding linear extension strain of $2.4 \%$. On cooling the transformation occurred between 895 and $875^{\circ} \mathrm{C}$. The bar made from powder formed by quenching a melt of the constituent oxides had noticeable cracks, while the other bar did not. This cracking was probably due to the greater amount of strain developed at the phase transformation. The fact that strain was greater in this sample could be the result of 


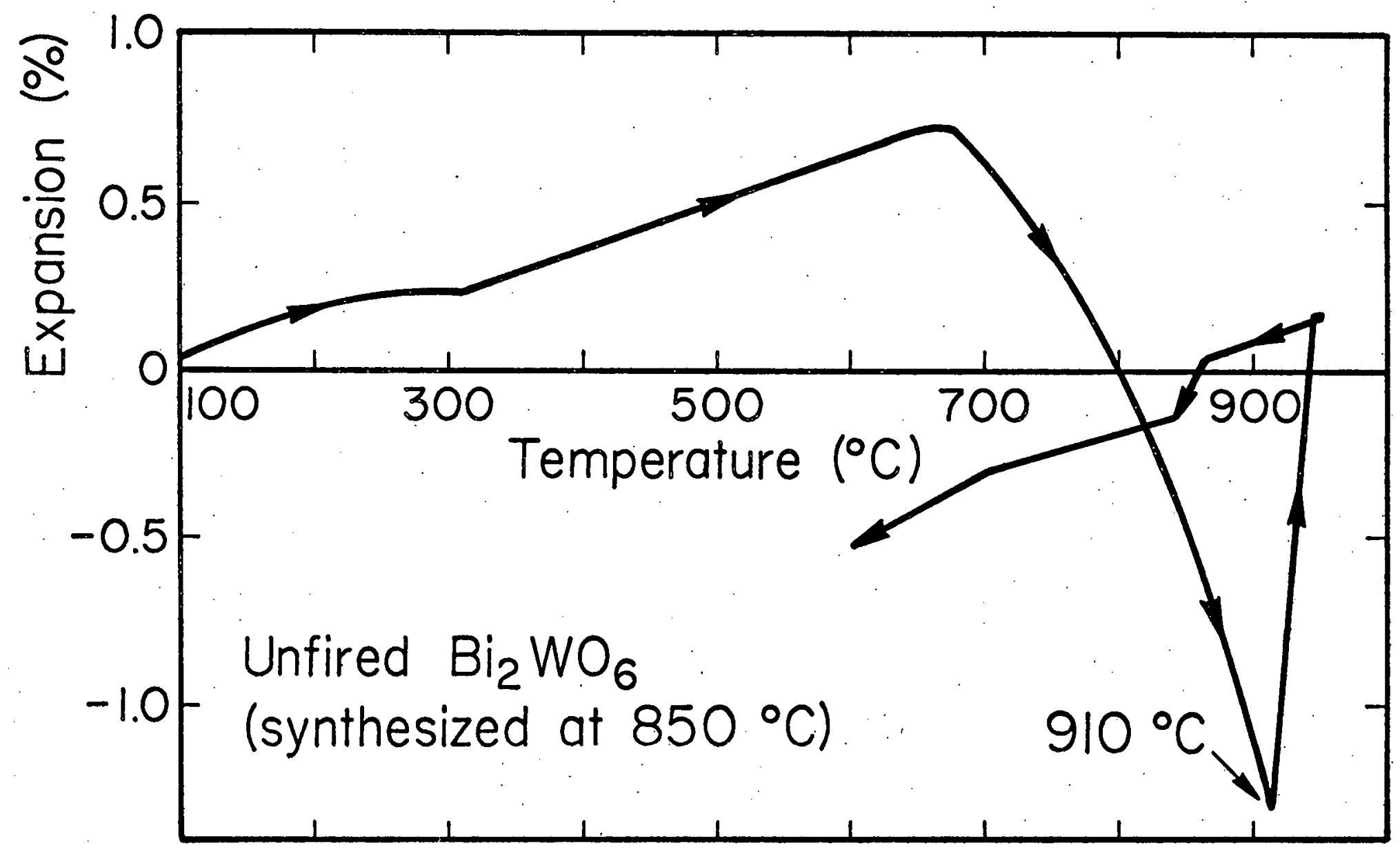

Figure 19. Thermal Expanston Behavior of Dry Pressed $\mathrm{BI}_{2} \mathrm{WO}_{6}$. 


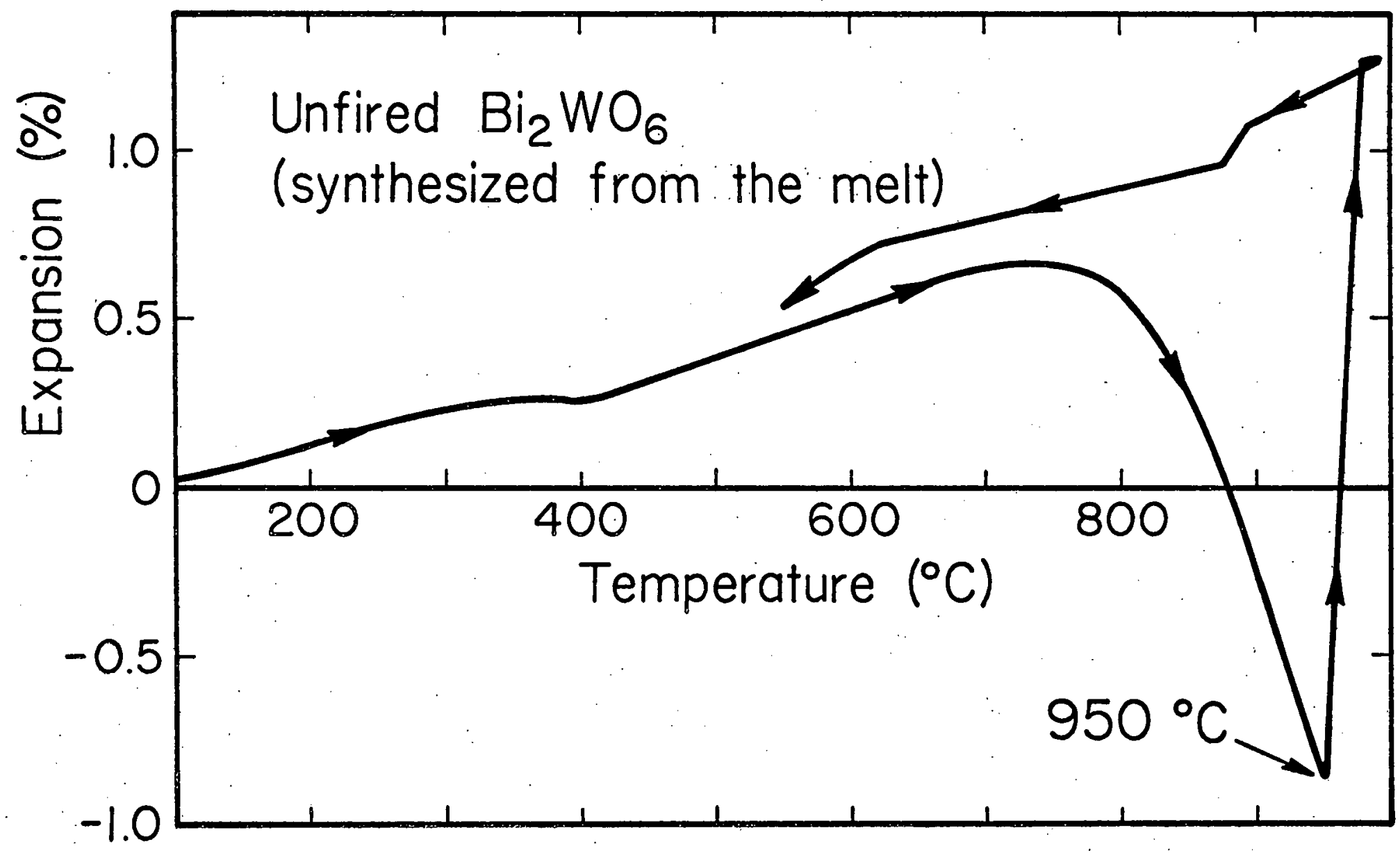

Figure 20. Thermal Expansion Behavior of Pressed $\mathrm{BI}_{2} \mathrm{WO}_{6}{ }^{\circ}$ 
residual stress release, which initially formed when the material was being prepared by rapid cooling through the phase transformation temperature region. Material synthesized at $850^{\circ} \mathrm{C}$ was not originally cooled through the transformation region, and would be expected to contain less residual stress. This was exemplified by the lack of cracking, and the smaller amount of strain developed at the phase transformation. The information collected showed that sintering could be accomplished between $700-900^{\circ} \mathrm{C}$ for $\mathrm{Bi}_{2} \mathrm{WO}_{6}$.

\section{Sintering}

Sintering of compacts at $916^{\circ} \mathrm{C}$ for 10 hours produced discs approximately $88 \%$ of theoretical density. Dry pressed pellets had a density of $78 \%$. Specimens sintered at $940^{\circ} \mathrm{C}$ cracked, so no density measurements were obtained. These results indicate that at the high temperature end of the sintering range, the densification rate was slow. The results are in agreement with other investigators mentioned in Chapter Two. It is believed the cracking of specimens at $940^{\circ} \mathrm{C}$ was due to the furnace cycling between 935 $945^{\circ} \mathrm{C}$. Evidently, the sample's temperature cycled within the temperature range of the phase transformation, and the resulting strain exceeded the strength of sintering $\mathrm{Bi}_{2} \mathrm{WO}_{6}{ }^{\circ}$

\section{E. Hot Pressing}

Hot pressing experiments were carried out at $850^{\circ} \mathrm{C}$ so as to stay well below the disruptive phase transformation. Figure 21 illustrates the linear shrinkage rate for $\mathrm{Bi}_{2} \mathrm{WO}_{6}$ during hot pressing. Pressure was applied at time zero, and the sample was heated from 790 to $850^{\circ} \mathrm{C}$ in the first half hour. The curves show an initial rapid shrinkage, which was attributed to a compaction of voids that were left behind after binder burnout and a subsequent realignment 


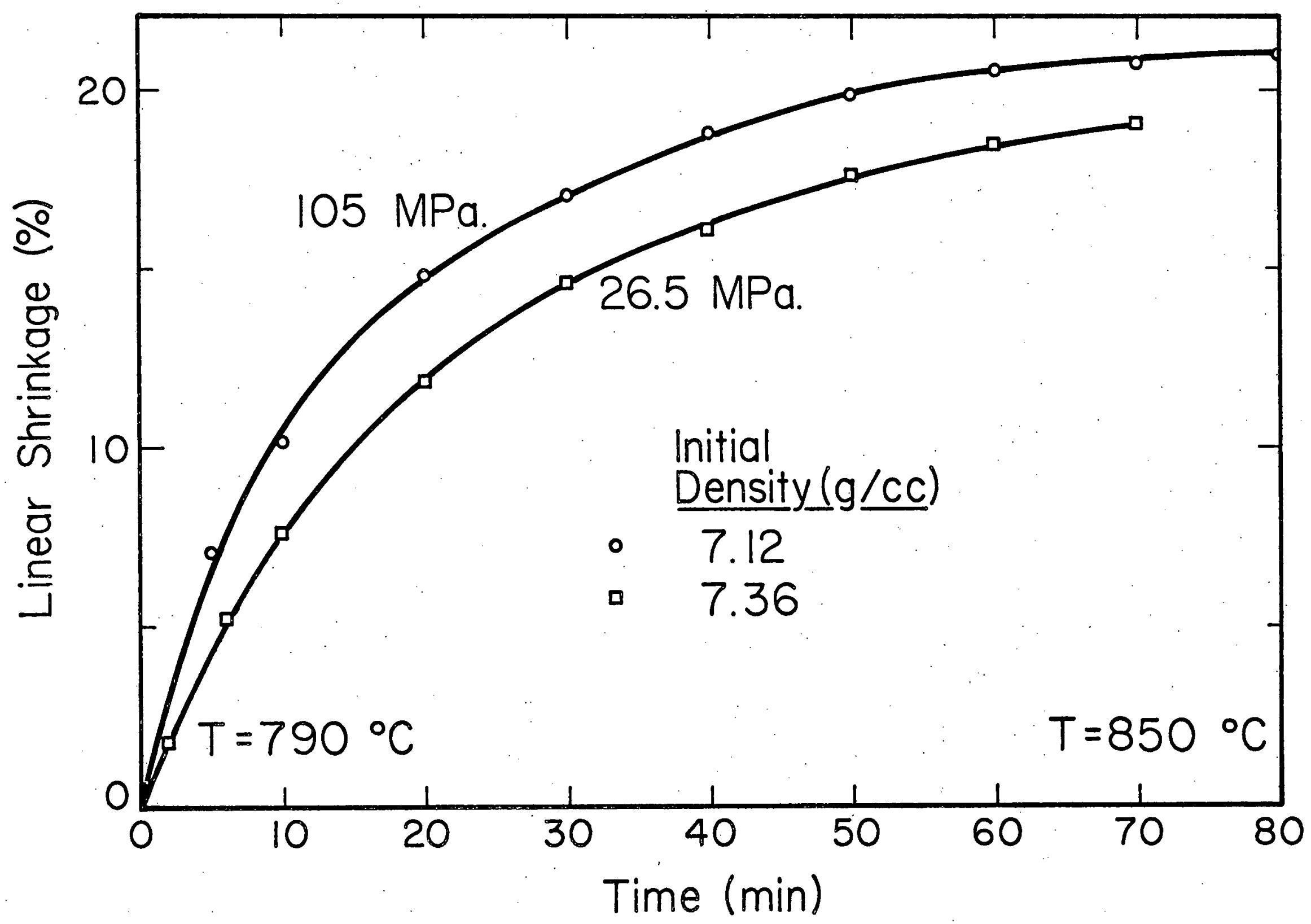

Figure 21. Shrinkage Rate During Hot Pressịn. 
of grains. Shrinkage rate decreased as hot pressing continued. This decrease in shrinkage rate represented the completion of void elimination by compaction, so that the shrinkage rate became dependent on the sintering rate of the materlal under pressure. 25

Figure 22 illustrates the effect pressure had on hot pressed density. The graph indicates that densities approaching single crystal value were achieved with pressures greater than $35 \mathrm{MPa}$ at $850^{\circ} \mathrm{C}$. Hot pressed compacts often had a dark central core. This was probably due to partial reduction of $\mathrm{Bi}_{2} \mathrm{WO}_{6}$ during binder burnout. The material probably did not reoxidize during hot pressing, due to a limited supply of oxygen entering the die cavity. When compacts were reheated in air at $850^{\circ} \mathrm{C}$, the dark area turned a yellowish green color characteristic of oxidized $\mathrm{Bi}_{2} \mathrm{WO}_{6}{ }^{\circ}$

\section{F. X-ray Diffractometry}

Diffraction patterns of $\mathrm{Bi}_{2}$ WO $_{6}$ powder and compacts with supposedly parallel and perpendicular particle alignment were determined. These compacts were previously prepared by the settling method and hot pressing. Comparison of peak intensities for the same set of crystal planes, but different samples, gave no conclusive results. The information did not indicate any preferred orientation in the hot pressed compacts.

G. Microstructure of Hot Pressed $\mathrm{Bi}_{2} \mathrm{WO}_{6}$

Figures 23-27 are fracturegraphs taken with the scanning electron microscope. The sample shown in Figure 23 is a hot pressed compact of $96 \%$ theoretical density. Some porosity can be seen and the overall grain morphology is rounded. The microstructure of hot pressed $\mathrm{Bi}_{2} \mathrm{WO}_{6}$ reported by Fay $^{11}$ was characterized by grains with a plate-like morphology. As mentioned 


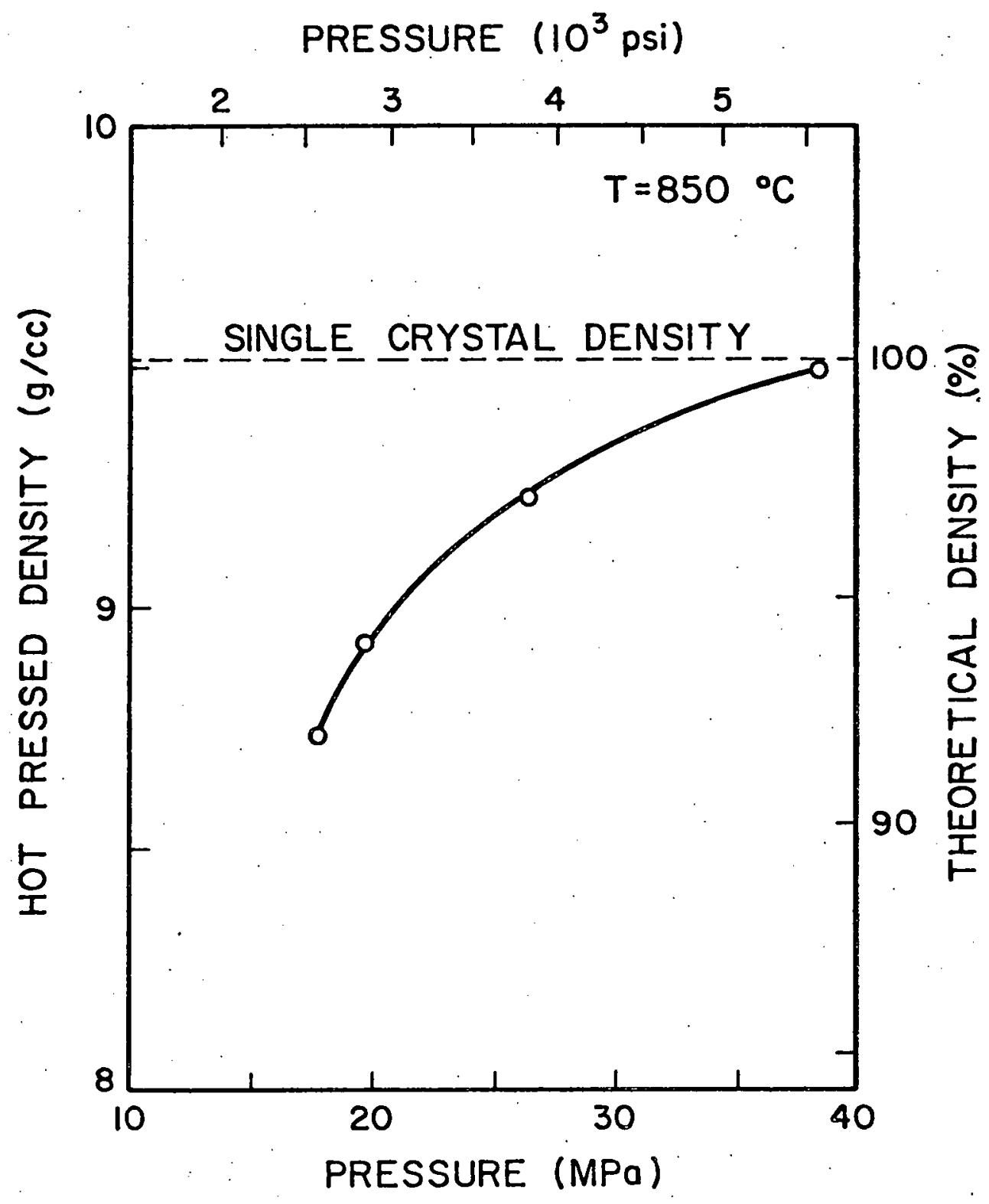

Figure 22. Pressure Dependence of Density

for Hot Pressed $\mathrm{Bi}_{2} \mathrm{WO}_{6}$. 

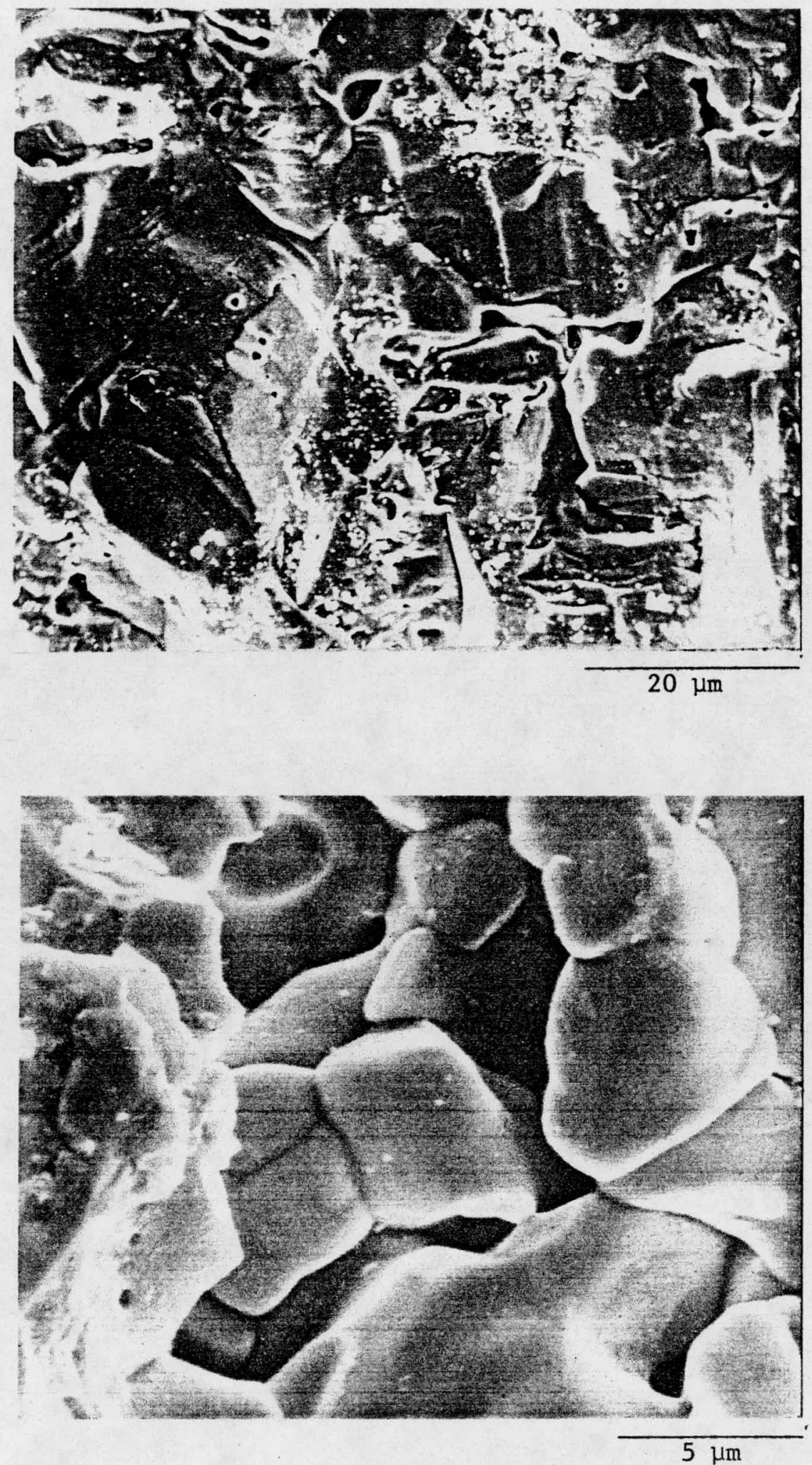

Figure 23. Hot Pressed $\mathrm{Bi}_{2} \mathrm{WO}_{6}$. 
earlier, this structure resulted from the powder preparation method, which was the quenching of a melt containing the constituent oxides. Evidently, this lead to a growth of crystallites with a plate-like morphology, similar to hydrothermally recrystallized $\mathrm{Bi}_{2} \mathrm{WO}_{6}{ }^{13}$

Figure 24 illustrates a fracture surface of hot pressed $\mathrm{Bi}_{2} \mathrm{WO}_{6}$ fabricated by the settling method. The original powder was ball milled, which may account for the smaller grain size when compared with the previous sample. The grains do not appear to have the desired plate-like morphology. Instead the grains appear as well faceted polyhedra as exemplified by a grain in the central portion of the upper fracturegraph in Figure 24.

Figure 25 illustrates the microstructure of hot pressed material fabricated by the tape casting procedure. The upper fracturegraph of the figure shows a layered structure caused by the lamination of the thin tape cast sheets. The fracturegraphs indicate no conclusive evidence of preferred grain orientation.

Figures 26 and 27 are fracturegraphs of hot pressed material that was initially dry pressed, and processed similarly to the samples shown in Figure 23. The only difference is that the sample pictured in Figures 26 and 27 was d.c. poled at $200^{\circ} \mathrm{C}$ and $60 \mathrm{kV} / \mathrm{cm}$ and had a piezoelectric coefficient $\mathrm{d}_{33}$ of $10 \mathrm{pC} / \mathrm{N}$. The fracturegraphs indicate the presence of areas between grains that appear to have a rough texture. This is especially noticeable in Figure 27. Unpoled samples did not exhibit these characteristic areas between grains. A possible explanation is electrochemical migration of $\mathrm{Bi}^{3+}, \mathrm{w}^{6+}$, or $0^{2-}$ ions in an electric field, resulting in localized changes in stoichiometry in these regions. However, elemental x-ray mapping indicates no detectable difference in bismuth or tungsten concentration in these regions when compared with grain interiors. Whatever the cause, this microstructural feature of 

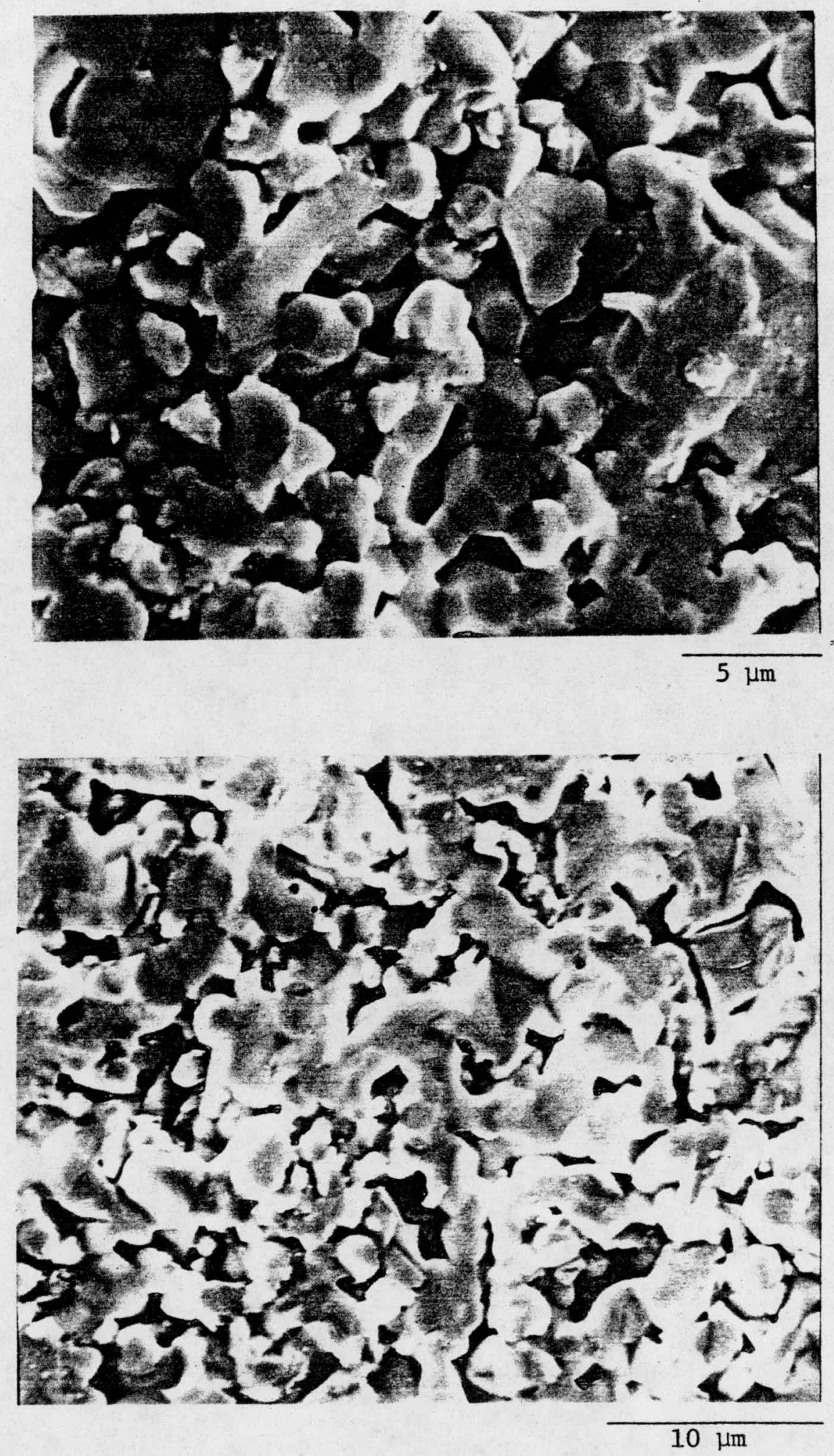

Figure 24. Hot Pressed $\mathrm{Bi}_{2}{ }^{\mathrm{WO}} 6$ Fabricated by the Settling Method. 

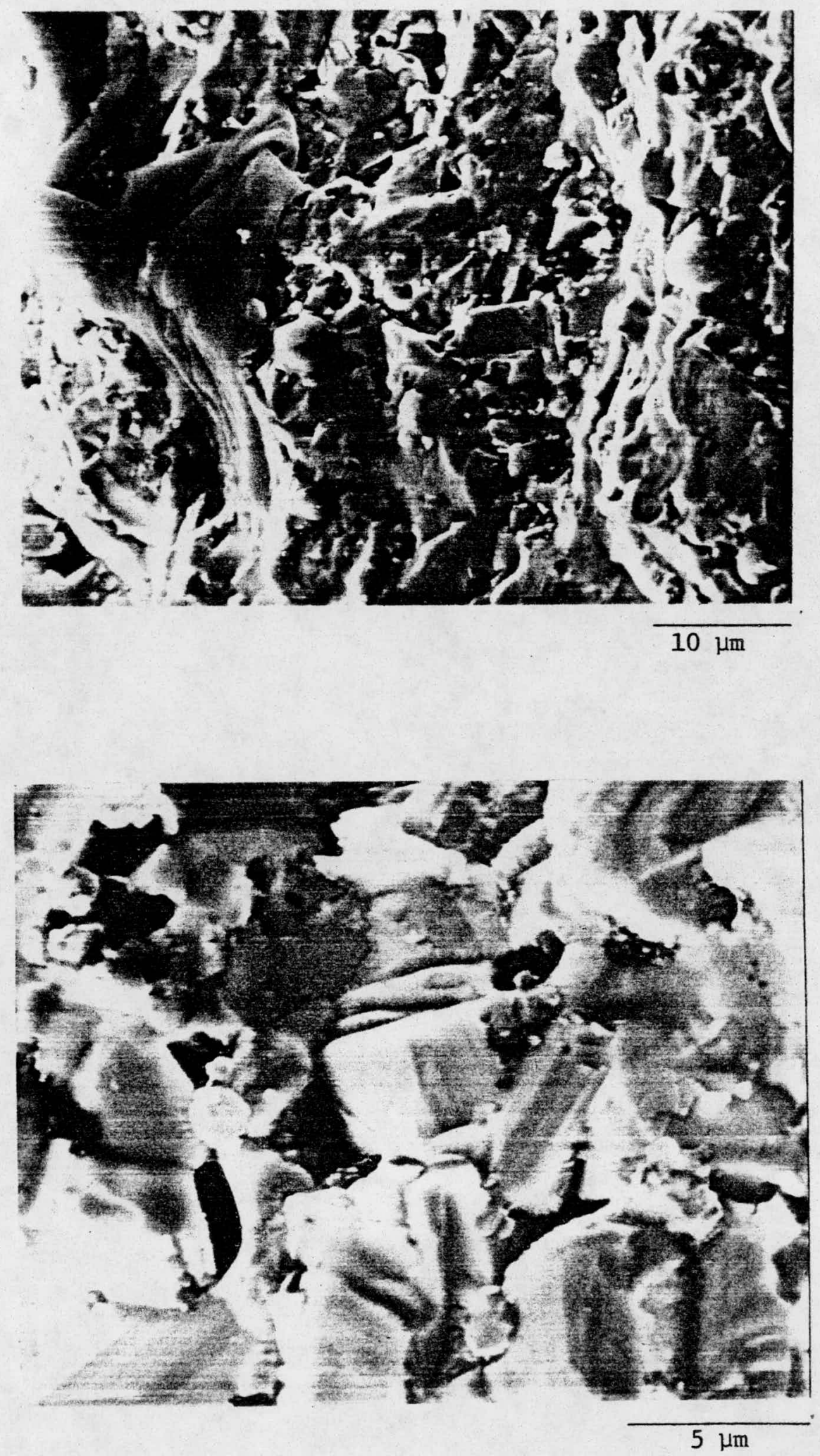

Figure 25. Hot Pressed $\mathrm{Bi}_{2} \mathrm{WO}_{6}$ Fabricated by Tape Casting. 

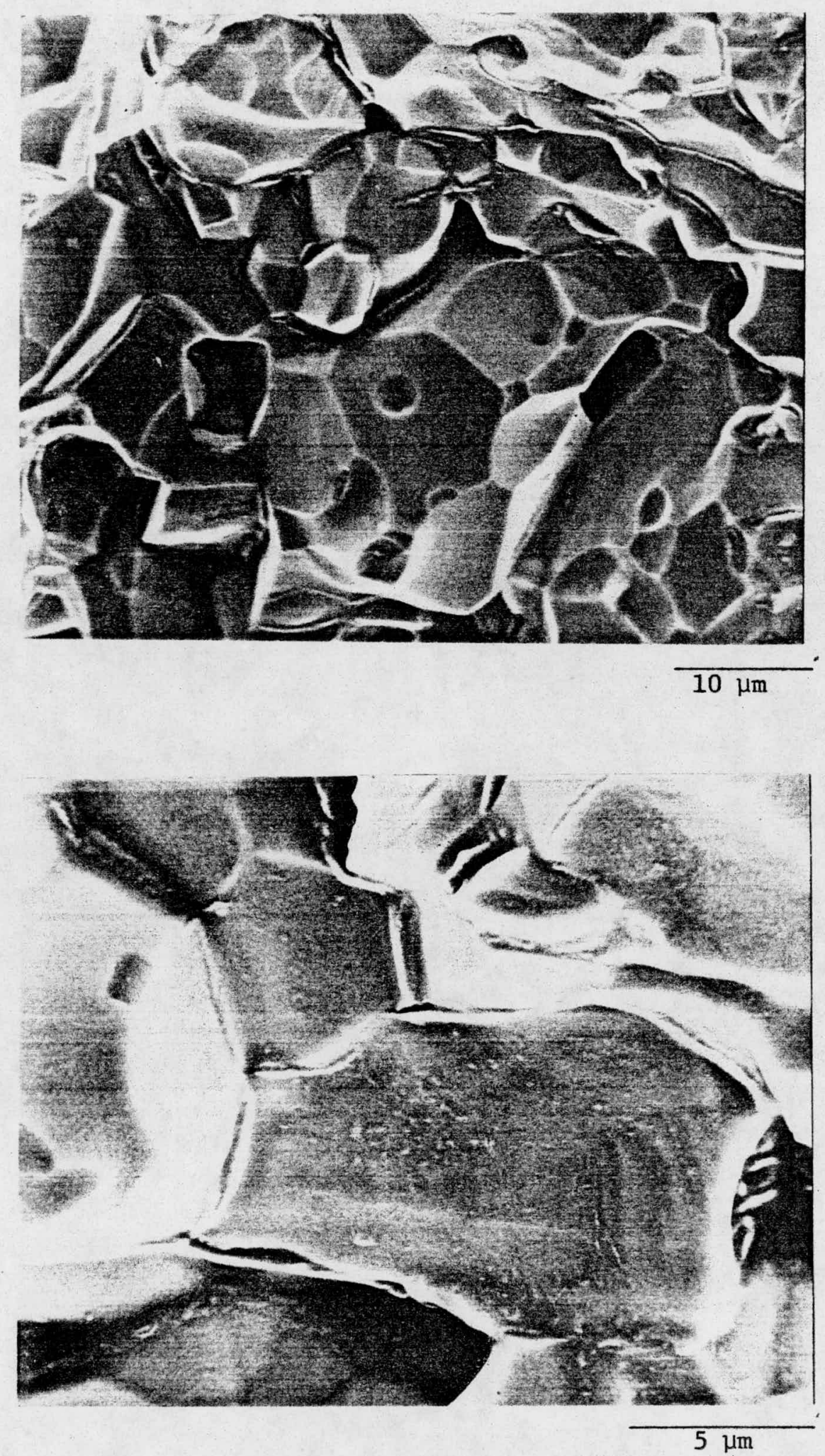

Figure 26. Poled Hot Pressed $\mathrm{Bi}_{2} \mathrm{WO}_{6}$ with Piezoelectric Response. 


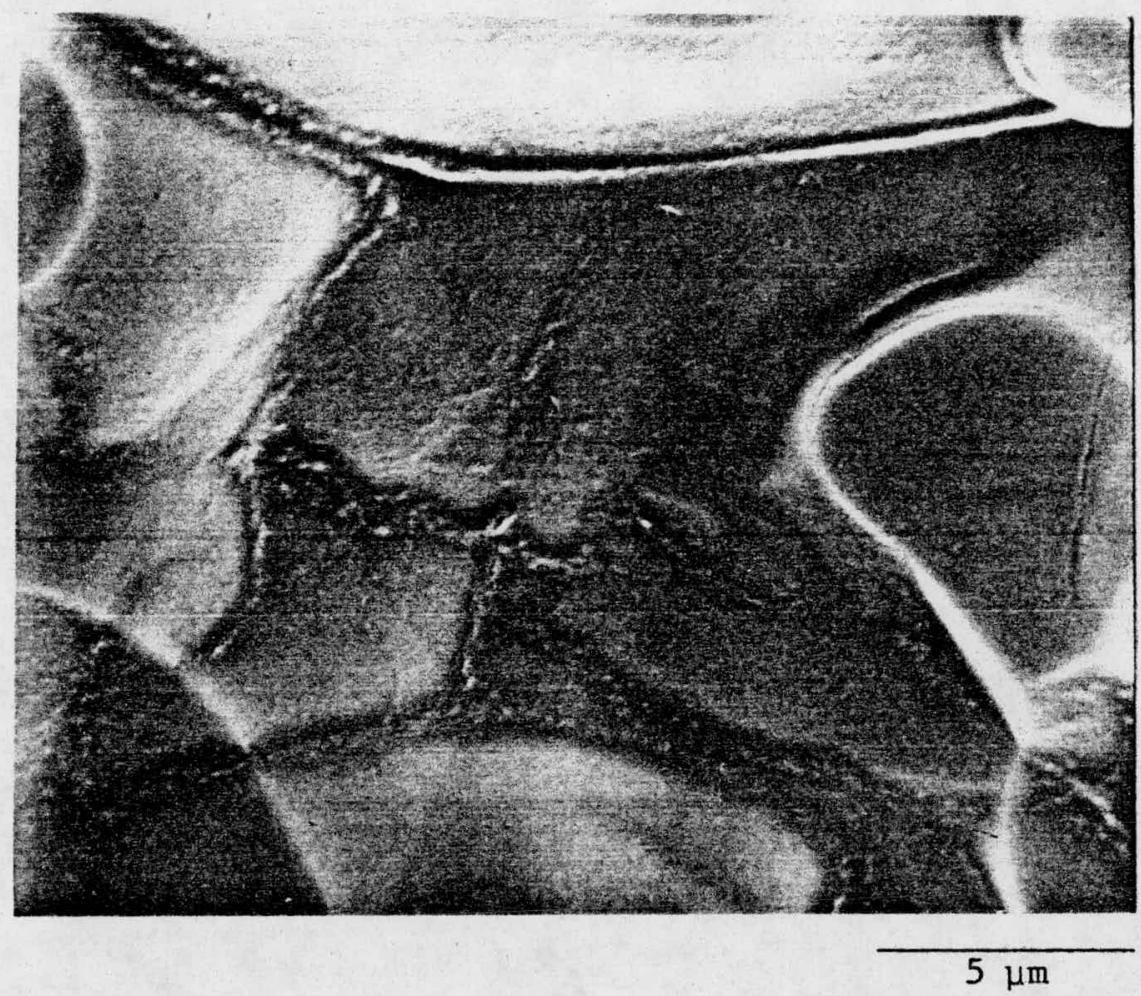

Figure 27. Poled Hot Pressed $\mathrm{Bi}_{2} \mathrm{WO}_{6}$ with Piezoelectric Response.

intergranular regions is definitely the result of d.c. poling experiments and most likely linked to the attainment of a net residual polarization $\left(\mathrm{P}_{\mathrm{r}}\right)$ and piezoelectric response $\left(d_{33}\right)$. 


\section{H. Differential Scanning Calorimetry}

A typical DSC plot for hot pressed $\mathrm{Bi}_{2} \mathrm{WO}_{6}$ is given in Figure 28, indicating an exothermic process occurs in the temperature region between 300 and $350^{\circ} \mathrm{C}$. The peak was related to a low enthalpy process of approximately $17 \mathrm{cal} . /$ mole, when calculated from the area underneath the curve. The process appears to be very sluggish judging from the broad, diffuse nature of the exotherm. On cooling and reheating, the peak was not found to occur. The peak appears to be connected with the release of residual stress from hot pressed samples. In fact, when a hot pressed sample was annealed at $550^{\circ} \mathrm{C}$ and slowly cooled to room temperature before running a DSC experiment, no detectable exotherm was found. The slope of the curves for the cooling portion of the first cycle and heating portion of the second cycle are due to differences in the thermal inertia between the hot pressed sample and the alumina standard.

\section{Electrical Measurements}

\section{1. d.c. Conductivity}

Figures 29 and 30 represent the temperature dependence of electrical conductivity for two sections of a hot pressed sample, which was fabricated by the settling method (95\% theoretical density). As can be seen from their slopes, the activation energy $\left(E_{a}\right.$, electron volts) is constant within experimental error. Equation 4.1

$$
\sigma=\sigma_{0} \exp \left(-E_{a} / k T\right)
$$

relates the conductivity to the activation energy $\left(E_{a}\right)$ and temperature ( $T$, degrees Kelvin). The other parameters used in equation 4.1 are $\sigma$ the 


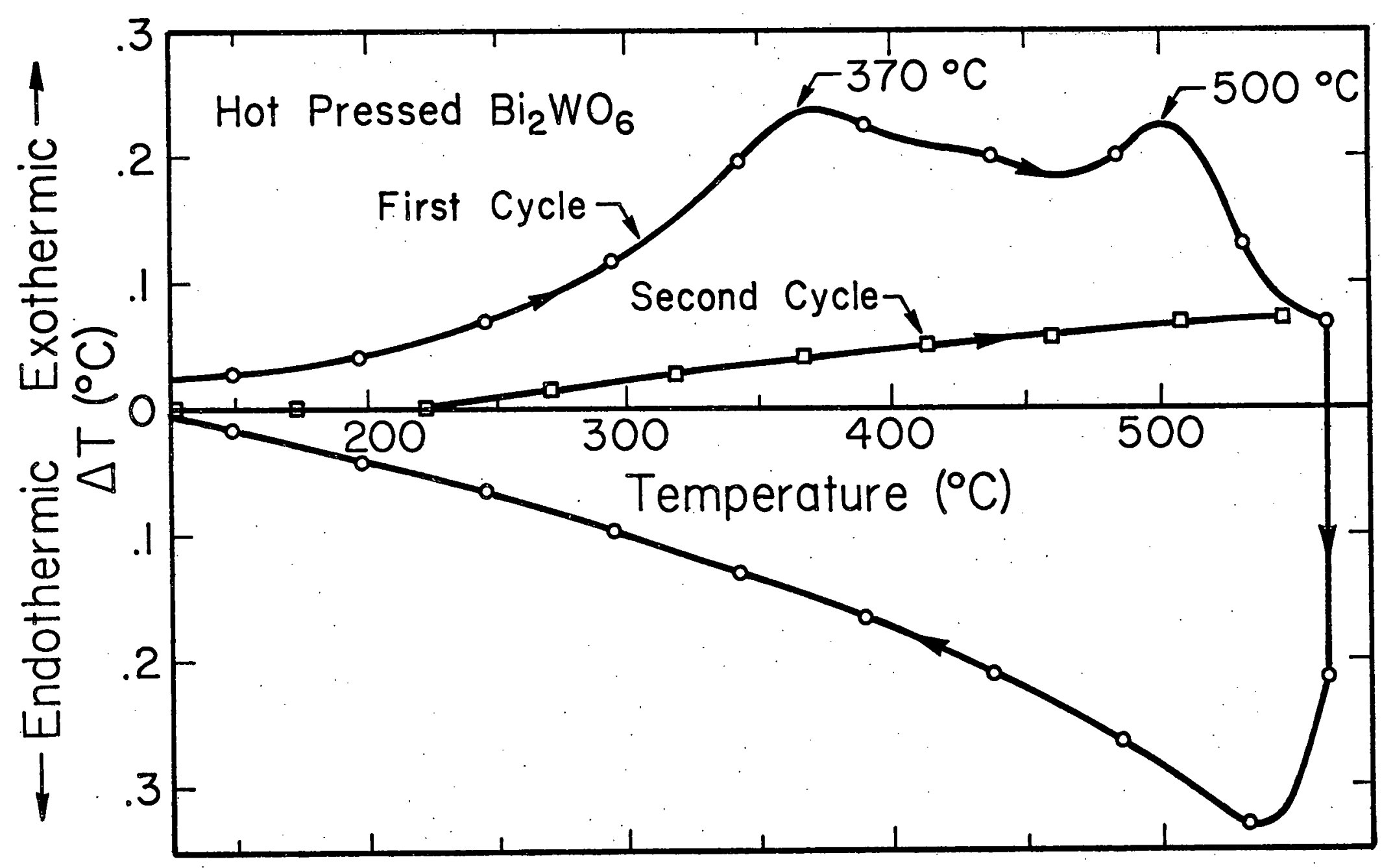

Figure 28. Differential Scanning Calorimetry of Hot Pressed $\mathrm{BI}_{2} \mathrm{WO}_{5}$ 


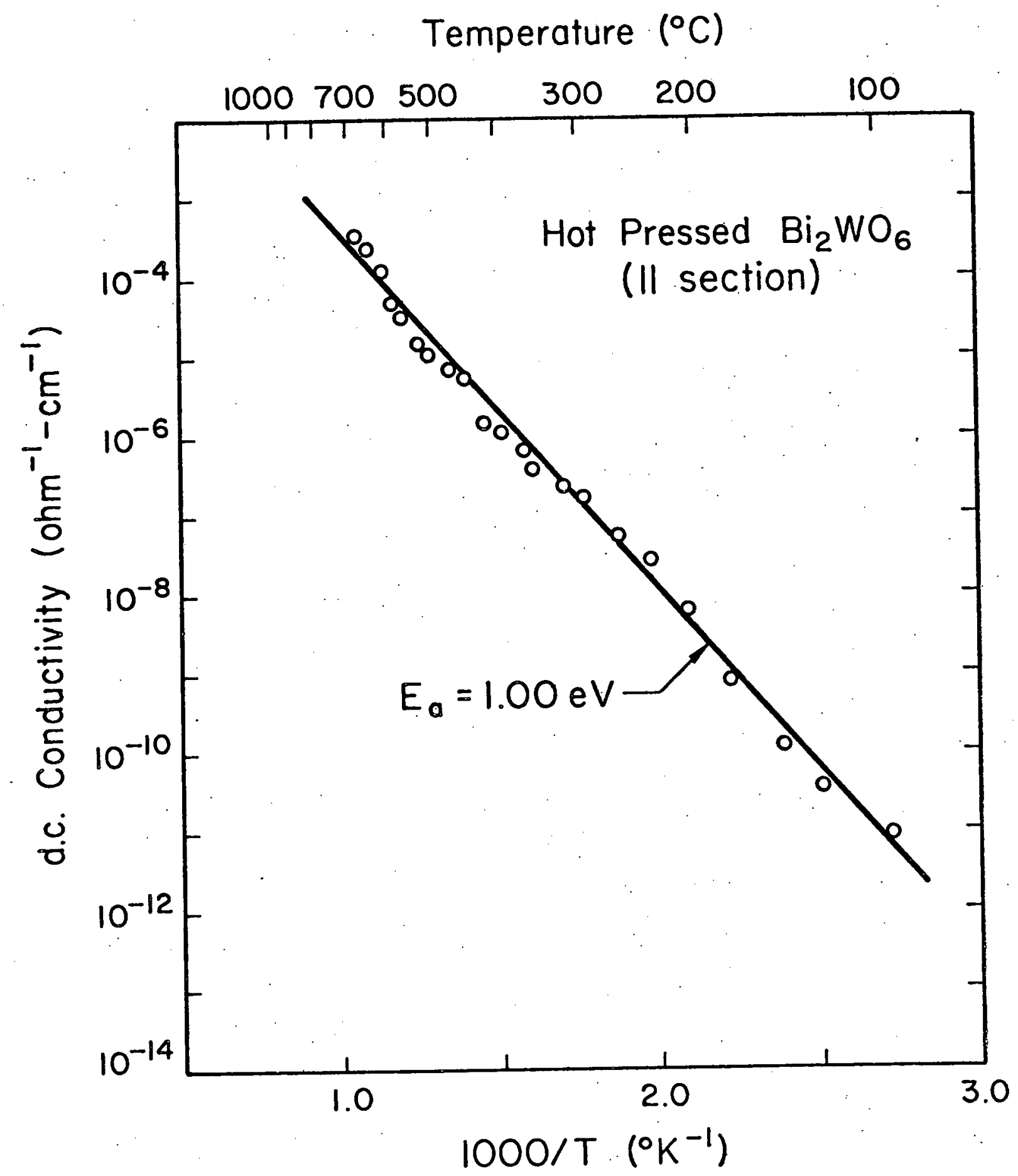

Figure 29. d.c. Conductivity - Inverse Temperature Dependence of $\mathrm{Bi}_{2} \mathrm{WO}_{6}$ Fabricated by the Settling Method. 


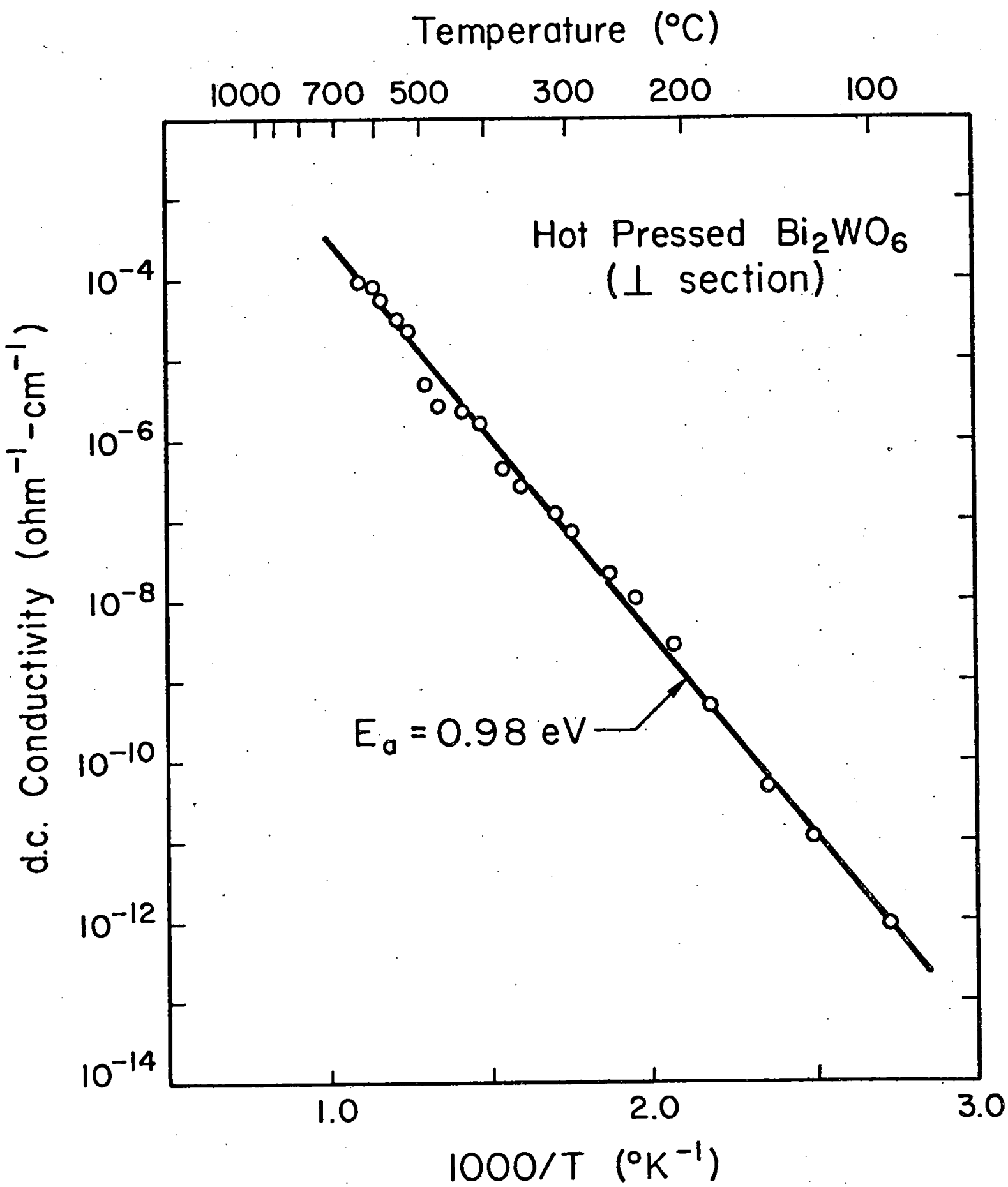

Figure 30. d.c. Conductivity - Inverse Temperature Dependence of ${ }^{B i}{ }_{2}{ }^{\mathrm{WO}} 6$ Fabricated by the Settling Method. 
d.c. conductivity $\left(\mathrm{ohm}^{-1}-\mathrm{cm}^{-1}\right), \sigma_{0}$ the pre-exponential term, and Boltzmann constant $\left(\mathrm{k}=0.8617 \times 10^{-4} \mathrm{eV} /{ }^{\circ} \mathrm{K}\right)$. For the $\|$ section $\mathrm{E}_{a}=1.00 \mathrm{eV}$, and for the $\perp$ section $E_{a}=0.98 \mathrm{eV}$. It is evident that there is no real difference in conductivity between the two sections. A similar plot published by Takahashi and Iwahara ${ }^{19}$ showed a linear Arrhenius behavior between 600 and $800^{\circ} \mathrm{C}$, the temperature range of their study. Using their data, an activation energy of $1.3 \mathrm{eV}$ was calculated. Thetr samples contained $5 \%$ open porosity.

\section{Dielectric Constant and a.c. Conductivity}

Figures 31-38 illustrate the temperature dependence of dielectric constant and a.c. conductivity for several samples of hot pressed $\mathrm{Bi}_{2}{ }^{\mathrm{WO}} 6{ }^{*}$ The measurements were made at three frequencies. Calculation of dielectric constant from capacitance measurements was previously described in Chapter Two. Values of a.c. conductivity ( in $\mathrm{ohm}^{-1}-\mathrm{cm}^{-1}$ ) were calculated from conductance data according to equation 4.2. The parameters used in this equation are $G$ the

$$
\sigma=\frac{\mathrm{d}}{\mathrm{A}} \mathrm{G}
$$

conductance in ohm-cm, d the sample thickness In centimeters, and $A$ the electrode area in square centimeters. The set of figures illustrate the room temperature dielectric constant for hot pressed $\mathrm{Bi}_{2}{ }^{\mathrm{WO}}{ }_{6}$ ranged between 40 and 100 depending upon the frequency and lossy nature of the sample. In all probability, a realistic value for the real part of the dielectric constant was $K^{\prime}=47$ at $1 \mathrm{MHz}$, with a corresponding dissipation factor of 0.006 .

Figures 31 and 32 illustrate the temperature dependence of dielectric constant and a.c. conductivity. for hot pressed $\mathrm{Bi}_{2} \mathrm{WO}_{6}$ formed by the dry pressing method. A peak in values occurediat $380^{\circ} \mathrm{C}$ in both graphs. This corres- 


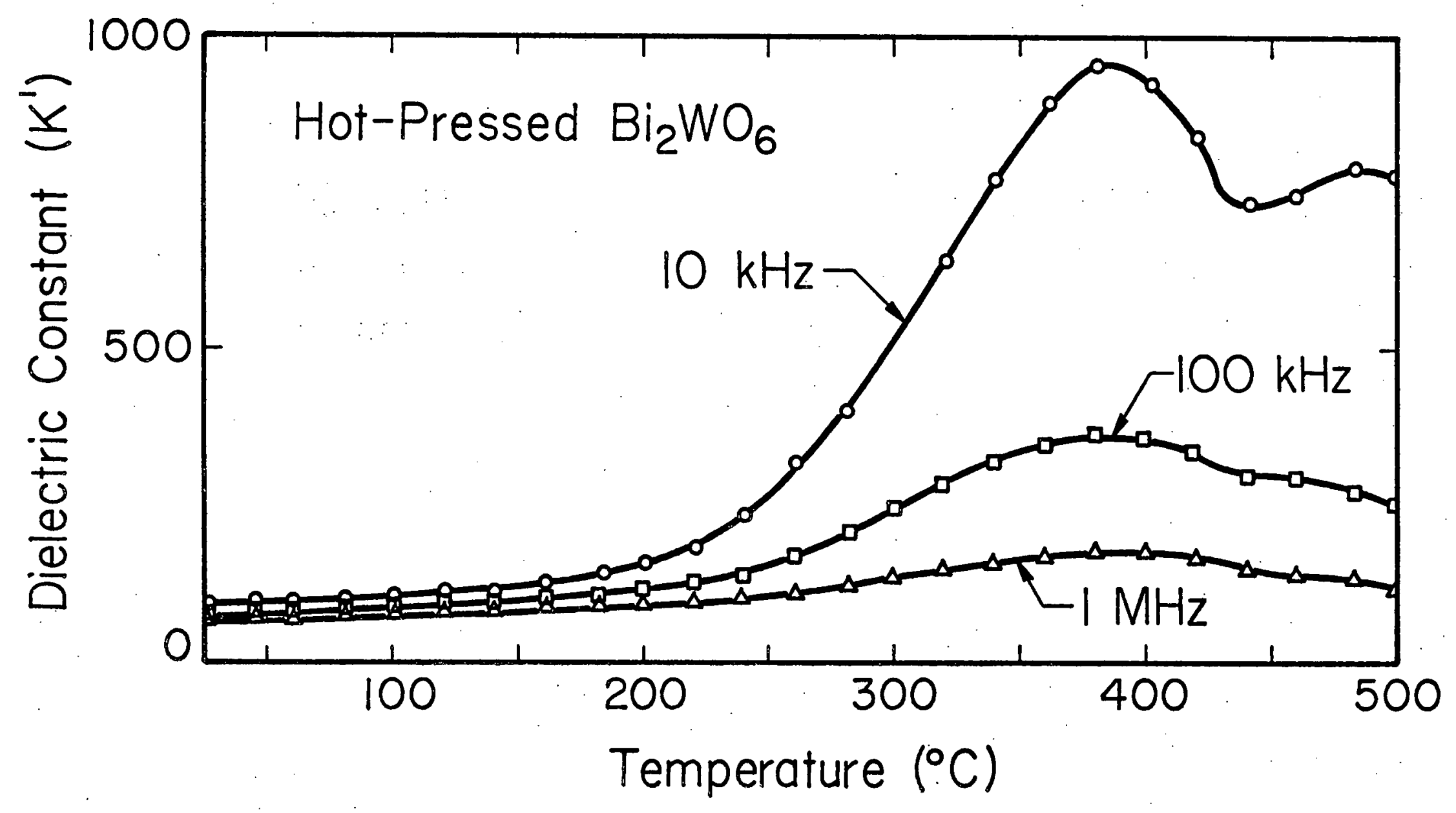

Figure 31. Temperature Dependence of. Dielectric Constant for Poled Hot Pressed $\mathrm{BI}_{2} \mathrm{WO}_{6}$. 


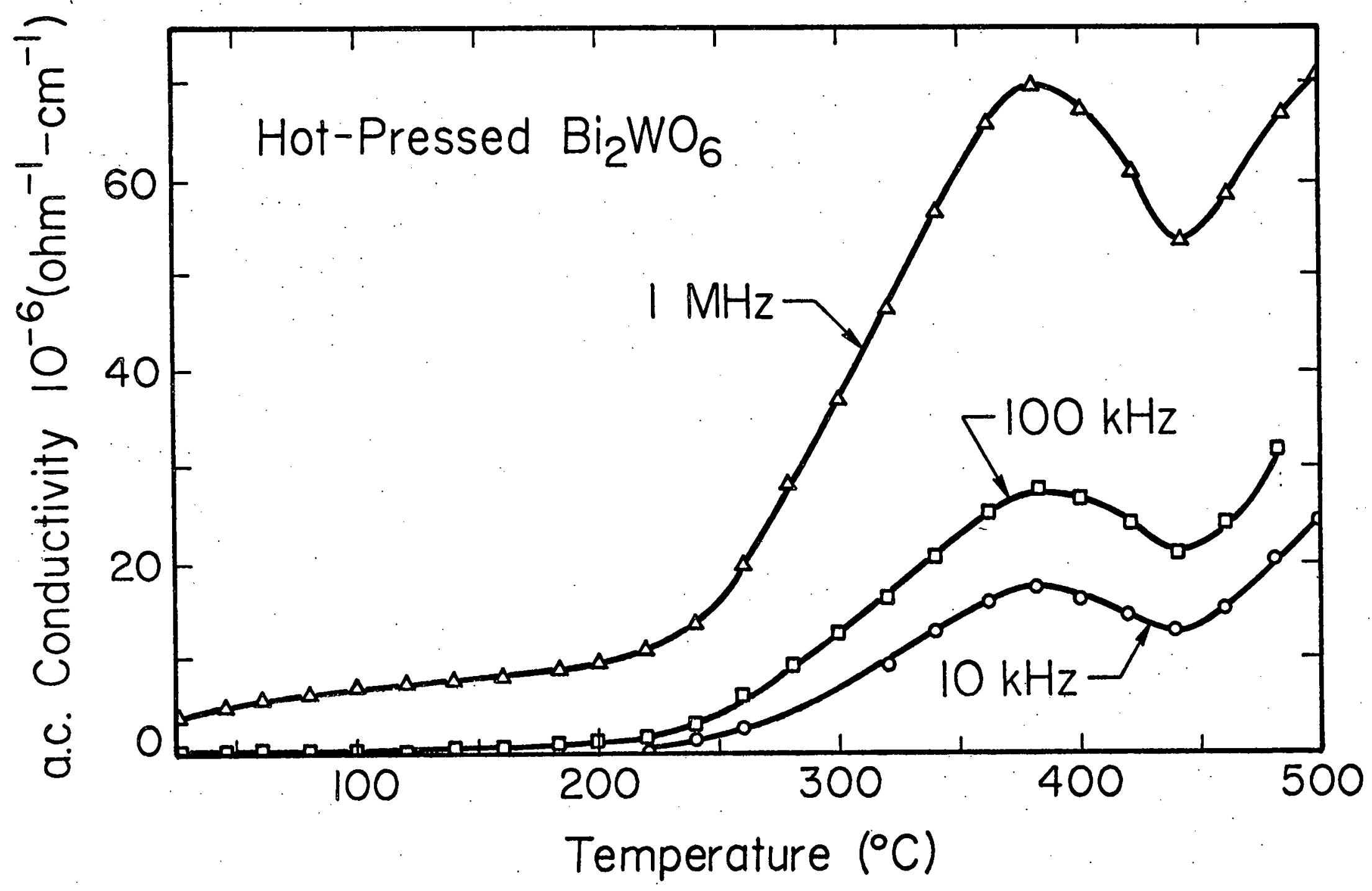

Figure 32. Temperature Dependence of a.c, Conductivity for Hot Pressed $\mathrm{BI}_{2} \mathrm{WO}_{6}{ }^{\circ}$ 


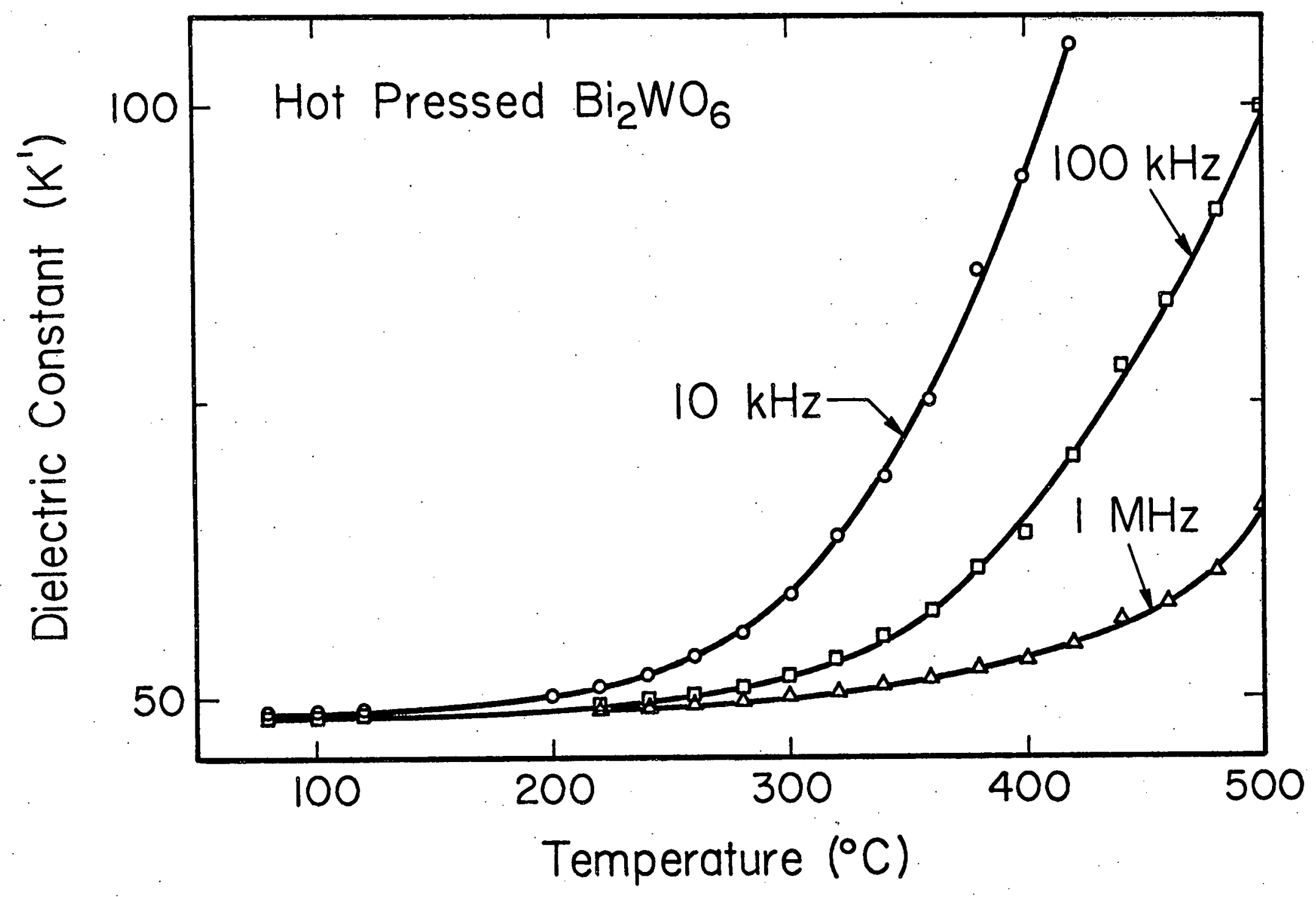

Figure 33. Temperature Dependence of Dielectric Constant for Annealed Hot Pressed $\mathrm{BH}_{2} \mathrm{WO}_{6}$. 


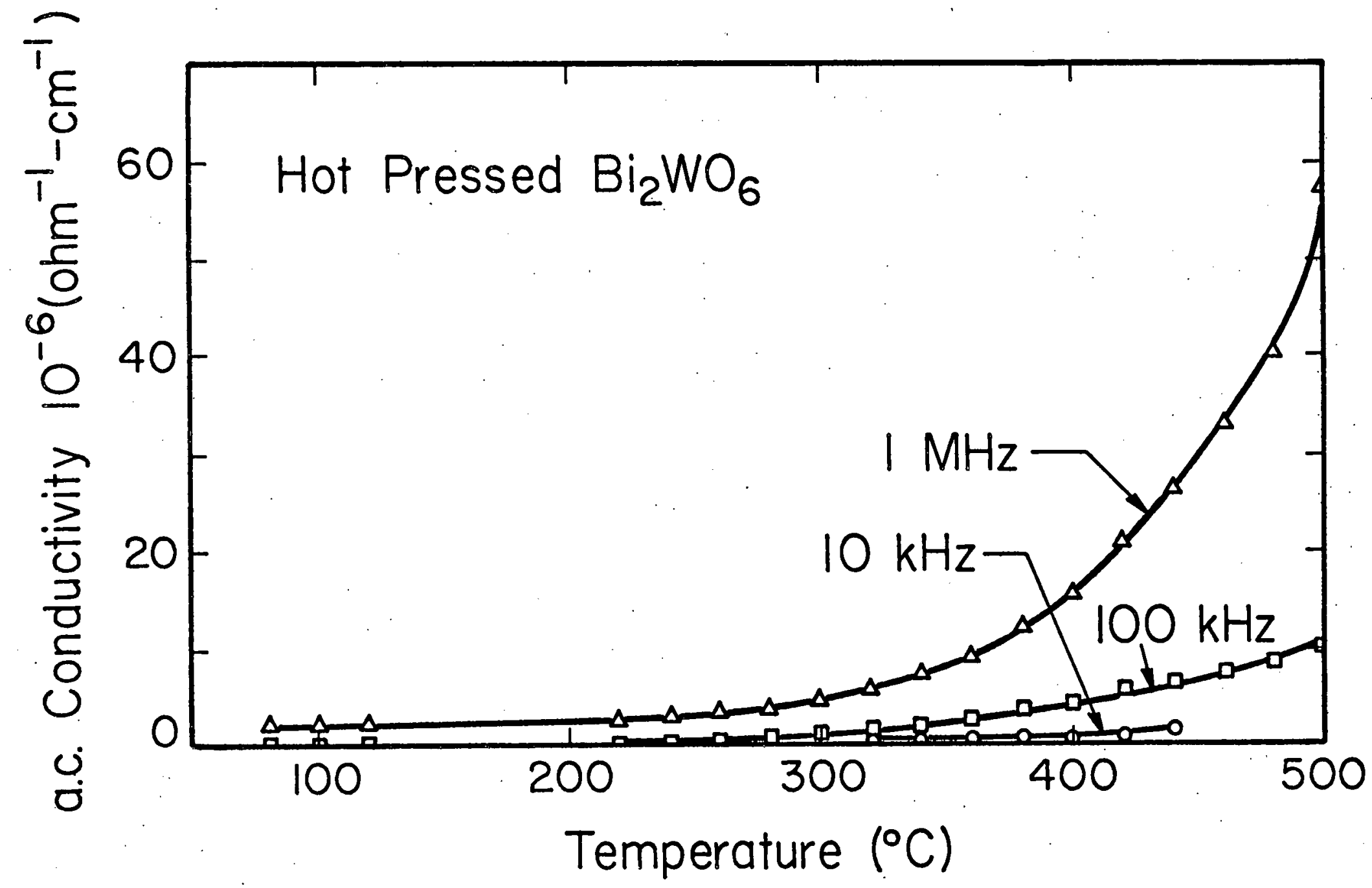

Figure 34. Temperature Dependence of a.c. Conductivity for Annealed Hot Pressed $\mathrm{BI}_{2} \mathrm{WO}_{6}$. 


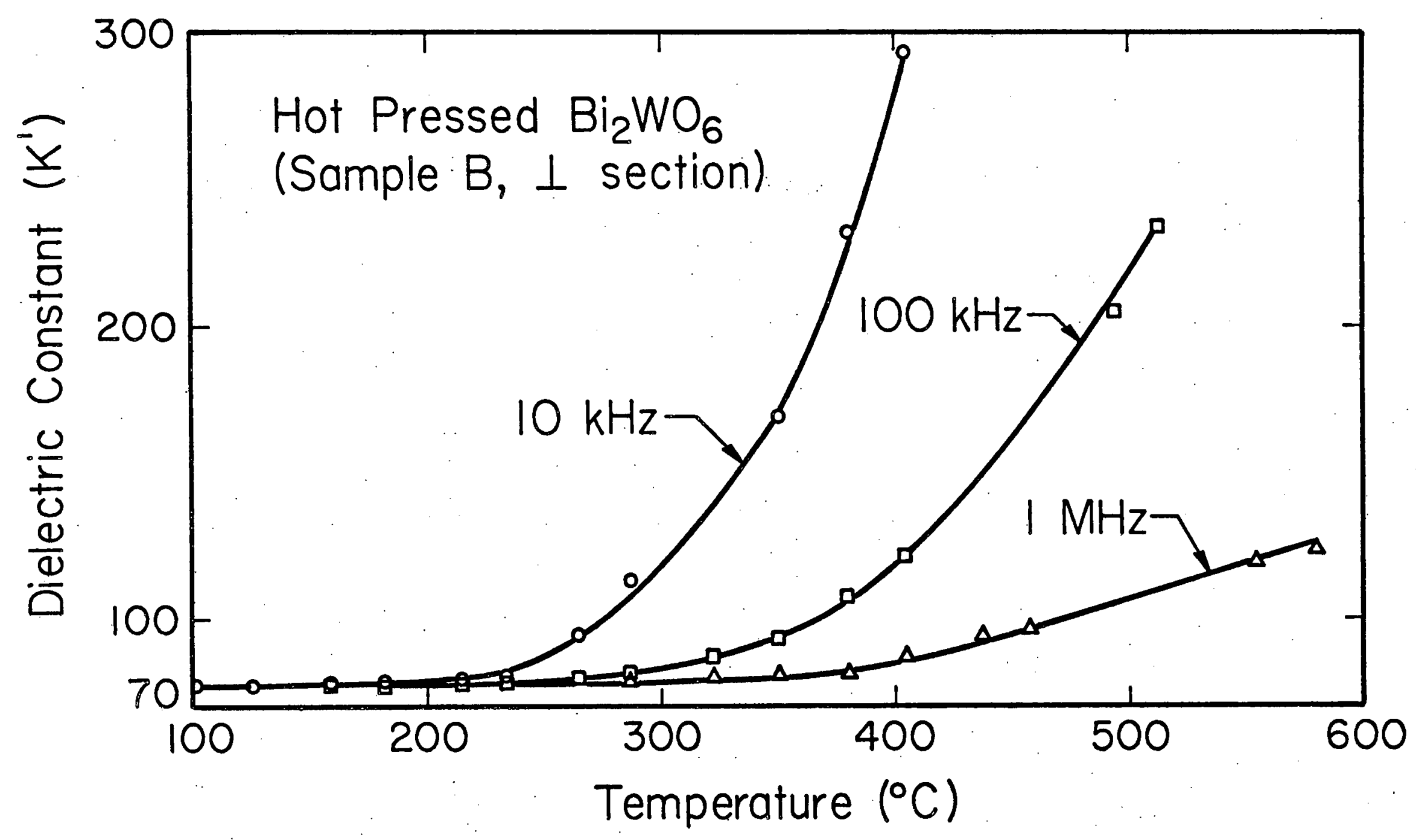

F1gure 35. Temperature Dependence of Dielectric Constant

for Annealed Hot Pressed $\mathrm{BI}_{2} \mathrm{WO}_{6}$ Fabricated by the Settling Method. 


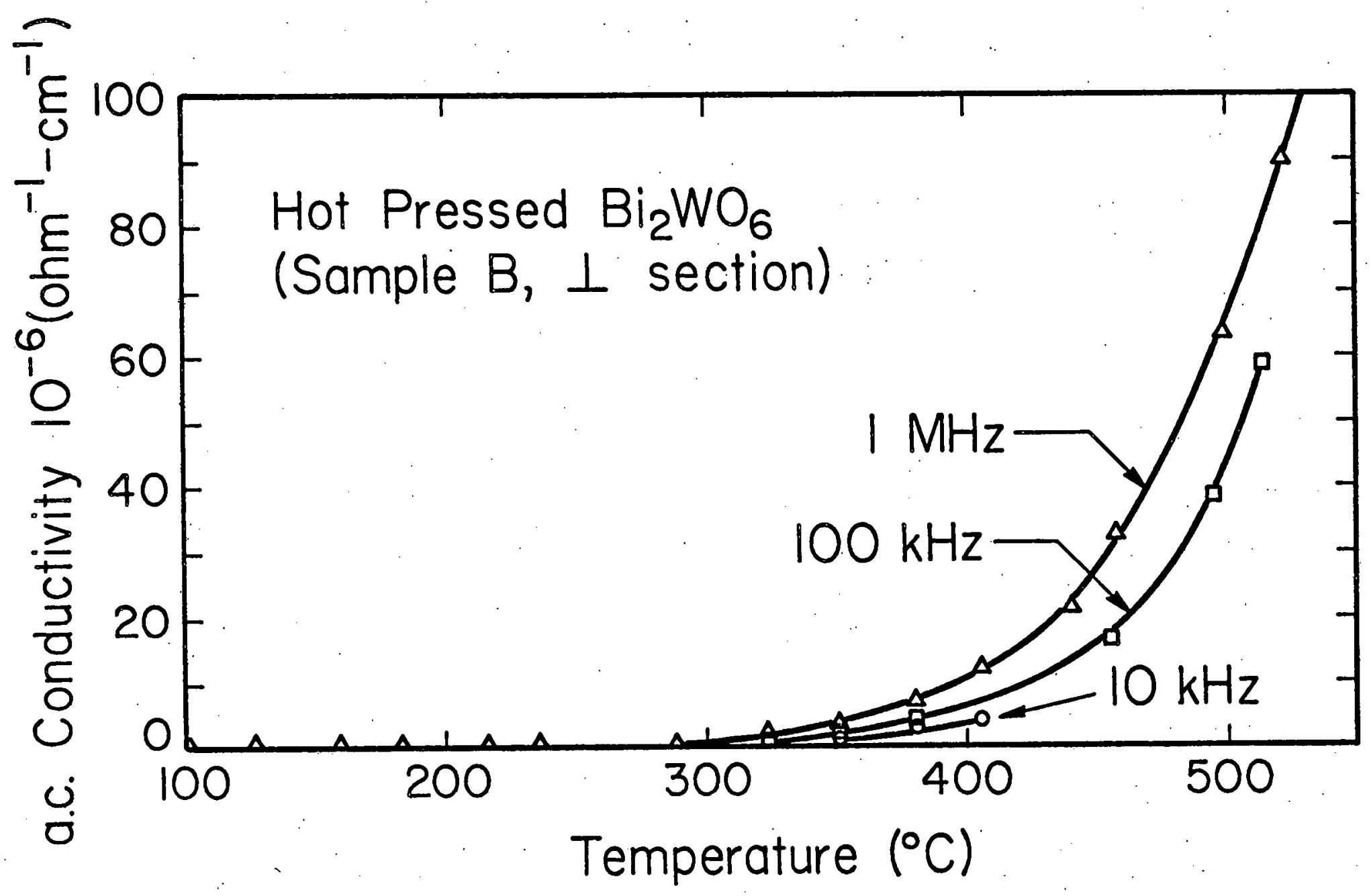

Figure 36. Temperature Dependence of a.c. Conductivity for Annealed Hot Pressed $\mathrm{BI}_{2} \mathrm{WO}_{6}$ Fabricated by the Settling Method. 


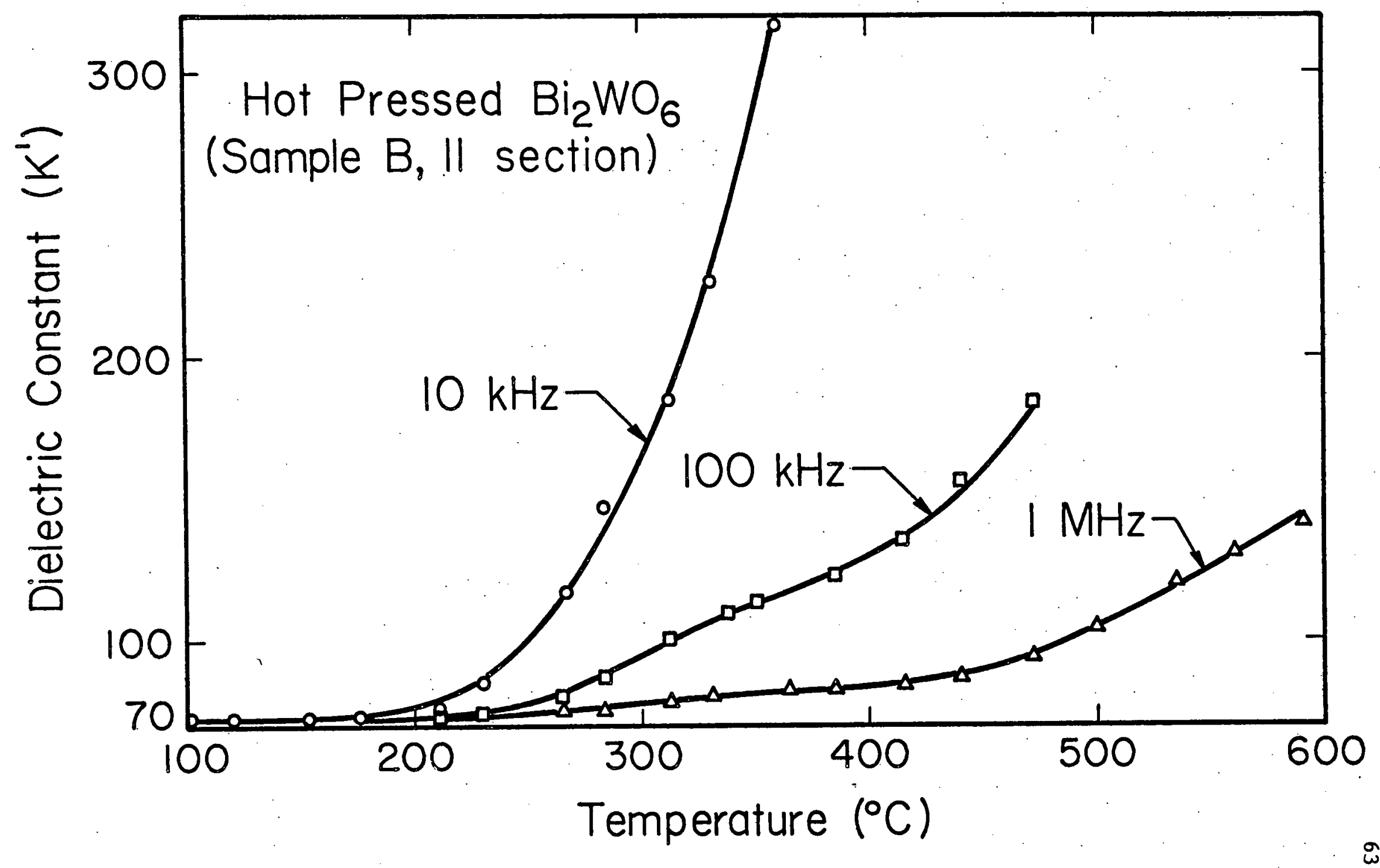

Figure 37. Temperature Dependence of Dielectric Constant for Annealed Hot Pressed $\mathrm{BI}_{2} \mathrm{WO}_{6}$. Fabricated by the Settling Method. 


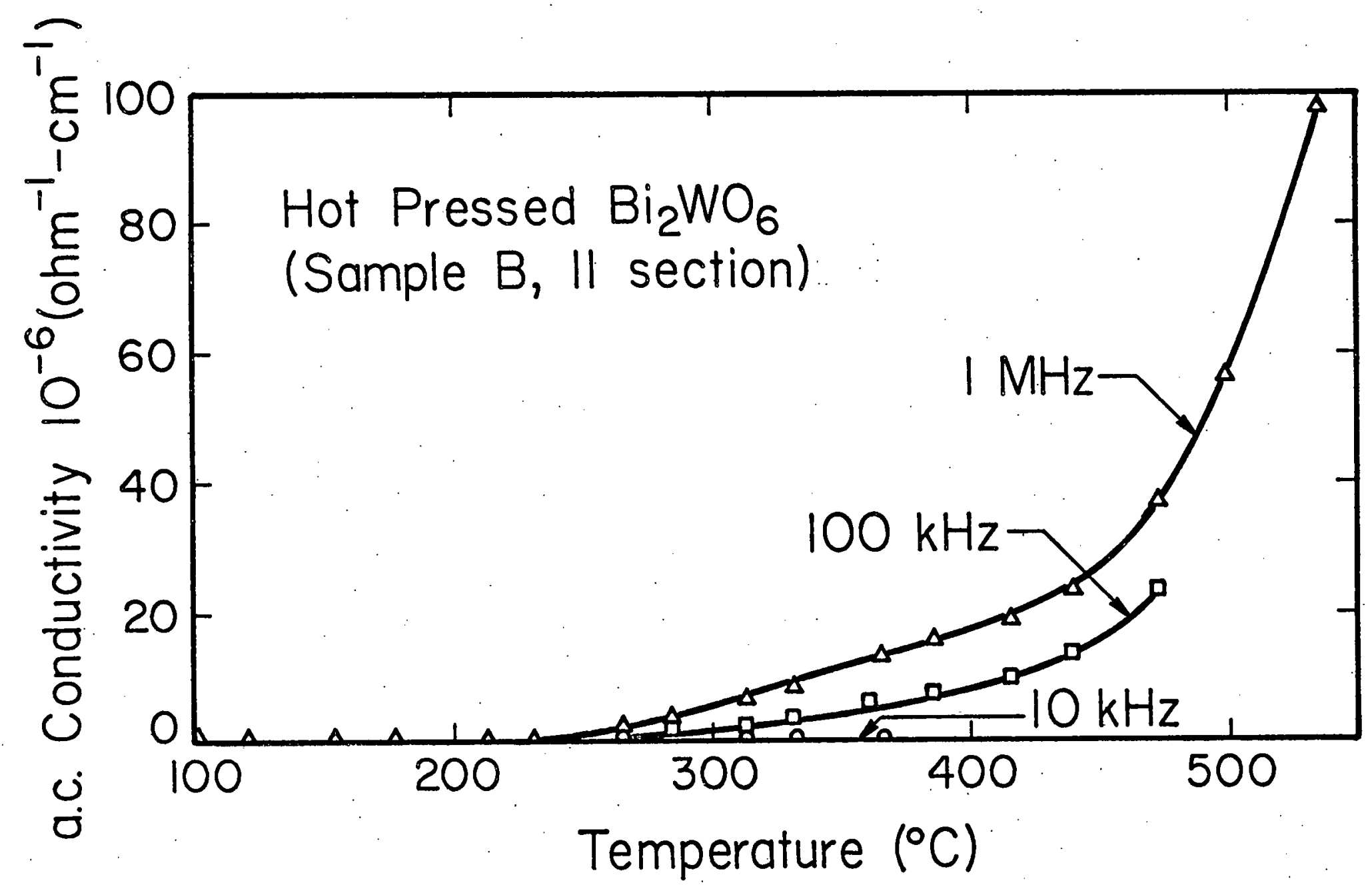

Figure 38. Temperature Dependence of a.c. Conductivity for Annealed Hot Pressed $\mathrm{BI}_{2} \mathrm{WO}_{6}$ Fabricated by the Settling Method. 
ponds to the peak reported by Ismailzada and Mirishli ${ }^{16}$ and Newkirk et al. ${ }^{10}$ in their dielectric constant data. The peak also corresponds to an exothermic peak observed by differential scanning calorimetry. Evidently, a stress relaxation represented by that exothermic peak is associated with the peak in dielectric constant and a.c. conductivity. Figures 33 and 34 are data for annealed hot pressed samples. The dielectric anomaly does not occur in these samples, neither does a DSC exotherm.

Figures 35-38 give the temperature dependence of dielectric constant and a.c. conductivity for annealed hot pressed compacts that were formed by the settling method. Two different sample "orientations" are given. Comparison of data show that the "orientation" of the section had no affect on the results.

\section{3. a.c. Poling}

Figures 39 and 40 are oscillographs of typical hysteresis loops observed for a.c. poled, hot pressed $\mathrm{Bi}_{2} \mathrm{WO}_{6}$ with aluminum electrodes. The a.c. poling fields applied across the samples were $60 \mathrm{kV} / \mathrm{cm}$ for sample $\mathrm{A}$ and $75 \mathrm{kV} / \mathrm{cm}$ for sample B. As the a.c. poling fields were increased to the values mentioned above, hysteresis loops grew to the size shown in the oscillographs. It was noted that increasing a.c. poling field caused the remanent polarization to increase, but not the coercive field. The shape of the hysteresis loops shown in Figures 39 and 40 are similar to those expected for ferroelectric behavior. When palladium-gold electrodes were utilized, the hysteresis loop had a similar shape to those exhibited in Figures 39 and 40 . However, the magnitude of the polarization was much smaller。 During the a.c. poling experiments, it was noted that the coercive field did not change significantly with temperature. 


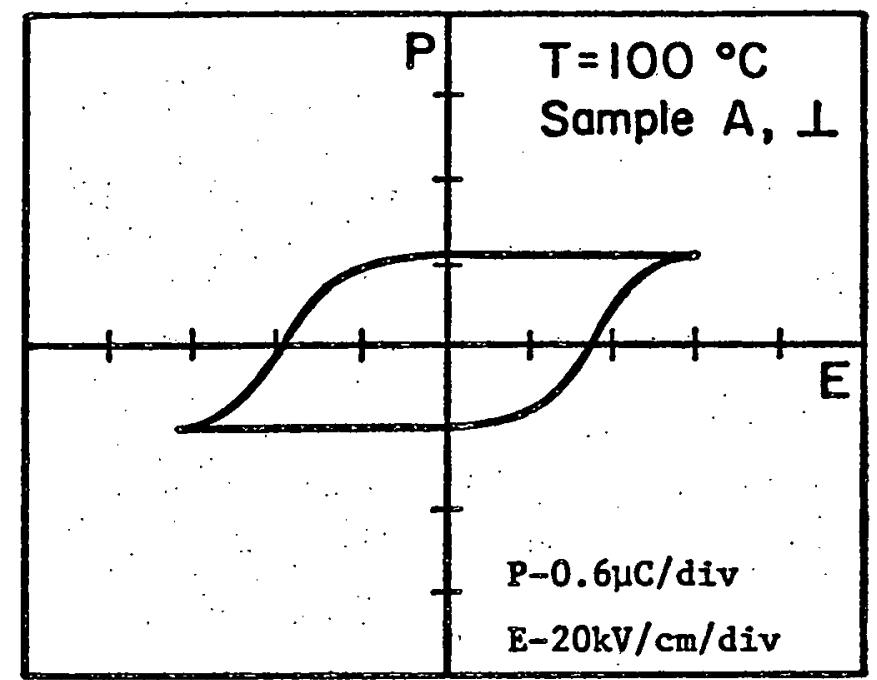

Figure 39. Hysteresis Loop for Hot Pressed $\mathrm{Bi}_{2}{ }^{\mathrm{WO}_{6}}$ Fabricated by the Settling Method.

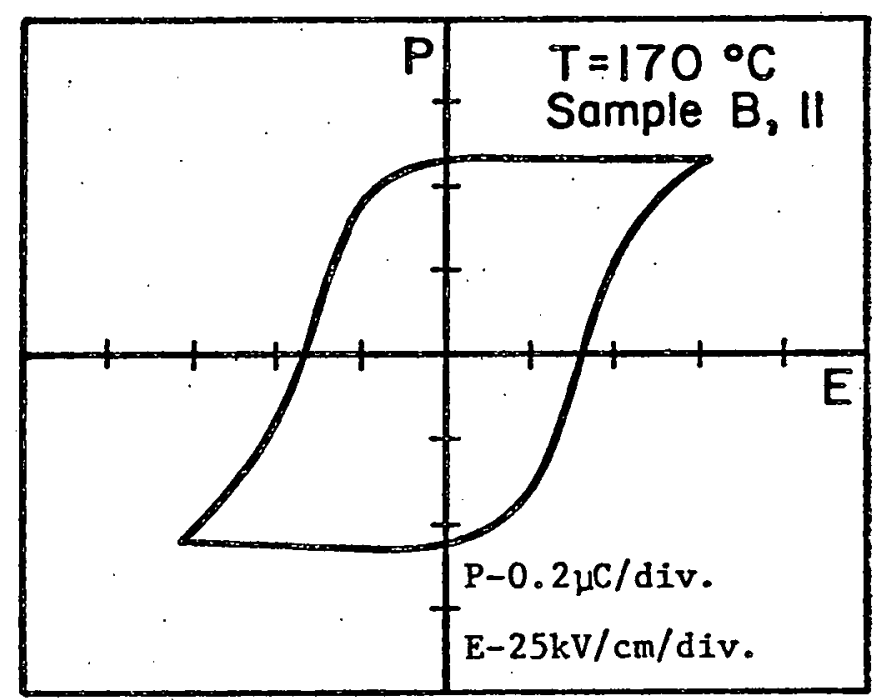

Figure 40. Hysteresis Loop for Hot Pressed $\mathrm{Bi}_{2} \mathrm{WO}_{6}$ Fabricated by the Settling Method. 
Figure 41 illustrates the temperature dependence of remanent polarization for two sections of hot pressed $\mathrm{Bi}_{2} \mathrm{WO}_{6}$ ceramic prepared by the settling method and metallized with aluminum electrodes. These data are anomalous in that remanent polarization is increasing with temperature, which is not characteristic of a ferroelectric material. For a ferroelectric, the remanent polarization remains constant or decreases with increasing temperature until the Curie point is reached, at which time the remanent polarization goes to zero. 20 The anomalous behavior illustrated in Figure 41 is therefore not attributable to ferroelectricity, but to some other effect. A plausible explanation is electrode polarization, whereby charge carriers migrate and pile up at "blocking" electrodes. Charge carriers may be electrons, holes, or lons, but most probably oxygen anions. For example, when either electrode becomes the anode, oxygen anions would migrate towards it, with a counterdiffusion of oxygen vacancies away. If the overpotential is sufficiently high, electrochemical oxidation (i.e. anodization) would occur at the electrodedielectric interface at the anode. Continued oxidation would form a blocking layer of aluminum oxide, which would cause the field to drop and limit further oxidation. A buildup of oxygen anions at both interfaces and an increased concentration of oxygen vacancies in the dielectric interior would cccur under the influence of an a.c. poling field. The anion space charge layers would act as trapping layers for injected holes, and for alternating field cycles, the resulting charge layers would be of unequal magnitude. Therefore, electrode polarization could give the hysteresis loop behavior. Since mobility of ions is temperature dependent, the remanent polarization would be expected to increase with increasing temperature as observed in Figure 41.

Figure 41 also indicates the perpendicular section had a greater remanent polarization. A possible explanation would be a difference in conductivity between the two sections. However, weak field conductivity data in Figures 


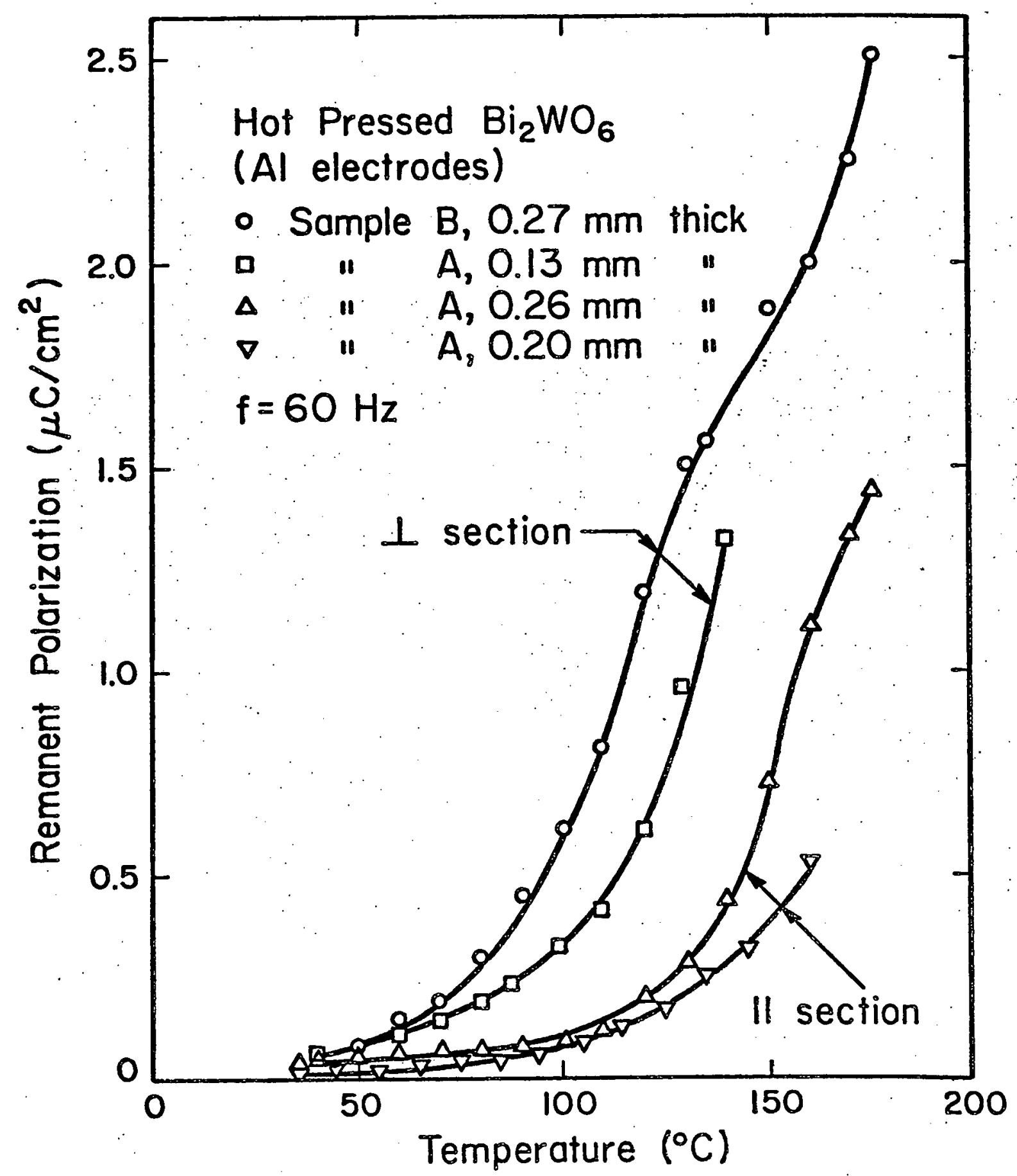

Figure 41. Temperature Dependence of Remanent Polarization for Hot Pressed $\mathrm{Bi}_{2} \mathrm{WO}_{6}$ Fabricated by the Settling Method. 
29 and 30 indicate a constant activation energy, which is independent of sample orientation. Perhaps the mobility under high fields exhibit a microstructural dependence. Another possibility is a difference in surface texture. This may somehow alter the electrode-dielectric interface between the two types of sections, and affect the polarization in the manner observed. The difference between the curves of the same "orfentation" appears to be a bulk effect. For each "orientation", the curve representing the greater remanent polarization is for a sample of greater thickness. The greater thickness would mean a greater number of oxygen defects between the electrodes. This increased quantity could allow an eventual greater accumulation of charge at the electrodes, leading to an enhanced polarization.

Figures 42 and 43 reinterpret data from Figure 41, together with data taken for samples metallized with palladium-gold electrodes. The graphs show the palladium-gold electrodes give a lower remanent polarization at all temperatures. The cause of this phenomenon may also be attributed to electrode polarization by the following reasoning. Aluminum readily oxidizes at low temperatures to form an adherent insulating oxide. 37 on the other hand, palladium-gold oxidizes to form a semiconducting oxide. ${ }^{38}$ Therefore, the "blocking" capability of palladium-gold electrodes would be much less or even zero. The fact that palladium-gold electrodes would not be able to "block" charge transport at the electrode-dielectric interface would prevent the buildup of space charge layers, and thus electrode polarization would not be expected. Figure 44 illustrates the temperature dependence of remanent polarization for hot pressed $\mathrm{Bi}_{2} \mathrm{WO}_{6}$ formed by tape casting. Again, electrode type affects the amount of remanent polarization observed. The graph also shows the forming technique did not enhance the degree of polarization. 


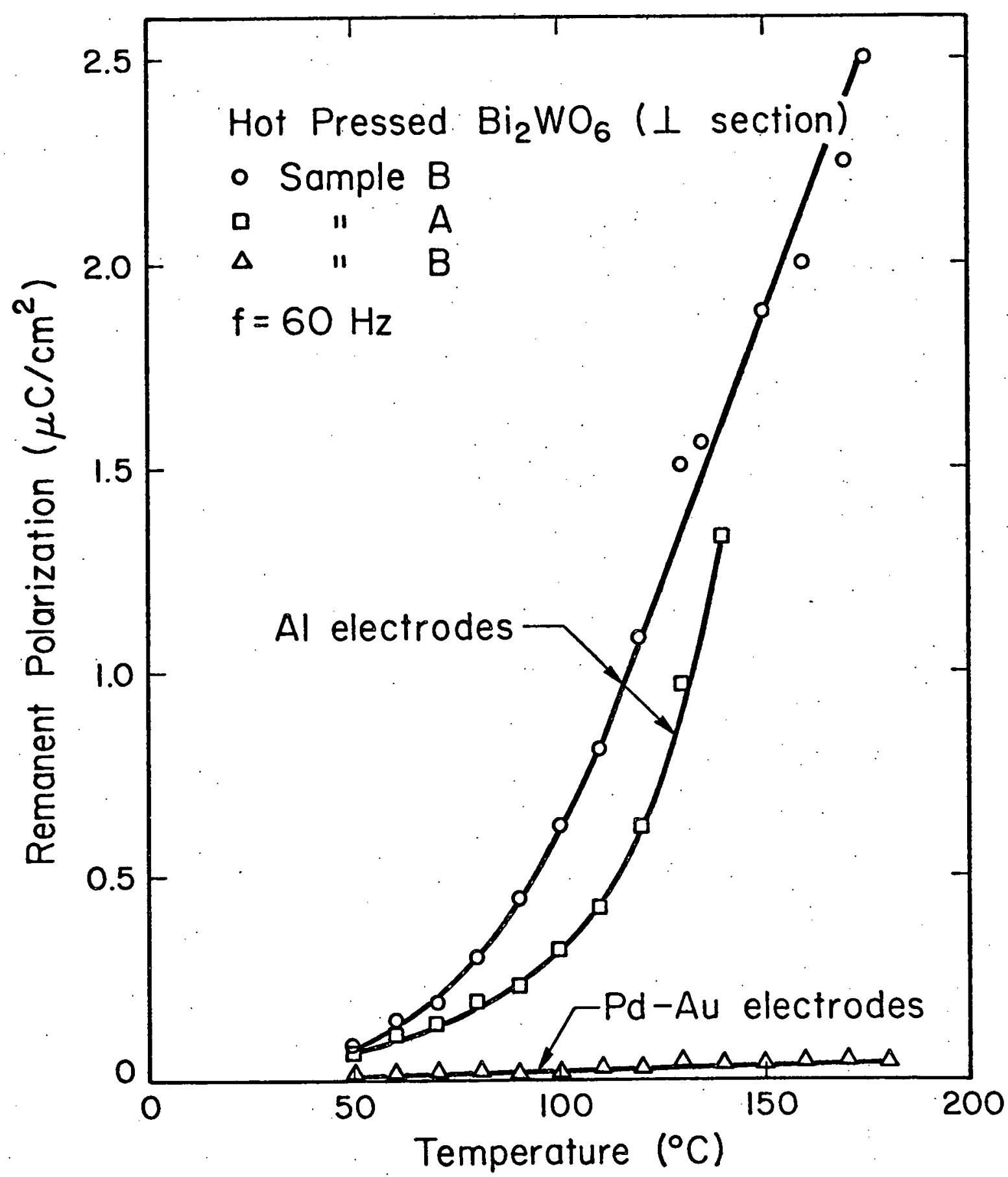

Figure 42. Temperature Dependence of Remanent Polarization for Hot Pressed $\mathrm{Bi}_{2}{ }^{\text {WO }} 6$ Fabricated by the Settling Method. 


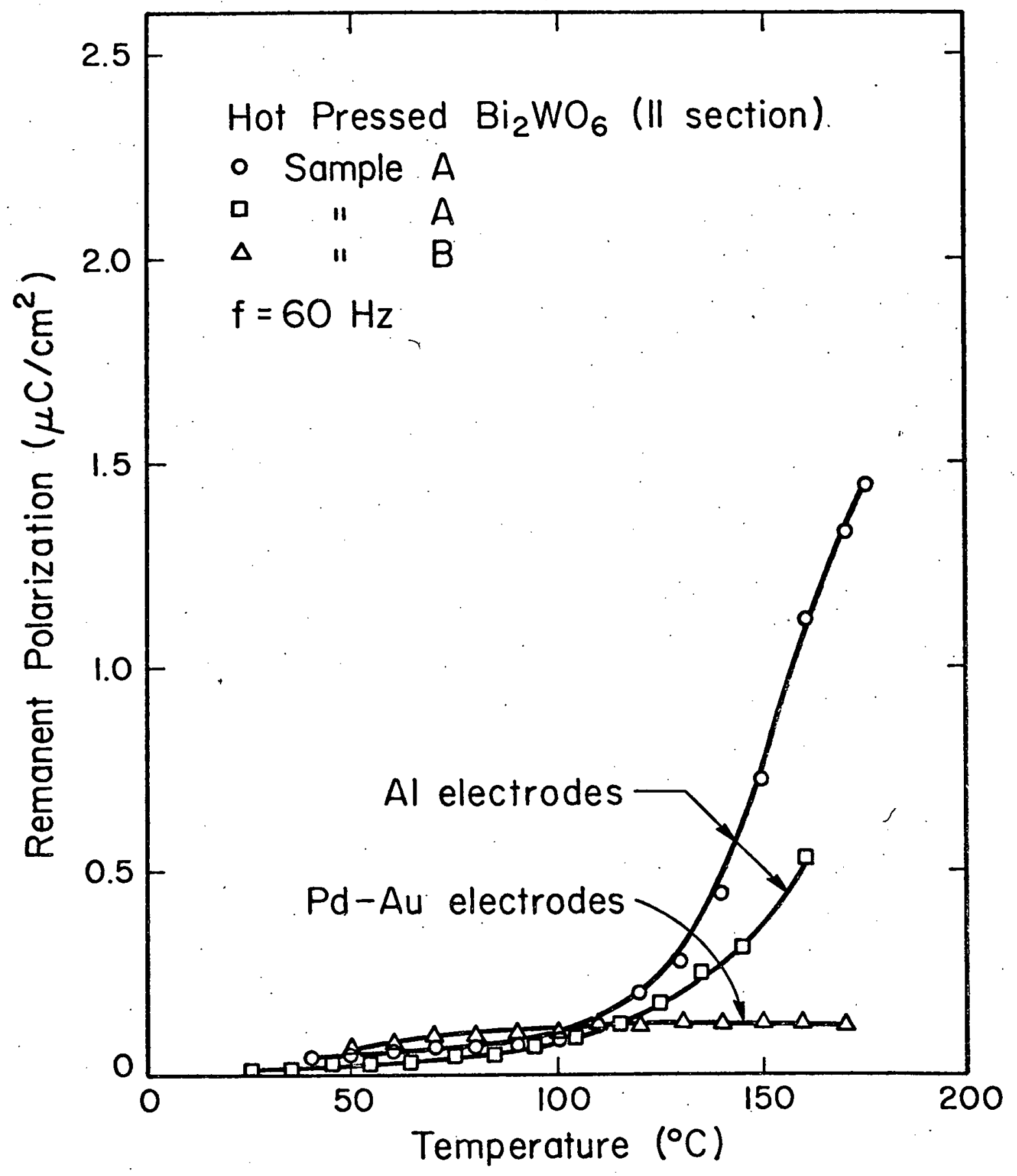

Figure 43. Temperature Dependence of Remanent Polarization for Hot Pressed $\mathrm{Bi}_{2} \mathrm{WO}_{6}$ Fabricated by the Settling Method. 


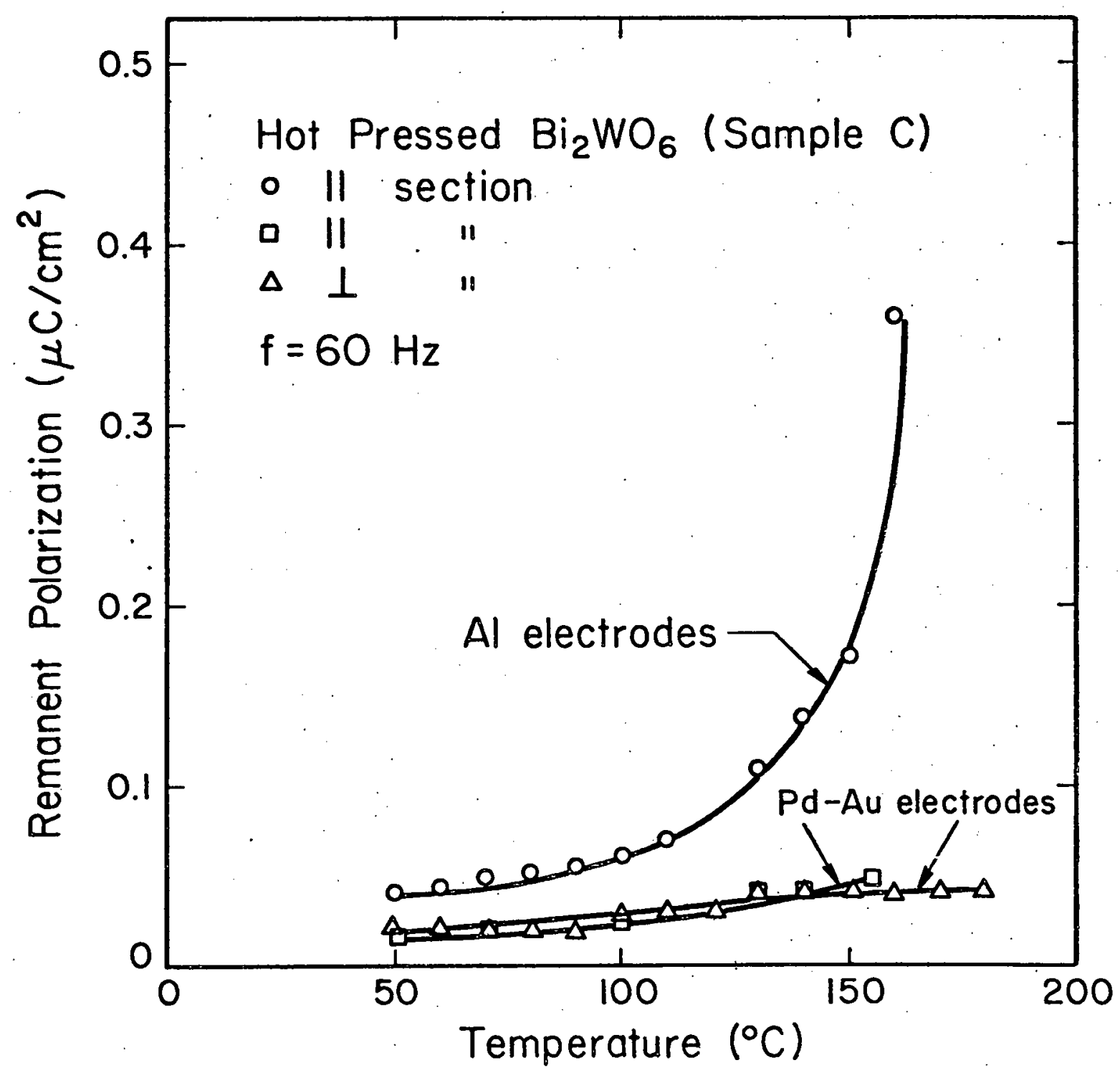

Figure 44. Temperature Dependence of Remanent Polarization for Hot Pressed $\mathrm{Bi}_{2} \mathrm{WO}_{6}$ Fabricated by the Tape Casting Method. 
4. Current-Voltage Analysis.

Figures 45 and 46 show the current density-applied field behavior for a hot pressed $\mathrm{Bi}_{2} \mathrm{WO}_{6}$ sample fabricated by the settling method. In each case Ohms

Law describes the weak field behavior, with a slope of one $(n=1) .^{39}$ At approximately $50 \mathrm{kV} / \mathrm{m}$, a sharp discontinuity is observed (in both graphs), and the slopes change to a value of 2 . For similar types of behavior reviewed by Lampert and Mark ${ }^{40}$ and 0 'Dwyer, 41 the current at low field levels is : controlled by electron trapping. At the fleld level represented by the discontinuity, the energy of injected electrons or holes is greater than the trap depth. This is the field level where the so called trap filled limit is reached. Thereafter, the upper segment of the curve is in accordance with. Child's law for solids (trap free square law), which describes field assisted excitation of trapped carriers. In Figure 46 another discontinuity occurs at $1000 \mathrm{kV} / \mathrm{m}$ for the perpendicular section. The high field portion of the curve also appears to have a slope of 2 from the small amount of data available. This phenomenon could be due to deeper electron traps reaching their trap filled limit. The reason that this occurs for the perpendicular section and not the parallel one is not obvious. Possibly, it is attributable to the same type of phenomenon that caused increased polarization for this section in the a.c. poling experiments. The two current density applied field diagrams show the electrode type has no affect on conductivity magnitude. This may be explained by bulk effects (i.e. traps) rather than electrode characteristics, such as electron processes and current leakage rather, than ionic phenomenon and blocking electrodes. The injection of electronic charge into dielectrics is often described by Fowler-Nordheim or Schottky-type mechanisms. However, Schottky plots (Figures 47 and 48) were not found to be applicable. That is, plots of current density $(J)$ versus the square root of applied field strength $(\sqrt{F})$ were found to 


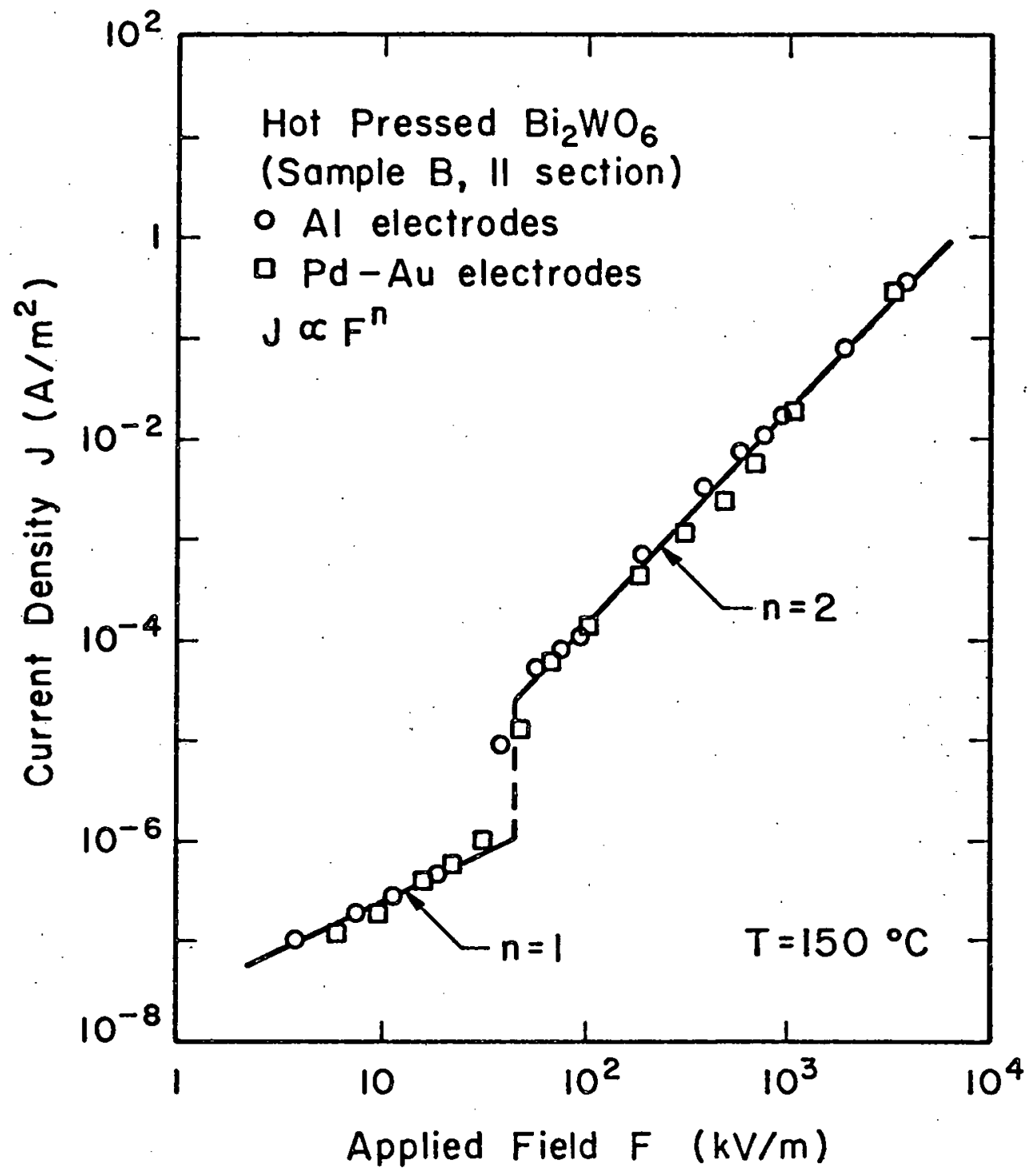

Figure 45. Current Density versus Applied Field. 


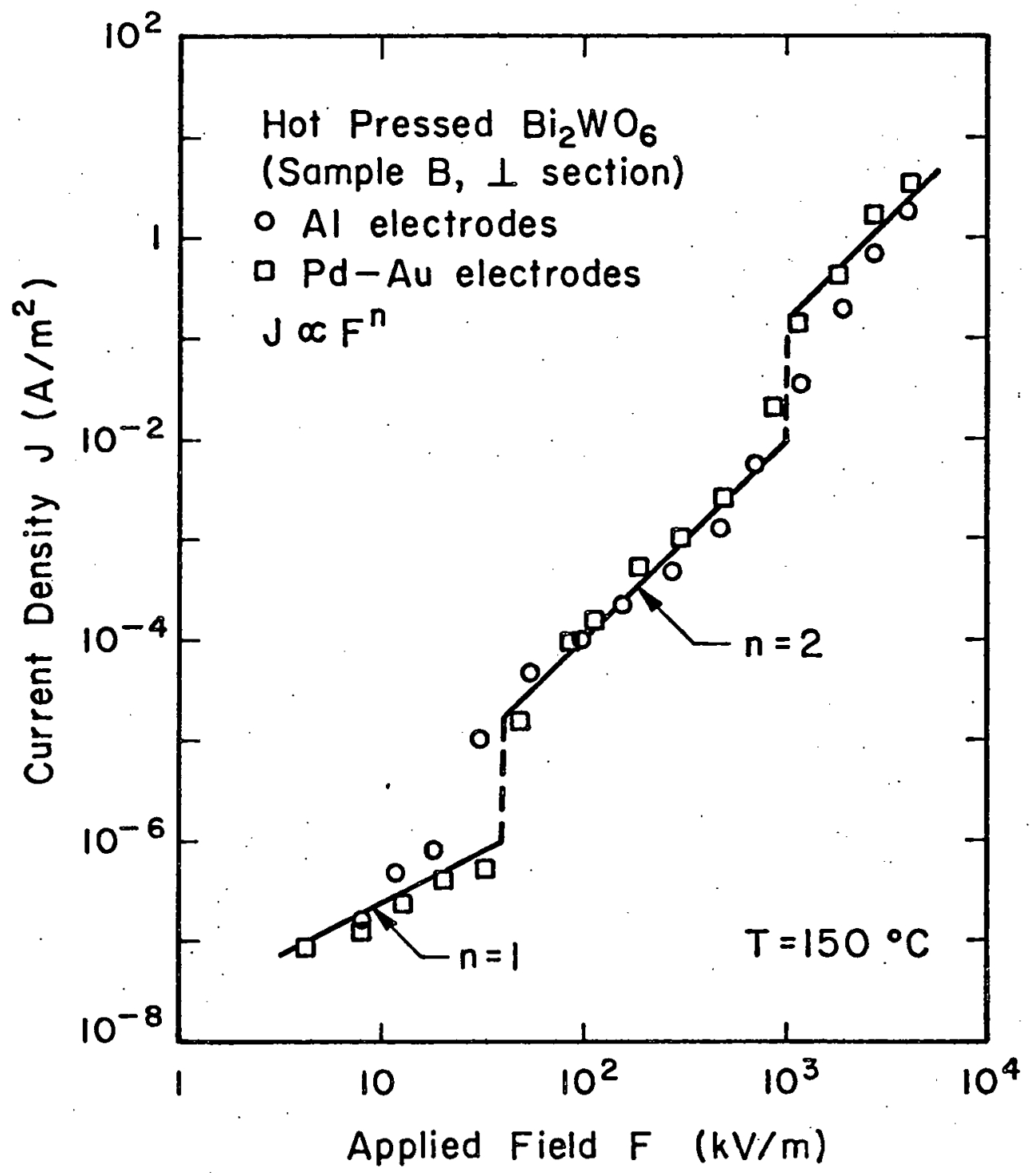

Figure 46. Current Density versus Applied Field. 


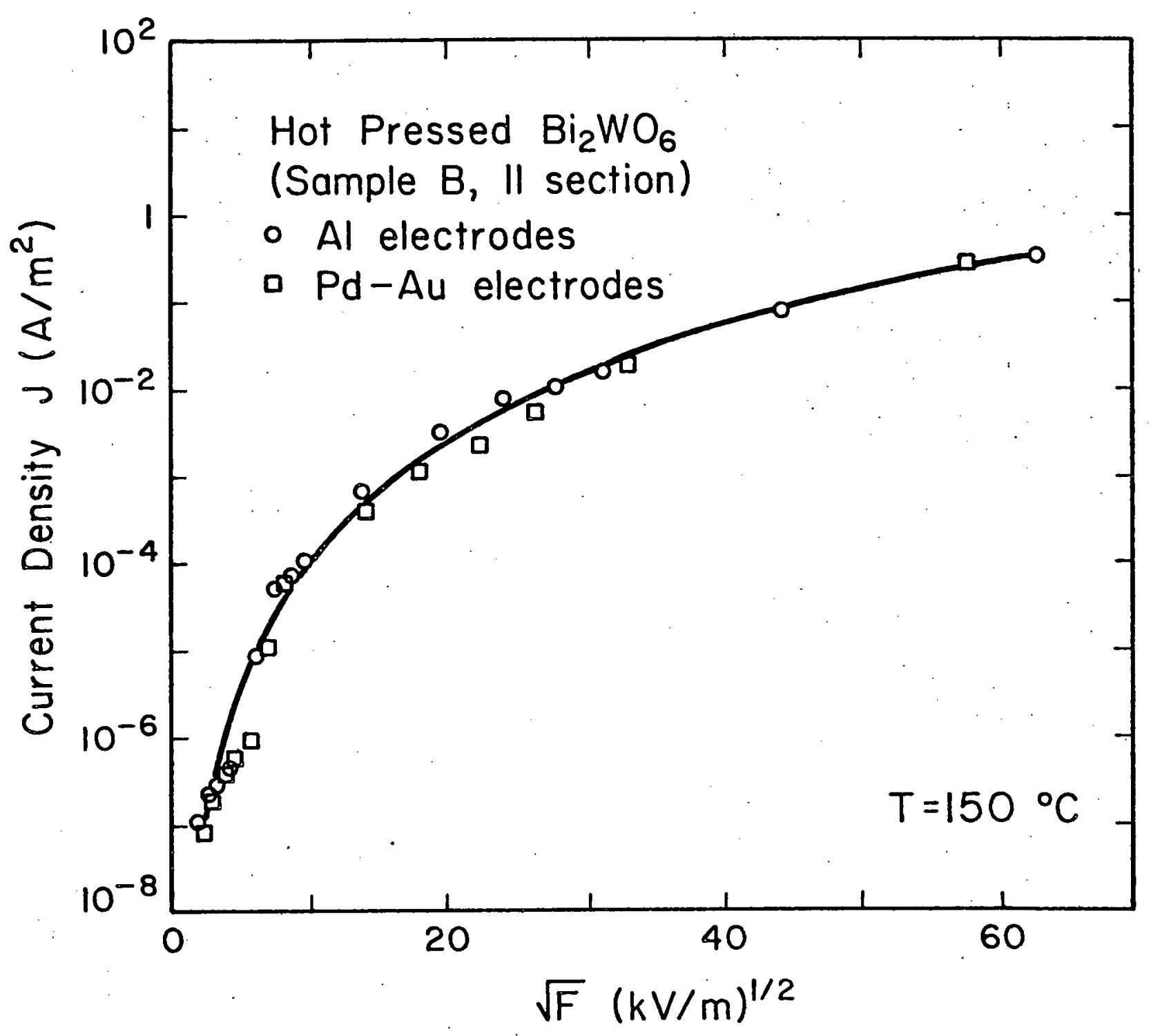

Figure 47. Schottky Plot for Hot Pressed $\mathrm{Bi}_{2} \mathrm{WO}_{6}$. 


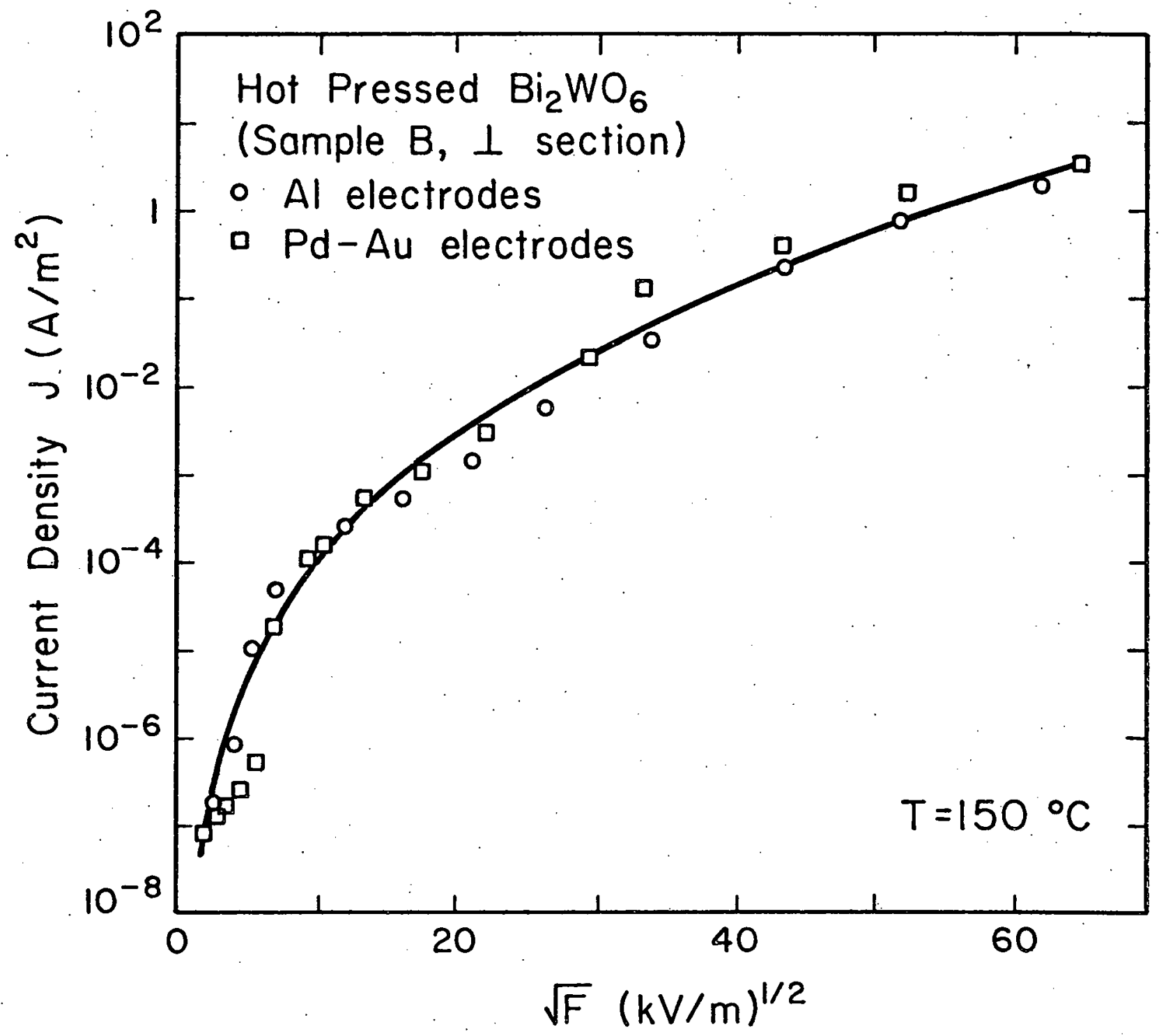

Figure 48. Schottky Plot for Hot Pressed $\mathrm{Bi}_{2} \mathrm{WO}_{6}$. 
be nonlinear, when a linear plot is expected. It is not certain why this is the case.

\section{Piezoelectricity}

Table I summarizes data obtained from measuring the piezoelectric response $\left(d_{33}\right)$ of d.c. poled, hot pressed samples of $\mathrm{Bi}_{2} \mathrm{WO}_{6}$. The definite result is that generally the use of aluminum electrodes allowed the development of a greater piezoelectric effect. This could again be explained by electrode polarfzation effects, whereas a.c. poled samples had no polarization at room temperature. Irreversible assymetric electrochemical changes can occur during d.c. poling, such as oxygen anions (2- ) migrating to the anode and oxygen vacancies $(2+)$ to the cathode. After cooling to room temperature and removing the external electric field, the oppositely charged space charge layers remained stable, apparently due to exceedingly slow self-diffusion rates. After approximately 2 months aging the piezoelectric coefficients were reproducible. The separation of charge resulting from space charge layers simulate a dipole, that causes a piezoelectric response measureable on a macroscopic scale.

The highly acentric structure of $\mathrm{Bi}_{2}{ }^{\mathrm{WO}_{6}}$ and second harmonic signal generation (SHG) show the material should have a large piezoelectric response. The reason that a true piezoelectric response was not observed in hot pressed $\mathrm{Bi}_{2} \mathrm{WO}_{6}$ could be due to any of the following three factors. First, the $\mathrm{Bi}_{2} \mathrm{WO}_{6}$ compacts used were fine-grained, which hinders domain wall movement during d.c. poling. Second, Diaz-Colon's ${ }^{23}$ use of Shuvalov notation showed $\mathrm{Bi}_{2} \mathrm{WO}_{6}$ may have only one orientatable polar axis. Third, the coercive field of $\mathrm{Bi}_{2} \mathrm{WO}_{6}$ may be higher than its dielectric strength. 
TABLE I

$$
\text { d.c. POLING RESULTS }
$$

\begin{tabular}{|c|c|c|c|c|c|}
\hline Sample & Section & Electrode & $\begin{array}{l}\text { Poling Field } \\
(\mathrm{kV} / \mathrm{cm}) \\
\end{array}$ & $d_{33} \times 10^{-12} \mathrm{C} / \mathrm{N}$ & Investigator \\
\hline$D *$ & $\perp$ & A1 & $\sim 60$ & 10.0 & Endevco \\
\hline$"$ & $"$ & $"$ & $"$ & 3.3 & $"$ \\
\hline$"$ & $"$ & $"$ & $\because$ & 10.4 & $"$ \\
\hline$"$ & $"$ & $"$ & $"$ & 8.9 & $"$ \\
\hline$"$ & 11 & $"$ & $"$ & 6.3 & $"$ \\
\hline $\mathbf{A}$ & $\perp$ & ii & $"$ & 2.5 & $"$ \\
\hline$"$ & $"$ & " & $"$ & 2 & .." \\
\hline$" 1$ & 11 & $"$ & $"$ & 7 & $"$ \\
\hline$"$ & $"$ & $"$ & $"$ & 6.5 & $"$ \\
\hline 18 & 1 & $"$ & 71 & 9 & Author \\
\hline$"$ & $"$ & $"$ & 44 & 4 & $"$ \\
\hline$"$ & 11 & $"$ & 35 & 5 & $"$ \\
\hline 89 & & $\mathrm{Pd}-\mathrm{Au}$ & 52 & 3 & $"$ \\
\hline or & 11 & $" 8$ & 29 & 2 & $"$ \\
\hline C & $\|$ & $\mathrm{A} 1$ & 67 & 6 & $"$ \\
\hline$"$ & $\perp$ & $\mathrm{Pd}-\mathrm{Au}$ & 40 & 0.5 & " \\
\hline$"$ & 11 & $"$ & 24 & 3 & $"$ \\
\hline
\end{tabular}

* Sample $\mathrm{D}$ is hot pressed $\mathrm{Bi}_{2} \mathrm{WO}_{6}$ fabricated by dry pressing. 
CHAPTER FIVE

CONCLUSION

Hot pressing produced dense compacts of $\mathrm{Bi}_{2} \mathrm{WO}_{6}$ that approached theoretical density. Pressures exceeding 35MPa applied for one hour at $850^{\circ} \mathrm{C}$ were needed to achieve high densities. No preferred orientation was found to occur by hot pressing or by the other two special fabrication techniques attempted: settling and tape casting. Failure to orientate grains of $\mathrm{Bi}_{2} \mathrm{WO}_{6}$ was thought due to the lack of particles. with a plate-like morphology produced by reaction sintering. If hydrothermally recrystallized material or material produced by melt quenching were used, it could be possible to orientate preferentially in dense compacts. Orientated microstructures are needed for polar properties.

The real part of the dielectric constant at room temperature was $\overline{\mathrm{K}}^{\prime}=47(\tan \delta=0.006$ at $1 \mathrm{MHz})$, and the activation energy for d.c. conductivity was $1 \mathrm{eV}$. Even though hot pressed samples exhibited hysteresis behavior in a.c. poling, it was thought not attributable to normal ferroelectric behavior. Electrode polarization processes were thought to be the likely cause of anomalous polarization-field behavior. Piezoelectric response was also attributed to macroscopic electrode polarization. Further experiments are suggested on single crystals and orientated, microstructures to determine intrinsic polar properties. 


\section{$\underline{\text { References }}$}

1. R. E. Newnham, R. W. Wolfe, and J. F. Dorrian, "Structural Basis of Ferroelectricity in Bismuth Titanate Family," Mater. Res. Bul1, 6[10] 1029 (1971).

2. R. W. Wolfe, R. E. Newnham, and M. I. Kay, "Crystal Structure of $\mathrm{Bi}_{2} \mathrm{WO}_{6}$," Solid State Comm., 7 [24]1797 (1969).

3. E. L. Gal'perin, L. Ya. Erma, I. K. Kolchin, M. A. Belova, and K. S. Chernyskev, "X-ray Examination of the $\mathrm{Bi}_{2} \mathrm{O}_{3}-\mathrm{WO}_{3}$ System," Russ. J. Inorg. Chem. 11[9] 1137 (1966).

4. G. Blasse, "Polymorphism of $\mathrm{Bi}_{2} \mathrm{MoO}_{6}$ ", J Inorg. Nucl. Chem. 28[4], 1124 (1966).

5. R. W. Wolfe, A Study of the Bismuth Titanate Family Ph.D. Thesis, Penn. State Univ., (1971).

6. S. N. Hoda, and L. L. Y Chang, "Phase Relations in the System $\mathrm{Bi}_{2} \mathrm{O}_{3}-$ WO $_{3}$," J. Am. Ceram. Soc. 57[7]323 (1974).

7. E. I. Speranskaya, Izv. Akad. Nauk SSR, Neorg. Mat: 6, 149 (1970).

8. N. P. Smolyaninov and I. N. Belyaev, "The $\mathrm{Bi}_{2} \mathrm{O}_{3}-\mathrm{PbO}-\mathrm{WO}_{3}$ System," Russ. J. Inorg. Chem. I[11] 1345 (1962)。

9. L. Rook, Unpublished work (1976).

10. H. W. Newkirk, P. Quadflicg, J. Liebertz, and A Kockel, Growth, Crystallography, and Dielectric Properties of $\mathrm{Bi}_{2} \mathrm{WO}_{6}, "$ Ferroelectrics 4 [1], 51 (1972).

11. R. Fay, Preparation and Properties of Bismuth Tungstate, M.S. Thesis, Univ. of I11., (1976).

12. D. A. Payne and R. S. Horsey, unpublished work (1973).

13. D. A. Payne and S. Theokritoff, "Hydrotermal Recrystallization of $\mathrm{Bi}_{2}{ }^{\mathrm{WO}_{6}}$," Mat. Res. Bul1. 10[6] 437 (1975).

14. V. Shukla, unpublished work (1977).

15. V. K. Yanovskii, V. I. Voronkova, A. L. Alksandrovoskii and V. A. D'yakov, Doklady Akad. Nauk SSSR, 222, 94 (1975).

16. I. G. Ismailzade and F. A. Mirish1i, "High-Temperature X-ray and Dielectric Investigation of $\mathrm{Bi}_{2} \mathrm{WO}_{6}{ }^{\prime \prime}$. Soviet Physic-Crysta1lography, $14[4] 636$ (1970).

17. W. D. Kingery, H. K. Bowen, and D. R. Uh1mann, Introduction to Ceramics, 2nd ed. , John Wiley \& Sons, N.Y., 914-5 (1976). 
18. ibid. 847.

19. T. Takahashi and H. Iwahara, "High Oxide Conduction in Sintered Oxides of the System $\mathrm{Bi}_{2} \mathrm{O}_{3}-\mathrm{WO}_{3} \cdot "$ J. App. Electrochem. 3[1]. 65 (1973).

20. B. Jaffe, W. R. Cook and H. Jaffe, Piezoelectric Ceramics, Academic Press, NY, p. 8-16 (1971).

21. A. A. Zaky and R. Hawley, Dielectric Solids, Dover Pub., N.Y., p. 66-70 (1970).

22. D. A. Payne, The Role of Internal Boundaries Upon the Dielectric Properties of Polycrystalline Ferroelectric Materials, Ph.D. Thesis, Penn. Univ., (1973).

23. F. Diaz-Colon, Dielectric and Electro-Optic Properties of Mixed Bismuth Oxide Layer Structure Compounds. Ph.D. Thesis, Penn. State Univ. (1973).

24. W. D. Kingery, H. K. Bower, and D. R. Uhlmann, Introduction to Ceramics, 2nd ed., John Wiley and Sons, 448-515 (1976).

25. M. H. Leipold, "Hot Pressing," Treatise on Materials Science and Technology, Vo1. 9, Ceramic Fabrication Processes, F. F. Y. Wang ed., Academic Press, NY, p. 95-134 (1976).

26. T. Vasilos and R. M. Spriggs, "The Hot Pressing of Ceramics," Proc. Brit. Ceram. Soc. 3, p. 195-221 (1965).

27. P. Murray, D. T. Livey, and J. Williams, "The Hot Pressing of Ceramics," Ceramic Fabrication Processes, W. D. Kingery ed., John Wiley and Sons, NY, 147-71 (1958).

28. S. S. Jackson, "Hot Pressing High Temperature Compounds," Powder Met.[8] 74 (1961).

29. A. G. Thomas and H. J. Jones, "Hot Pressing of Ceramic Powders," Powder Met. [6] 160 (1960).

30. A. J. Mountuala, "Hot-Pressing Piezoelectric and Ferroelectric Materials," Am. Ceram. Soc. Bul1. 42[3] 1.20 (1963).

31. C. A. Johnson, Superplasticity in Bi $2 \underset{-}{0}$, Ph.D. Thesis, Penn. State Univ. (1974).

32. P. M. Sutton, "Space Charge and Electrode Polarization in Glass," J. Am. Ceram. Soc. 47[4] 188 (1964).

33. P. B. Macedo, C. T. Moynihan and R. Bose, "The Role of Ion Diffusion in Polarization in Vitreous Ionic Conductors," Physics and Chem. of Glasses, 13 [6] 171 (1972).

34. C. Kim and M. Tomozawa, "Electrode Polarization of Glasses," J. Am. Ceram. Soc., 59[3-4]127 (1976). 
35: C. Wentworth and G. W. Taylor, "Processing Parameters and Electrical Properties of Doctor-Bladed Ferroelectric Ceramics," Am. Ceram. Soc. Bull. 46[12] 1186 (1967).

36. W. D. Kingery, "Pressure Forming of Ceramics," Ceramic Fabrication Processes, W. 0. Kingery ed., John Wiley and Sons, N.Y. p. 55 (1958).

37. K. Hauffe, Oxidation of Metals, Plenum Press, N.Y. p. 248 (1965).

38. E. M. Wise, Palladium, Academic Press, N.Y., P. 24-5 (1968).

39. D. A. Payne, "Concerning the Physics of Failure of Barium Titanate Capacitors," Proc. VI Reliab. Phys.: Symp., (1967).

40. M. A. Lampert and P. Mark, Current Injection in Solids, Academic Press, N.Y. P. 18-25 (1970).

41. J. J. O'Dwyer, The Theory of Electrical Conduction and Breakdown in Solid Dielectrics, Clarendon Press, Oxford, p. 159-84 (1973). 
APPENDIX A

Chemicals Utilized

Materia1

$\mathrm{Bi}_{2} \mathrm{O}_{3}$

$\mathrm{WO}_{3}$

$\mathrm{WO}_{3}$
Formula Wt. (g)

465.96

231.85

231.85
Brand

99.7\% Baker

Reagent

99.7\% Alfa Products

99.9\% Materials Research Corporation 